\title{
Photocatalytic Radical Ortho-Dearomative Cyclization: Access to
}

\section{Spiro[4.5]deca-1,7,9-trien-6-ones}

Wuheng Dong, ${ }^{* \dagger, \$}$ Yao Yuan, ${ }^{\S}$ Caiyun Liang,,${ }^{\ddagger}$ Feng Wu, ${ }^{\S}$ Siyuan Zhang, ${ }^{\S}$ Xiaomin Xie, ${ }^{\S}$ and Zhaoguo Zhang *,

${ }^{\dagger}$ Medicine Center, Guangxi University of Science and Technology, Liuzhou, Guangxi 545006, China

$¥$ Guangxi Key Laboratory of Green Processing of Sugar Resources, Liuzhou, Guangxi 545006, China

$\S$ Shanghai Key Laboratory for Molecular Engineering of Chiral Drugs, School of Chemistry and Chemical Engineering, Shanghai Jiao Tong University, 800 Dongchuan Road, Shanghai 200240, China Fax: (+86)-0772-2056100; phone: (+86)- 0772-2056100; E-mail: wuheng190429@gxust.edu.cn Fax: (+86)-21-5474-8925; phone: (+86)-21-5474-8925; E-mail: zhaoguo@ sjtu.edu.cn

\section{Contents}

The spectrum of $7 \mathrm{~W}$ blue LED..........................................................

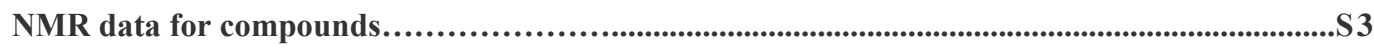


1. The spectrum of $7 \mathrm{~W}$ blue LED

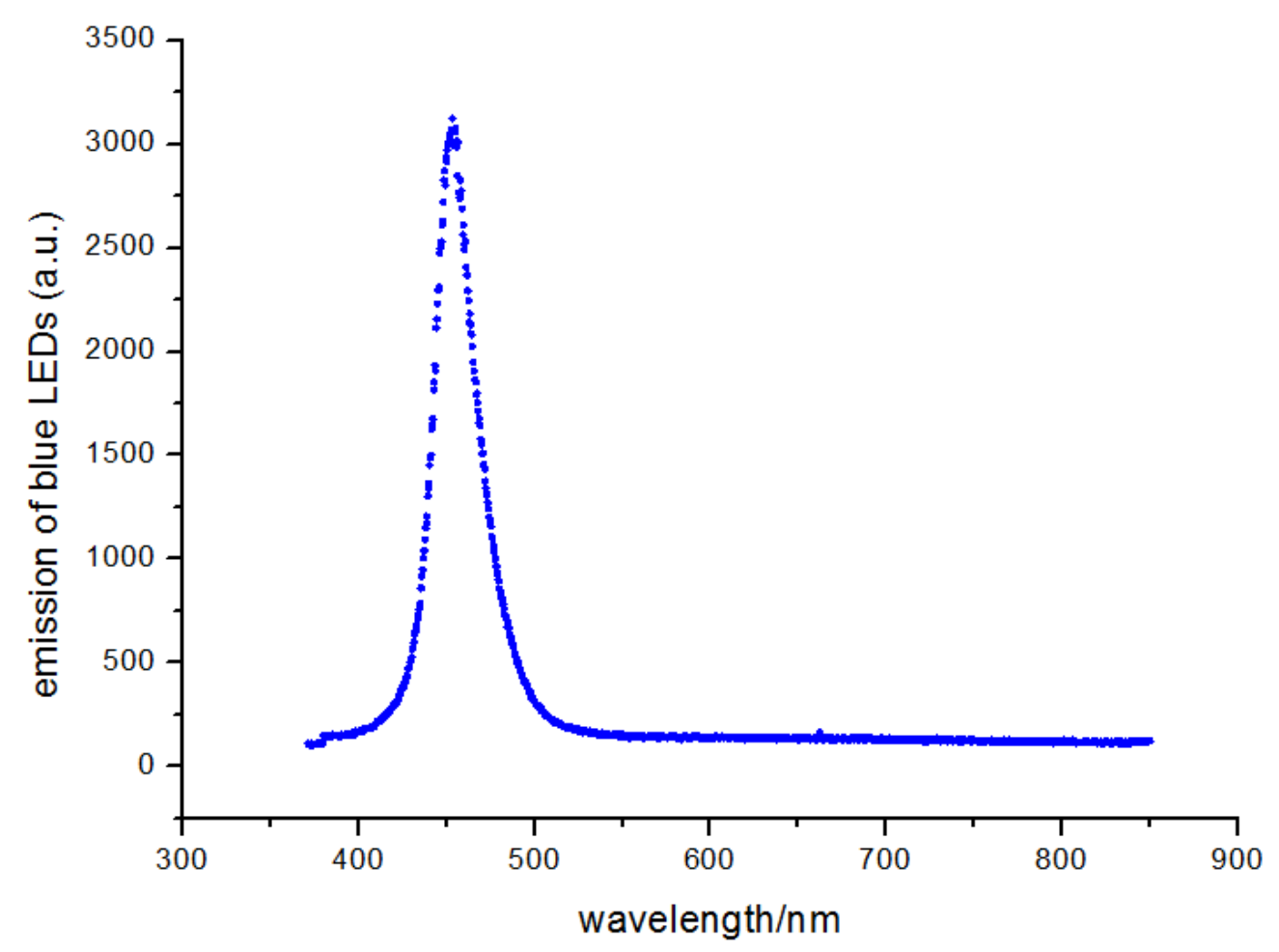



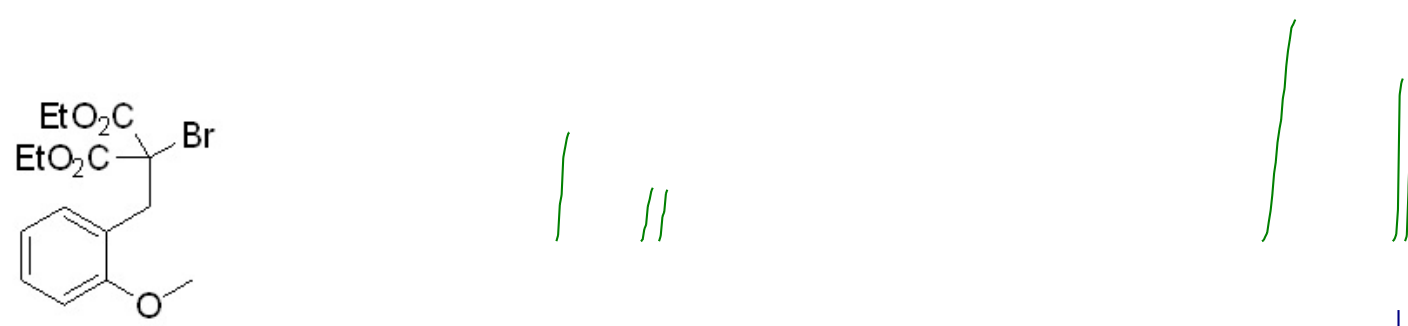

${ }^{1} \mathrm{H}$ NMR $\left(500 \mathrm{MHz}, \mathrm{CDCl}_{3}\right)$

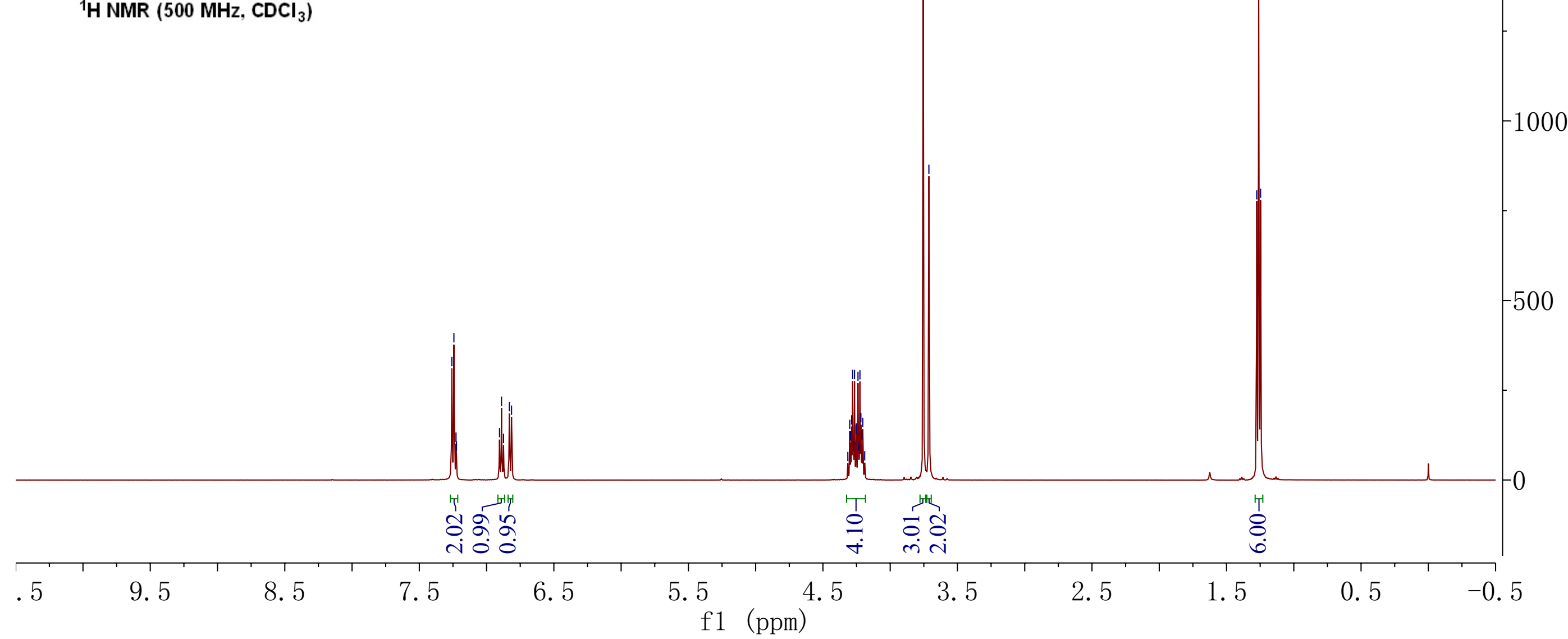




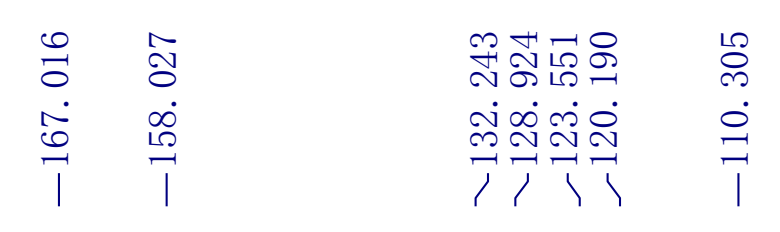

$\mathrm{EtO}_{2} \mathrm{C} \succ \mathrm{Br}$

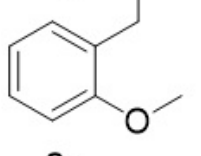

2a

${ }^{13} \mathrm{C}\left\{{ }^{1} \mathrm{H}\right\}$ NMR (126 MHz, $\left.\mathrm{CDCl}_{3}\right)$

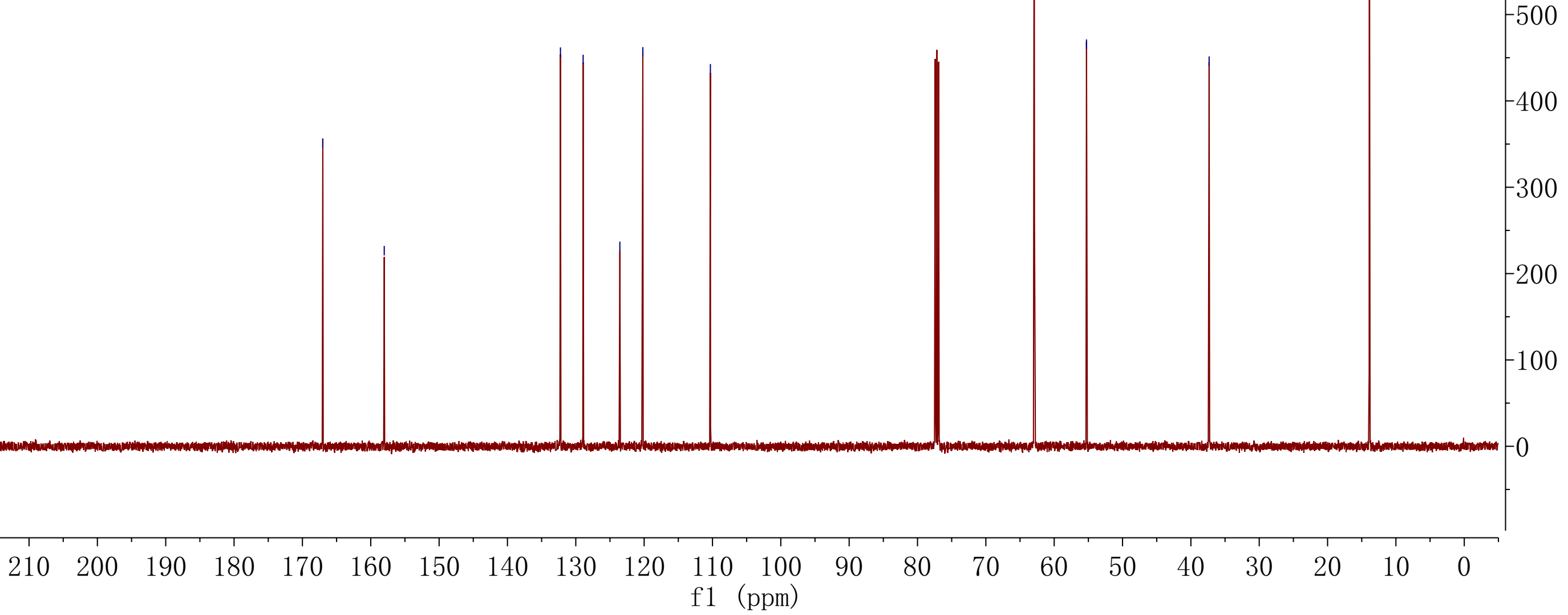




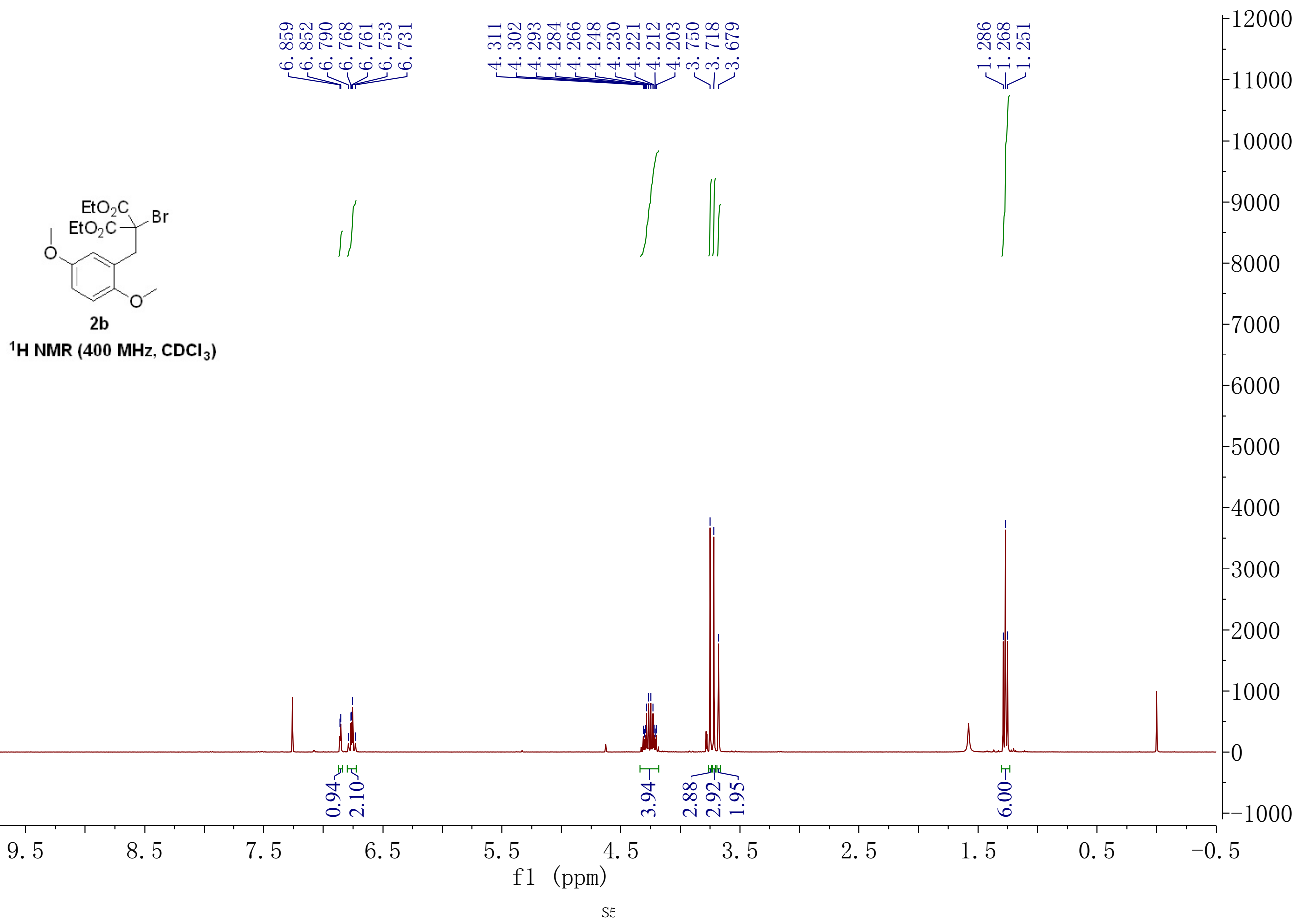




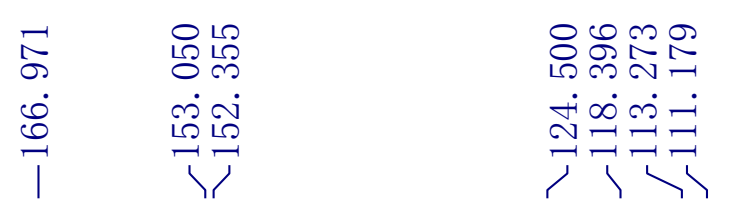

${ }^{13} \mathrm{C}\left\{{ }^{1} \mathrm{H}\right\}$ NMR (100 MHz, $\left.\mathrm{CDCl}_{3}\right)$

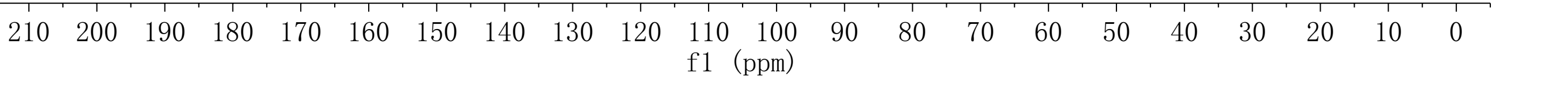




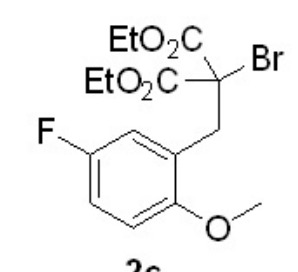

$1 / 1$

2c

${ }^{1} \mathrm{H}$ NMR $\left(400 \mathrm{MHz}, \mathrm{CDCl}_{3}\right)$

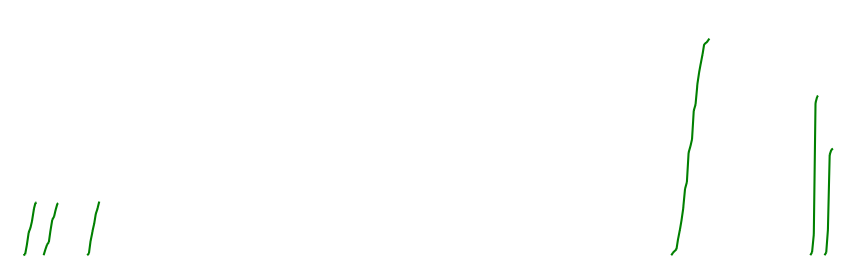

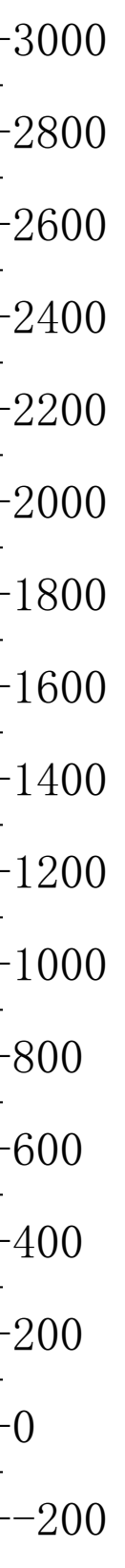

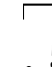

9.5

8.5

7.5

6.5

5. 5

f1 (ppm)

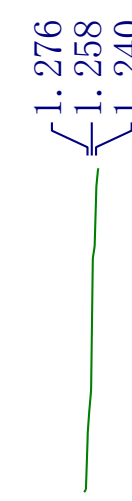

$-3000$

2. 5

1. 5

0.5

$-0.5$ 


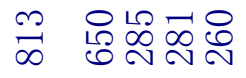

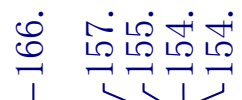

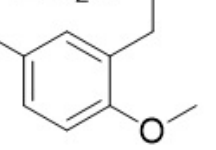

2c

${ }^{13} \mathrm{C}\left\{{ }^{1} \mathrm{H}\right\}$ NMR $\left(100 \mathrm{MHz}, \mathrm{CDCl}_{3}\right)$

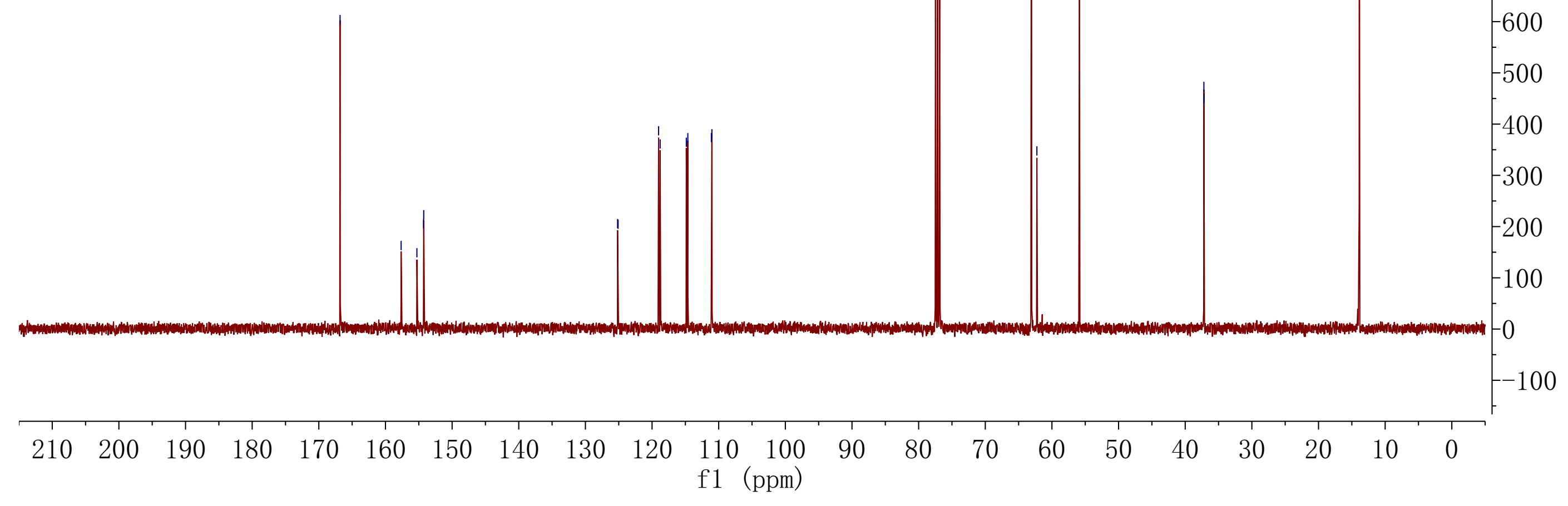




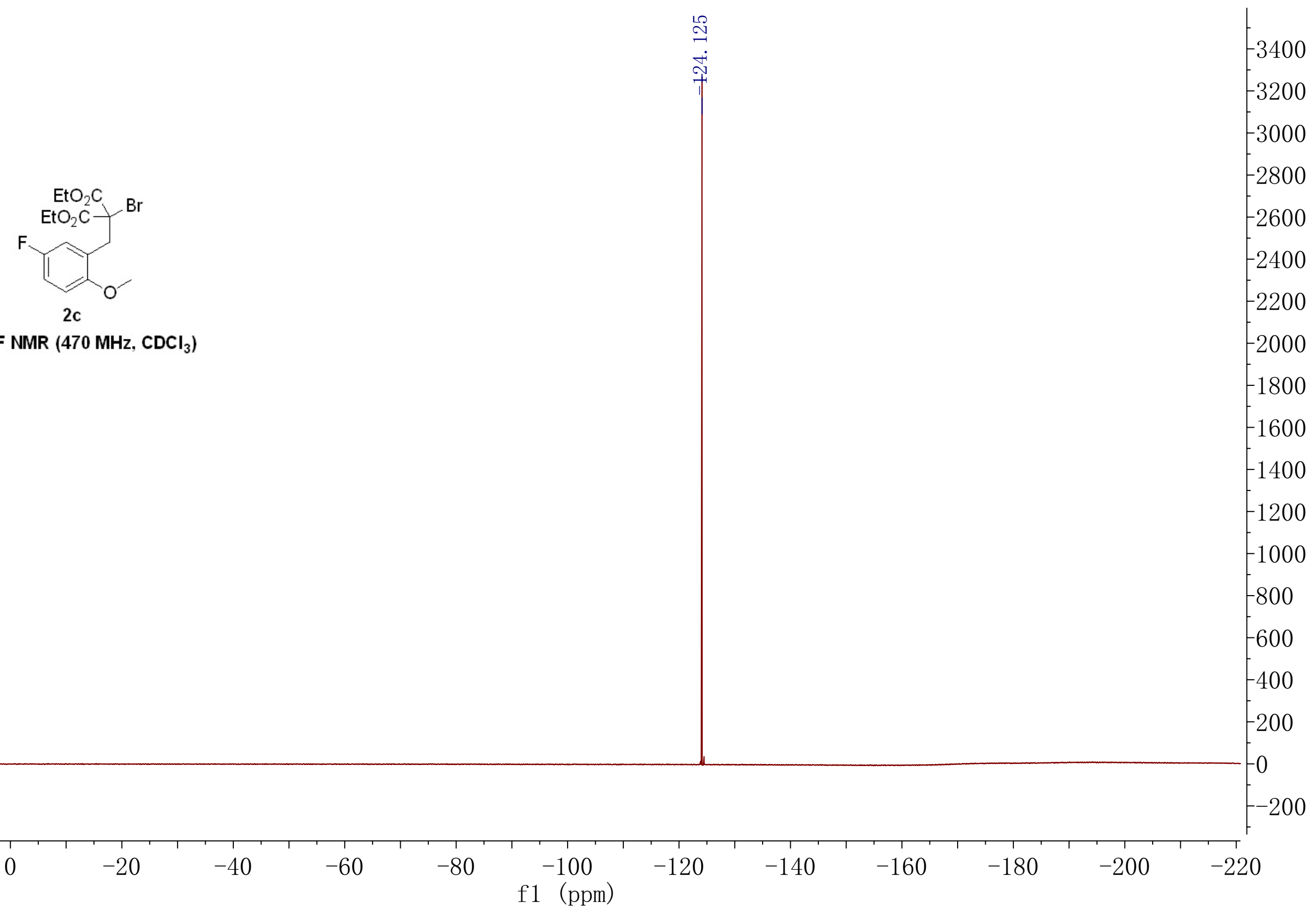


$\mathrm{Br}$ $\mathrm{EtO}_{2} \mathrm{C}-\mathrm{Br}$

B

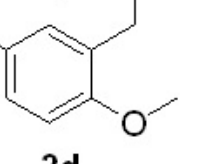

${ }^{1} \mathrm{H}$ NMR $\left(400 \mathrm{MHz}, \mathrm{CDCl}_{3}\right)$

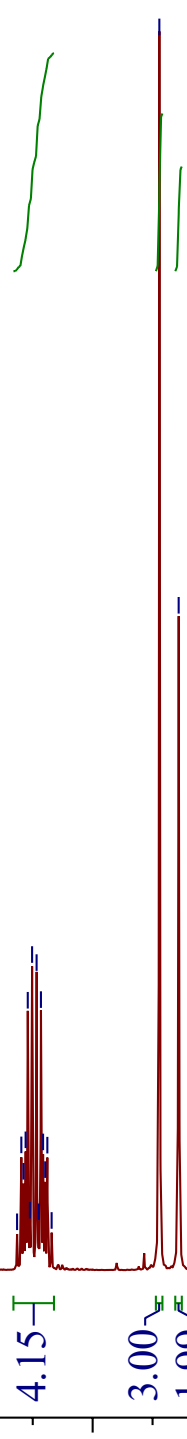

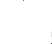

9.5

8.5

7.5

6.5

5.5

f1 (ppm)

$4.5 \quad 3.5$ 


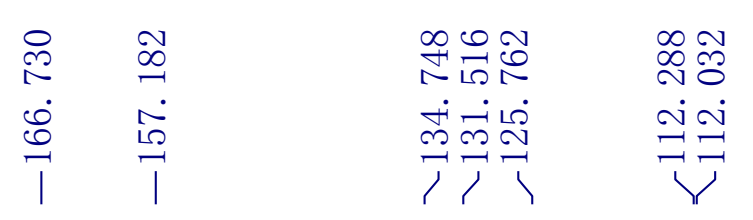

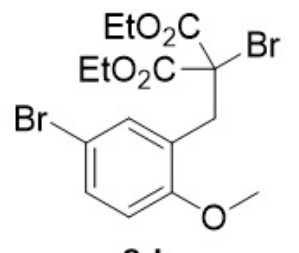

2d

${ }^{13} \mathrm{C}\left\{{ }^{1} \mathrm{H}\right\}$ NMR $\left(100 \mathrm{MHz}, \mathrm{CDCl}_{3}\right)$

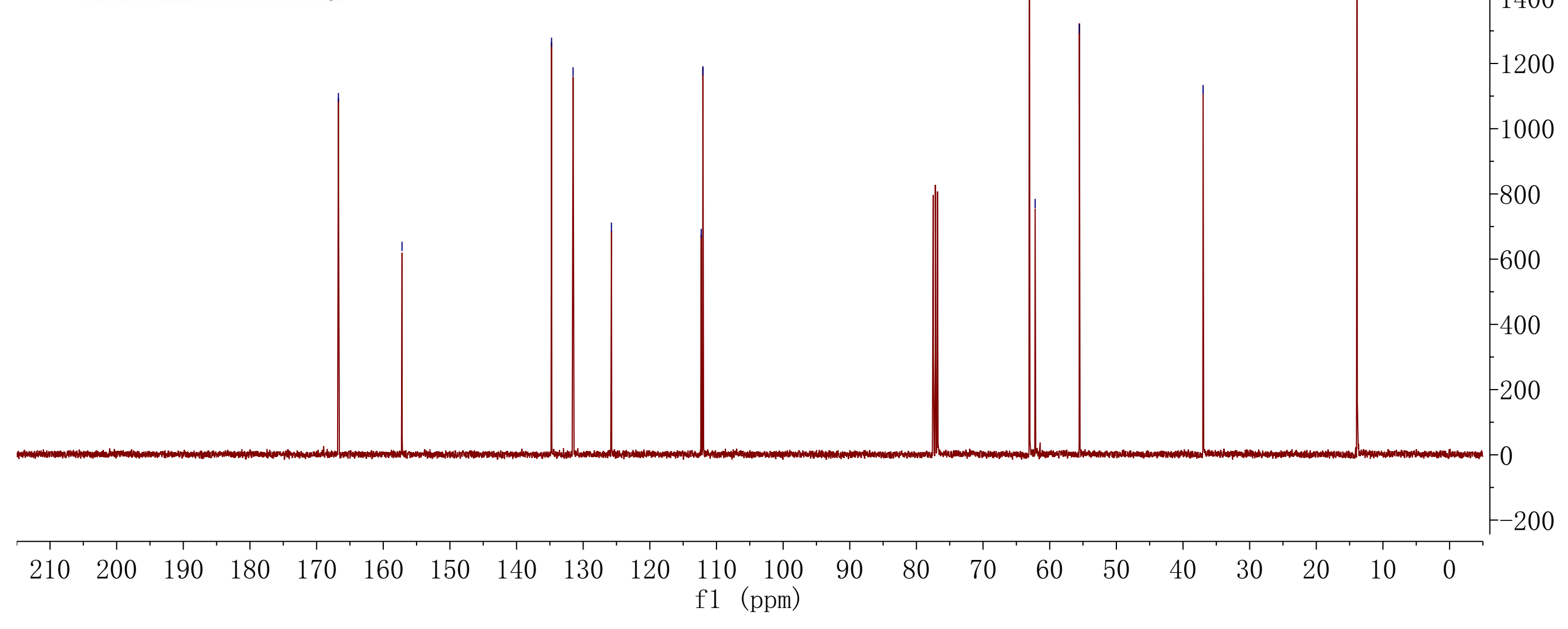



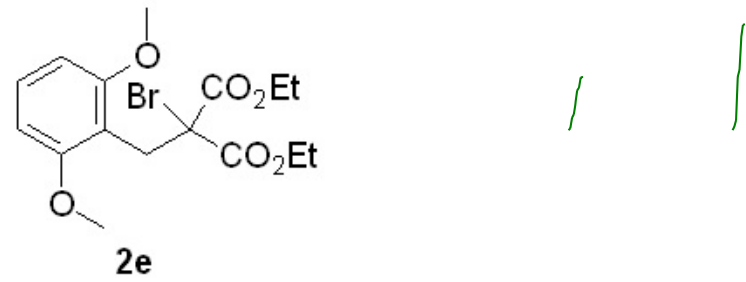

${ }^{1} \mathrm{H}$ NMR $\left(500 \mathrm{MHz}, \mathrm{CDCl}_{3}\right)$
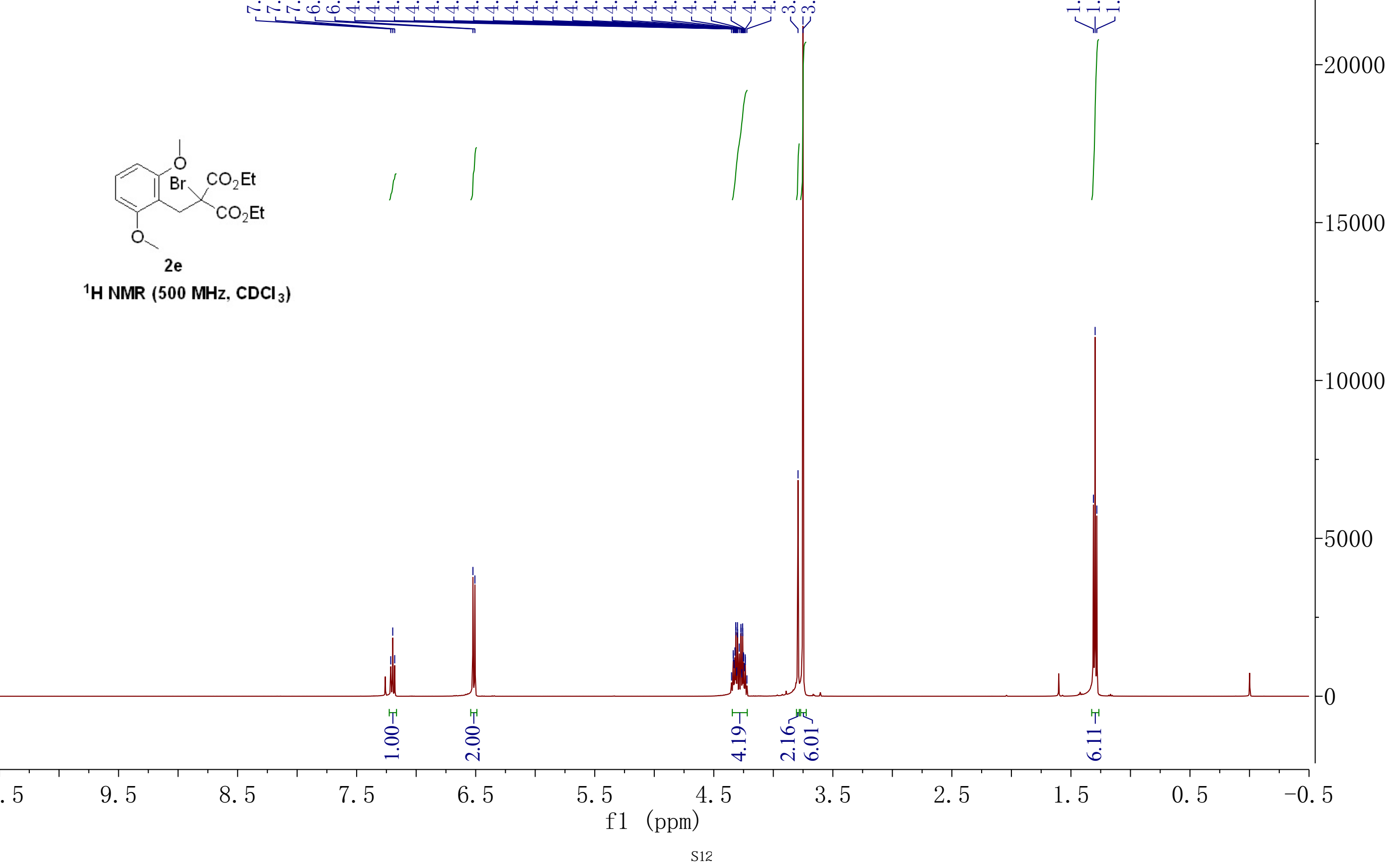


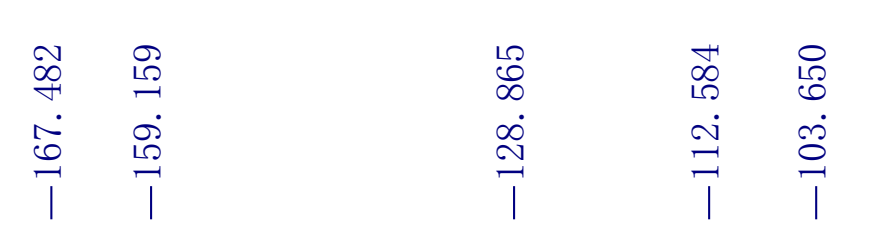

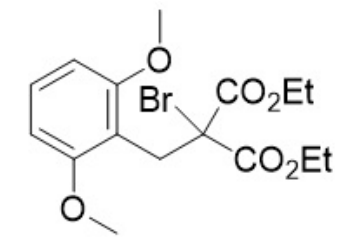

$2 \mathrm{e}$

${ }^{13} \mathrm{C}\left\{{ }^{1} \mathrm{H}\right\}$ NMR $\left(126 \mathrm{MHz}, \mathrm{CDCl}_{3}\right)$ 


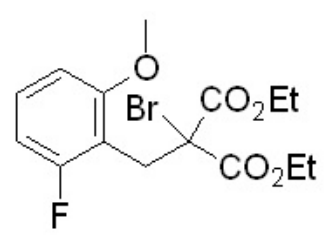

2f

${ }^{1} \mathrm{H}$ NMR $\left(500 \mathrm{MHz}, \mathrm{CDCl}_{3}\right)$
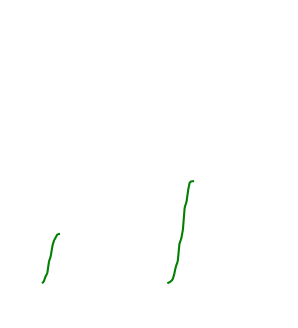


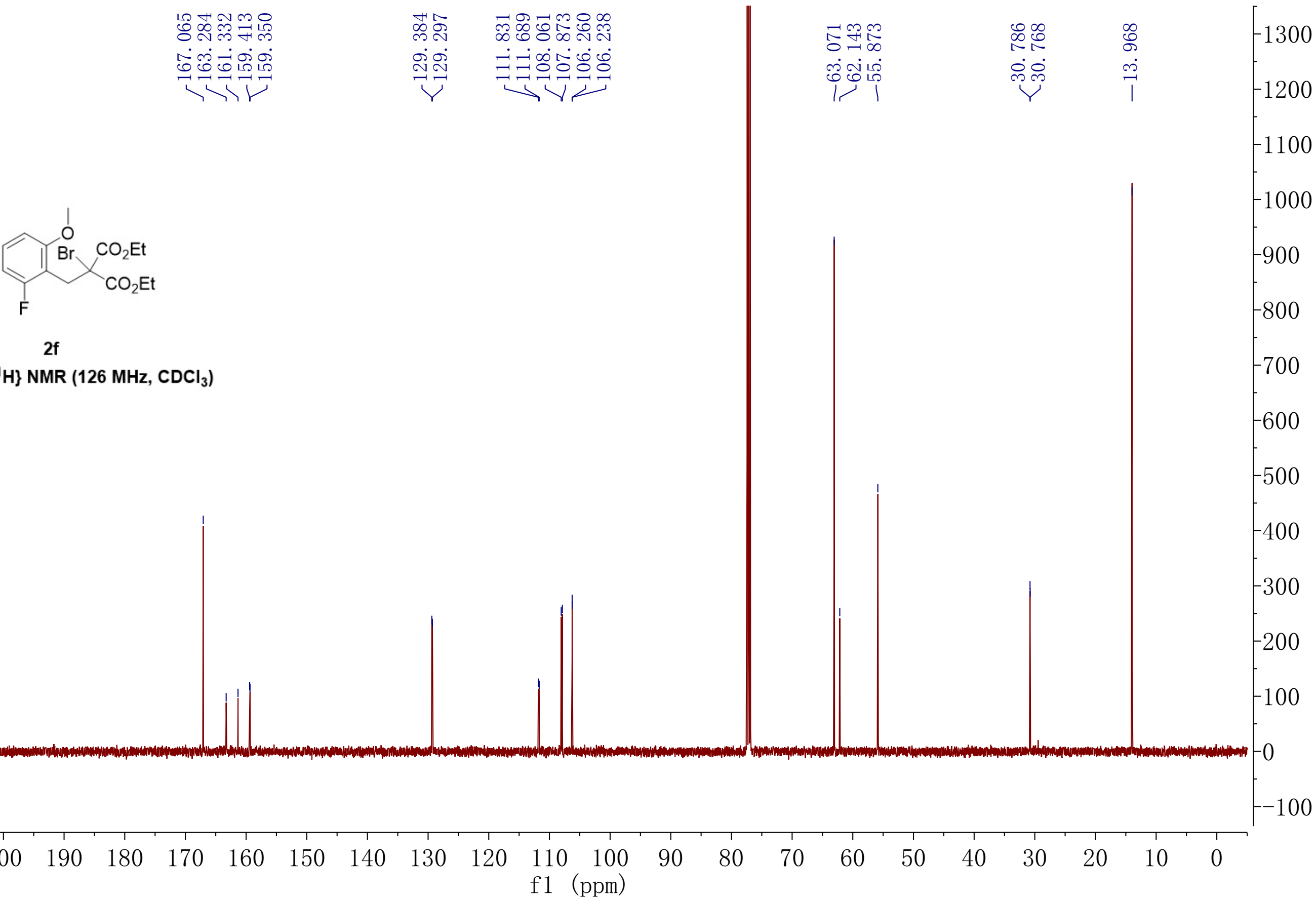




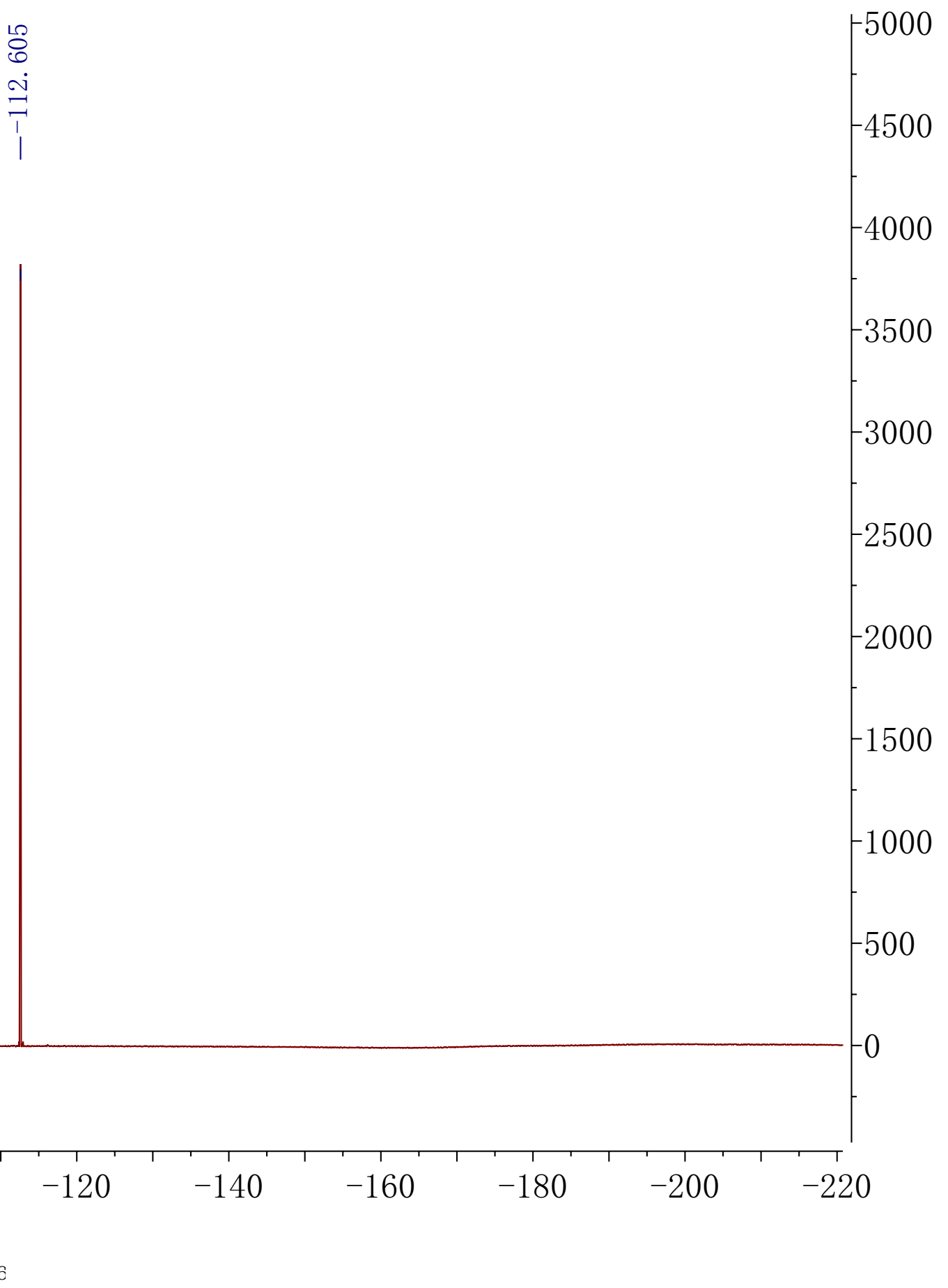




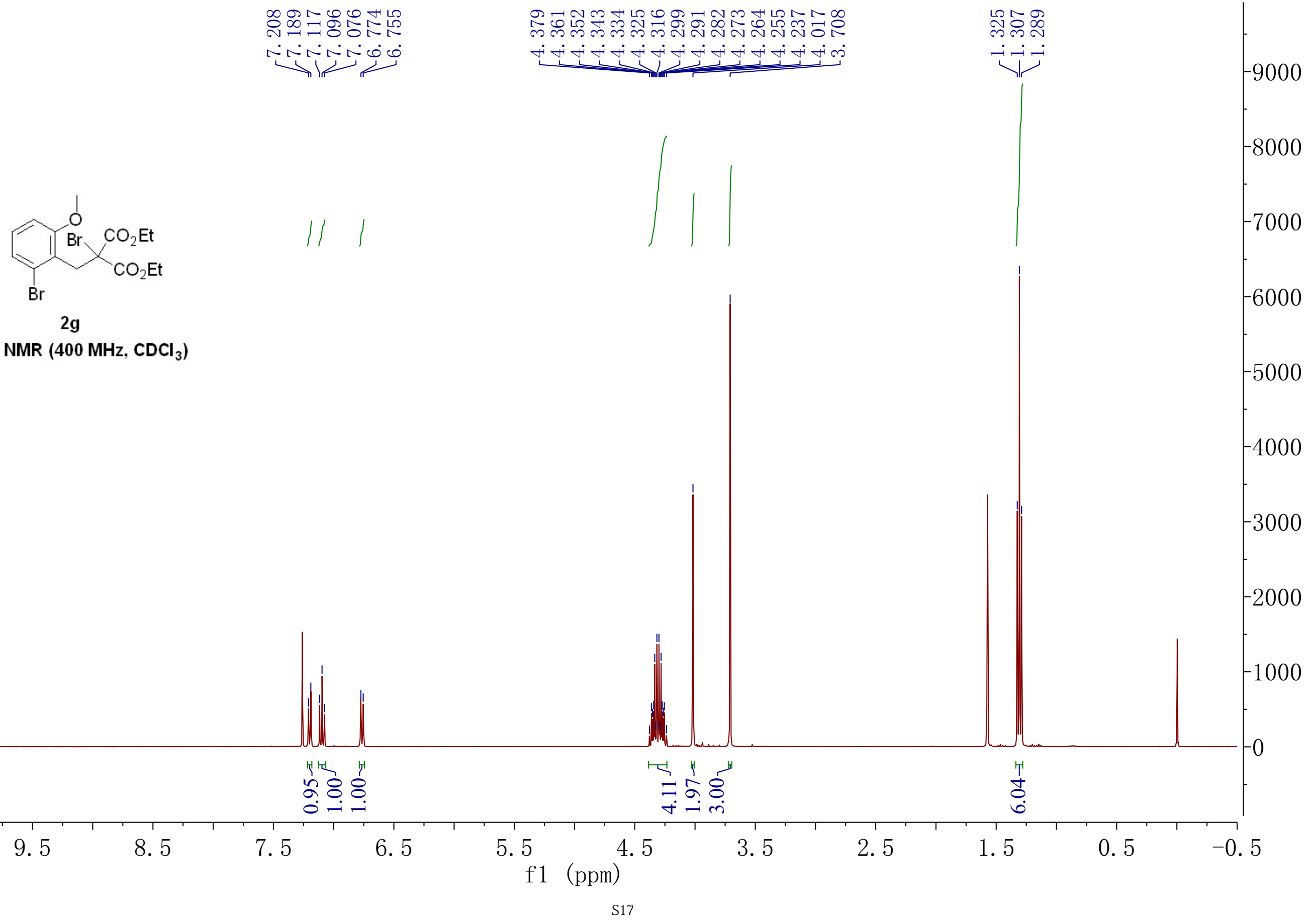




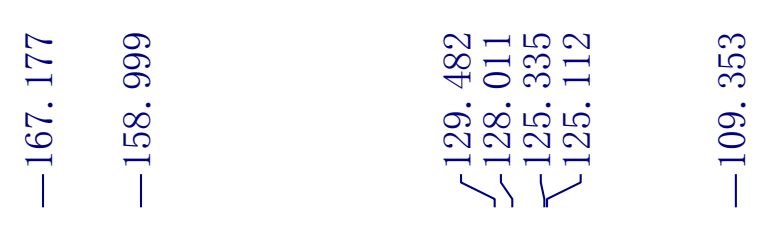

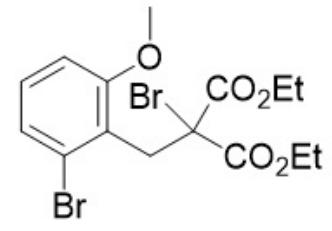

2g

${ }^{13} \mathrm{C}\left\{{ }^{1} \mathrm{H}\right\}$ NMR $\left(100 \mathrm{MHz}, \mathrm{CDCl}_{3}\right)$
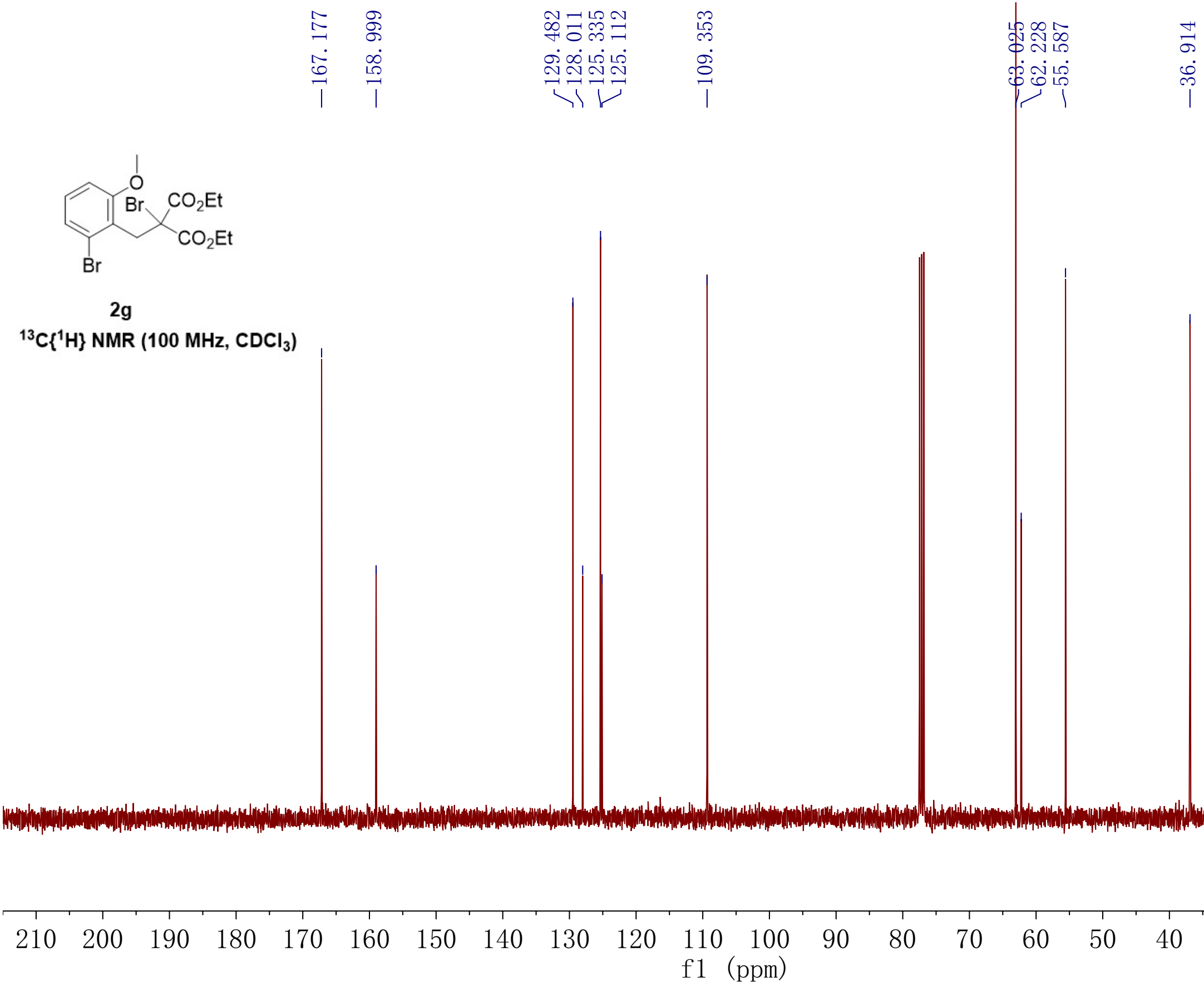
$\stackrel{\mathrm{EtO}_{2} \mathrm{C}}{\mathrm{EtO}_{2} \mathrm{C}}>\mathrm{Br}$

${ }^{1} \mathrm{H}$ NMR $\left(400 \mathrm{MHz}, \mathrm{CDCl}_{3}\right)$
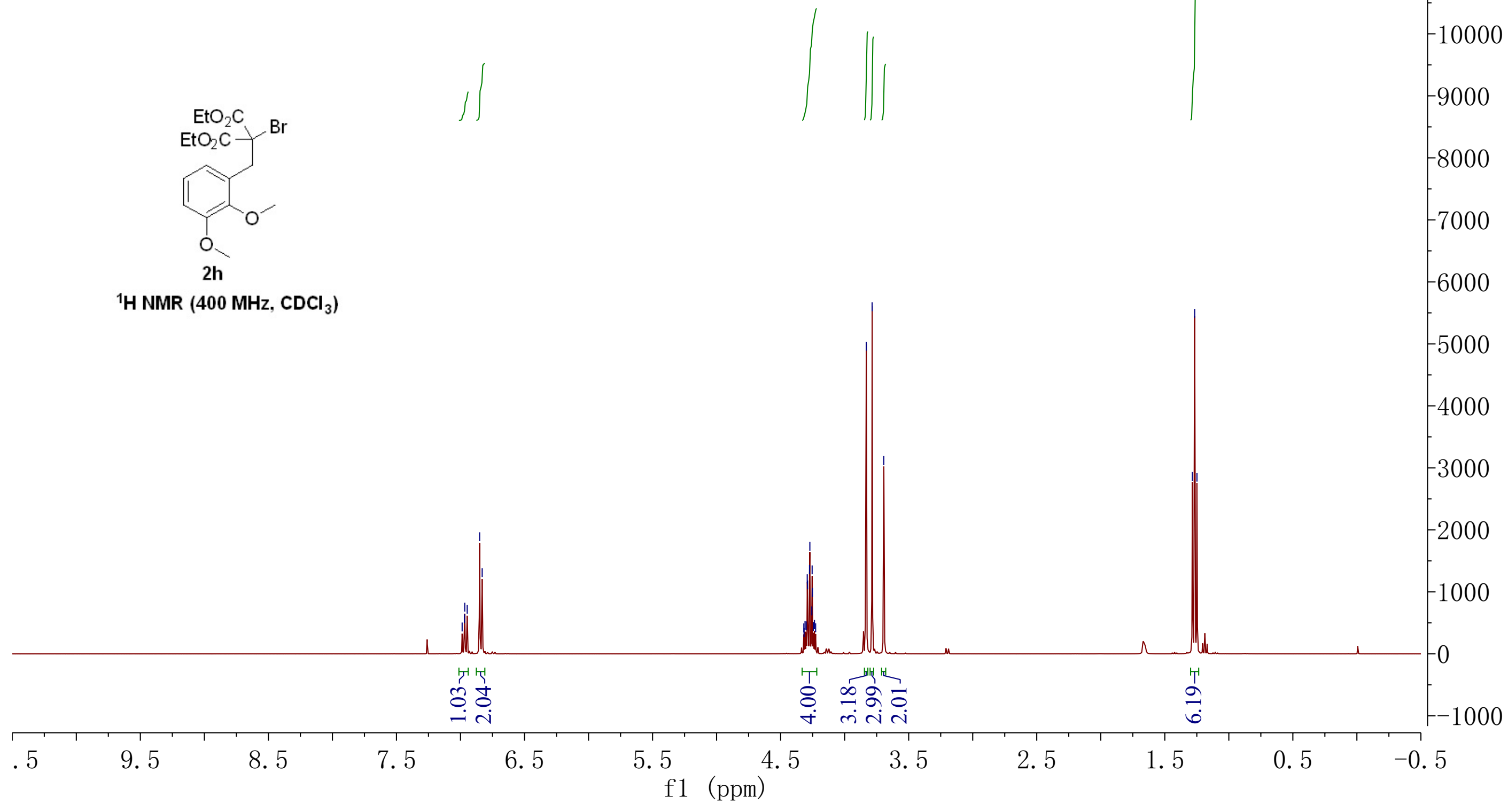


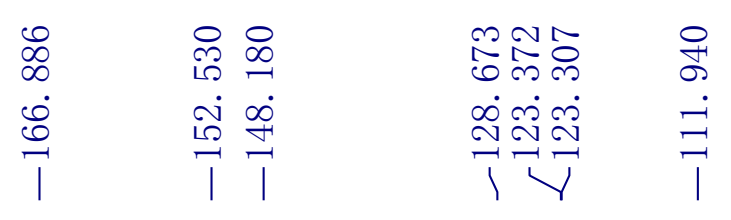

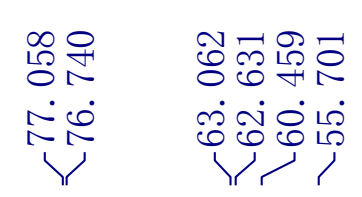

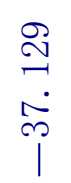

0
$\stackrel{0}{*}$
$\stackrel{9}{1}$

3400

$\mathrm{EtO}_{2} \mathrm{C}-\mathrm{Br}$

$\mathrm{EtO}_{2} \mathrm{C}-$

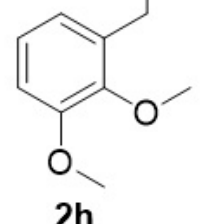

${ }^{13} \mathrm{C}\left\{{ }^{1} \mathrm{H}\right\} \mathrm{NMR}\left(100 \mathrm{MHz}, \mathrm{CDCl}_{3}\right)$ |
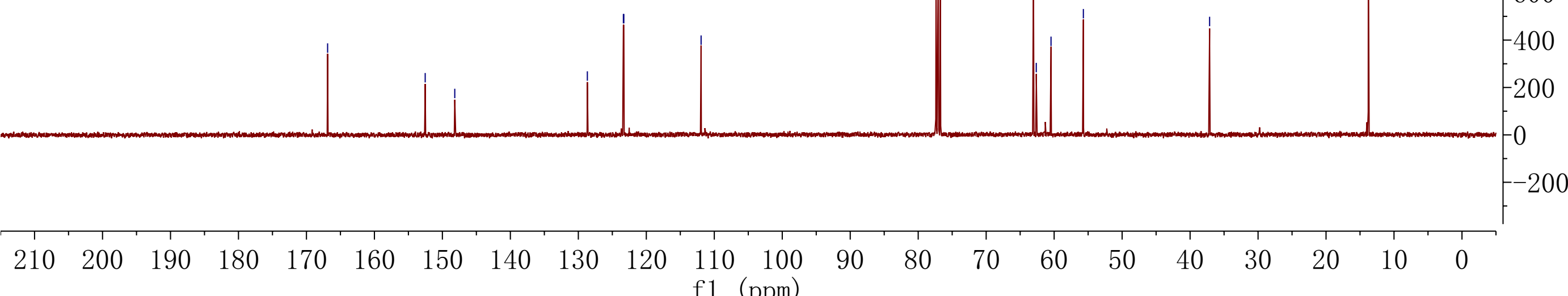


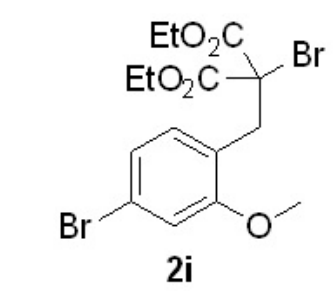

${ }^{1} \mathrm{H}$ NMR $\left(400 \mathrm{MHz}, \mathrm{CDCl}_{3}\right)$
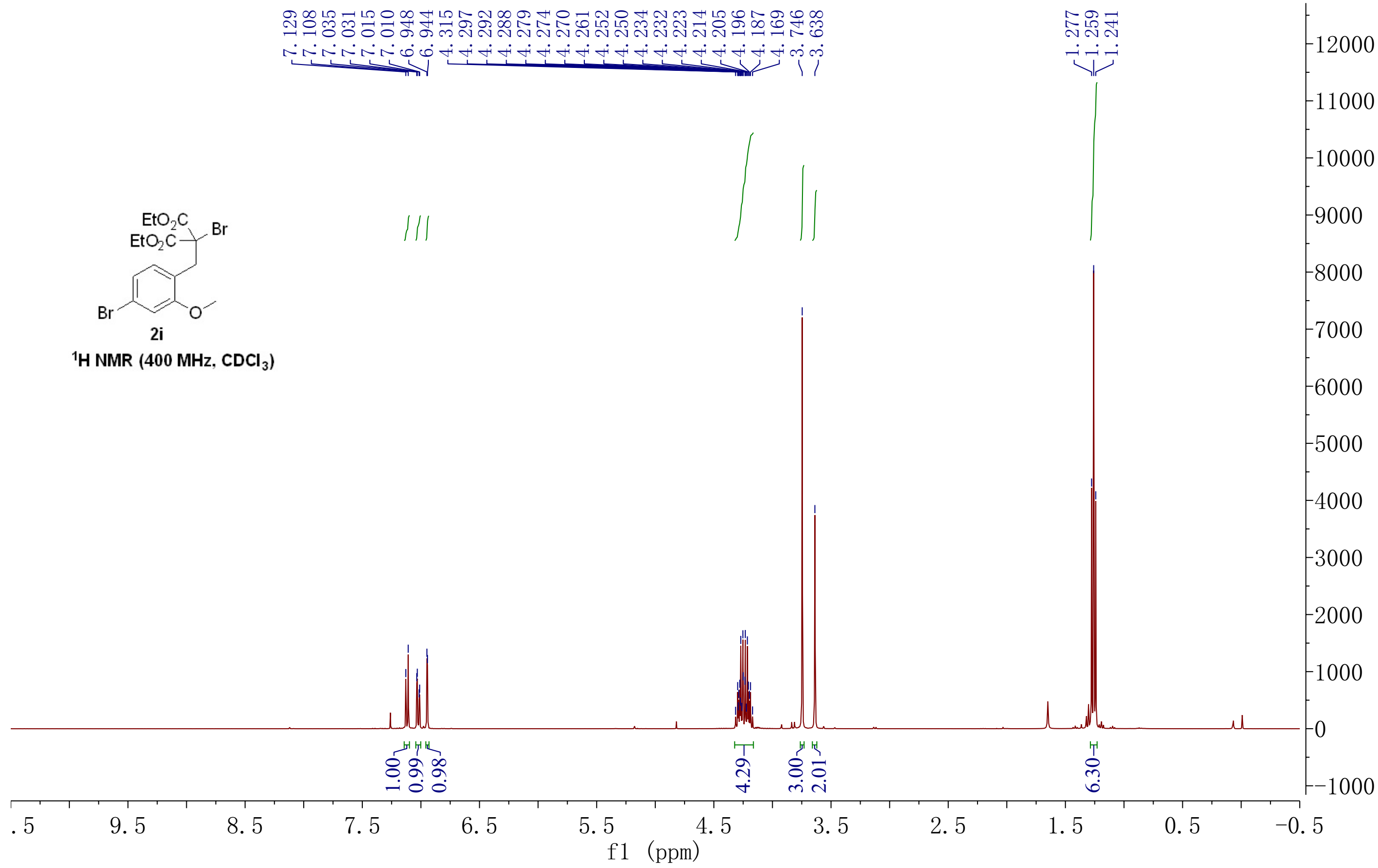


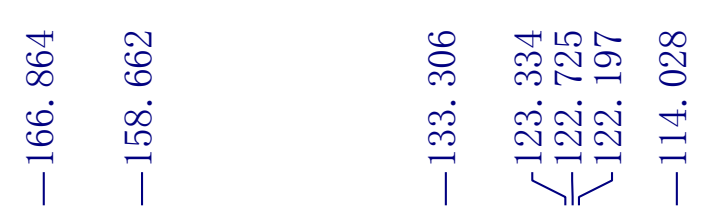

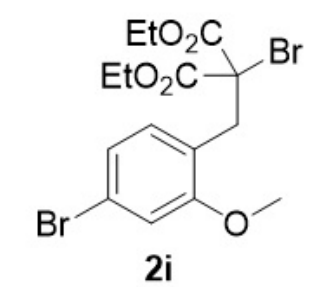

${ }^{13} \mathrm{C}\left\{{ }^{1} \mathrm{H}\right\}$ NMR $\left(100 \mathrm{MHz}, \mathrm{CDCl}_{3}\right)$

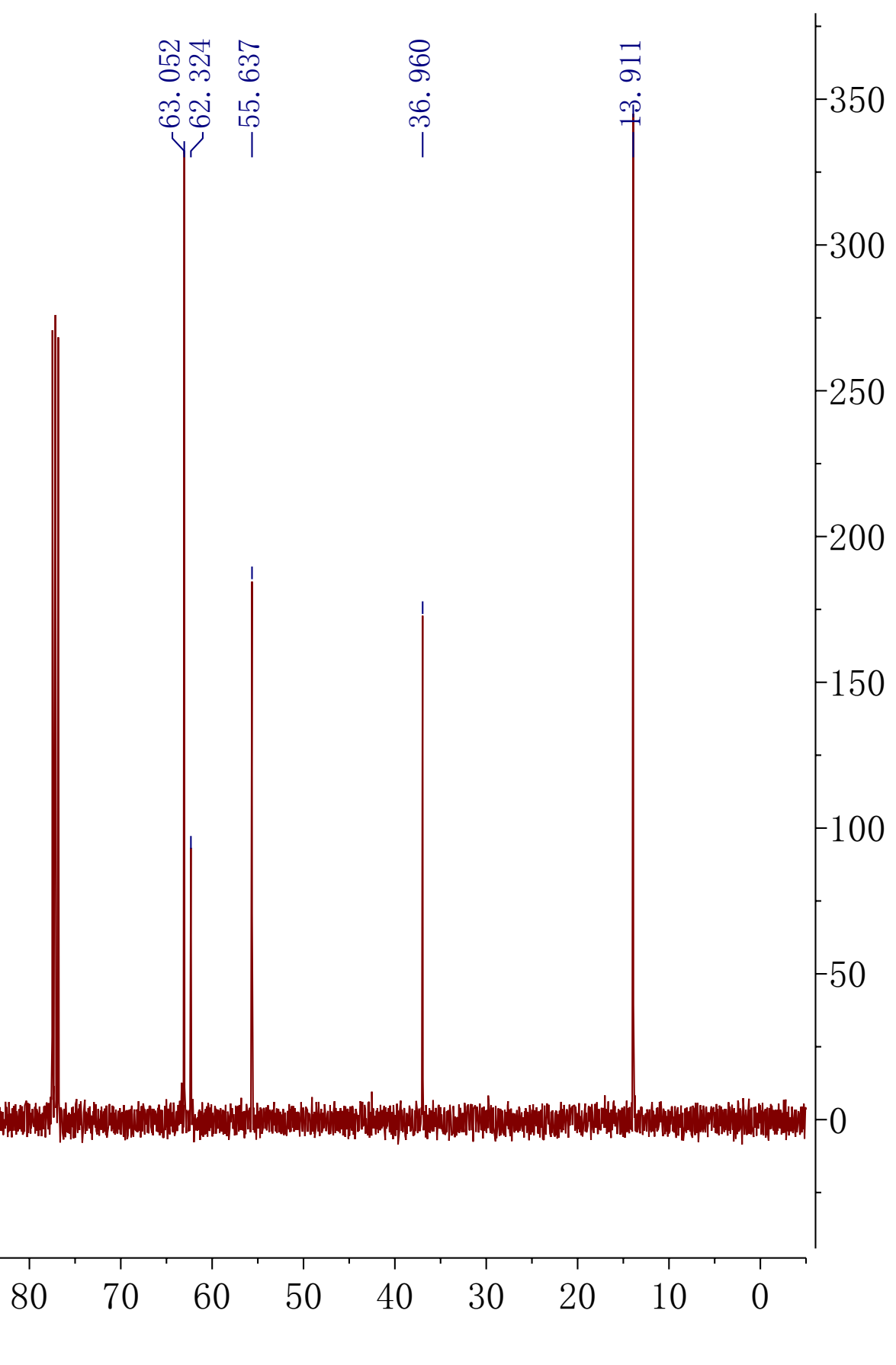




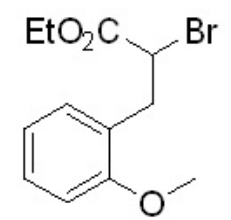

$2 \mathrm{j}$

${ }^{1} \mathrm{H}$ NMR $\left(400 \mathrm{MHz}, \mathrm{CDCl}_{3}\right)$
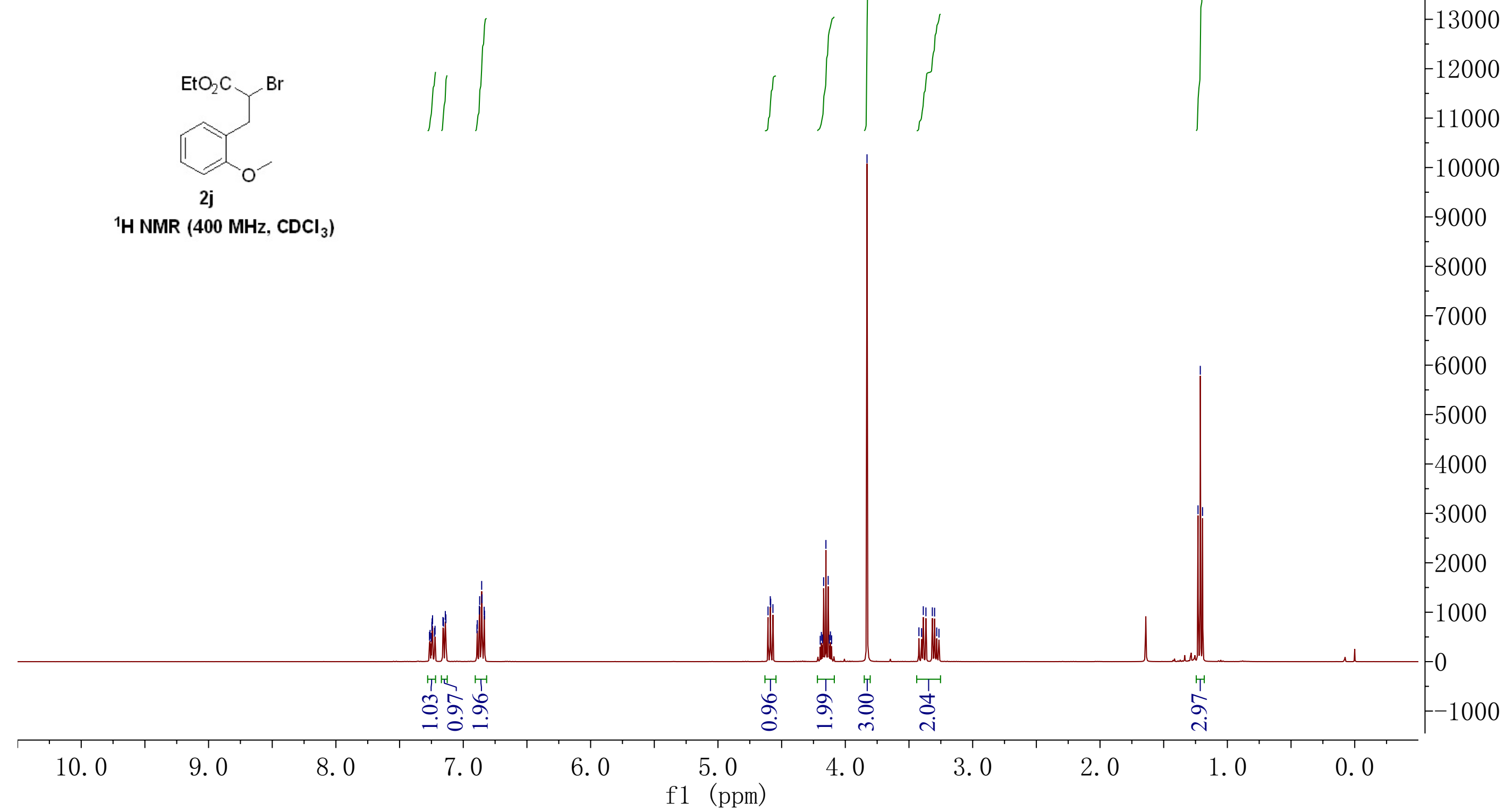


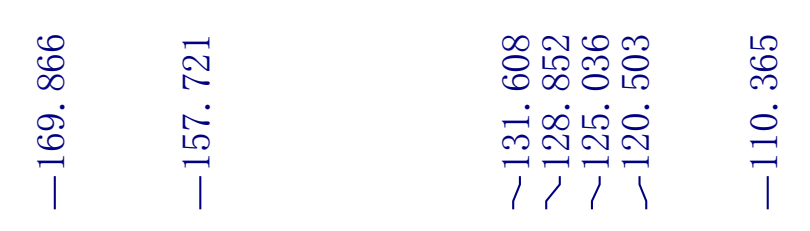

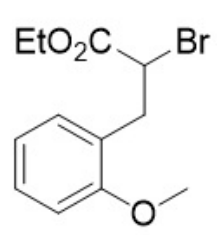

2j

${ }^{13} \mathrm{C}\left\{{ }^{1} \mathrm{H}\right\}$ NMR $\left(100 \mathrm{MHz}, \mathrm{CDCl}_{3}\right)$

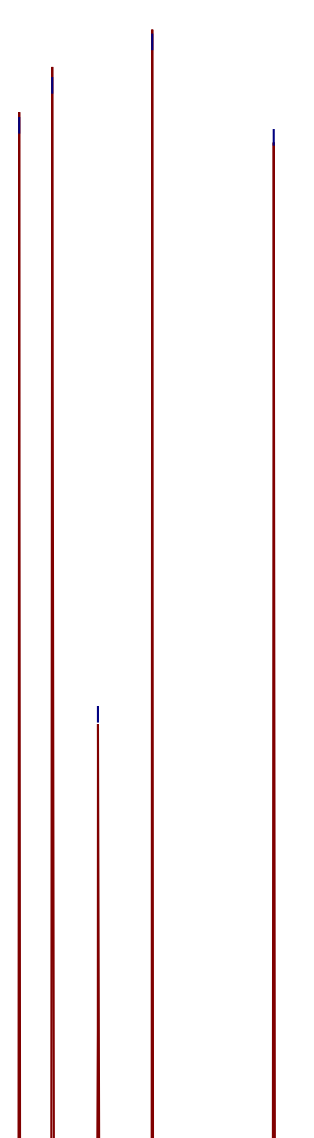

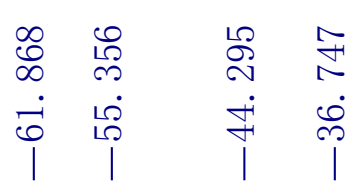

$\overrightarrow{2}$
$\stackrel{2}{\rho}$
$\stackrel{\sim}{1}$

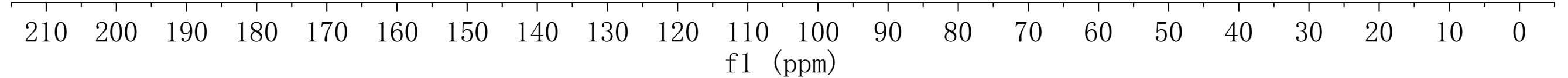




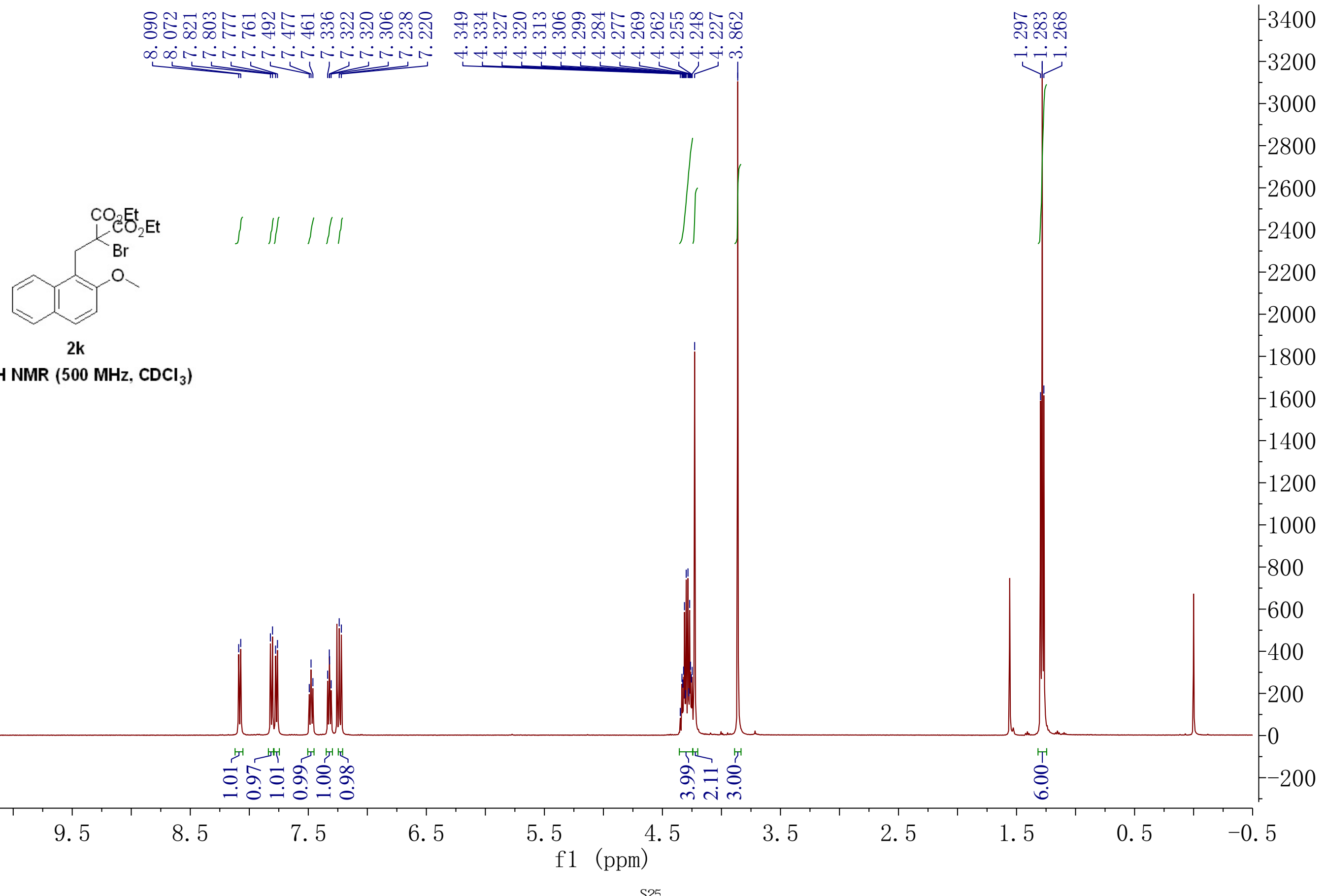




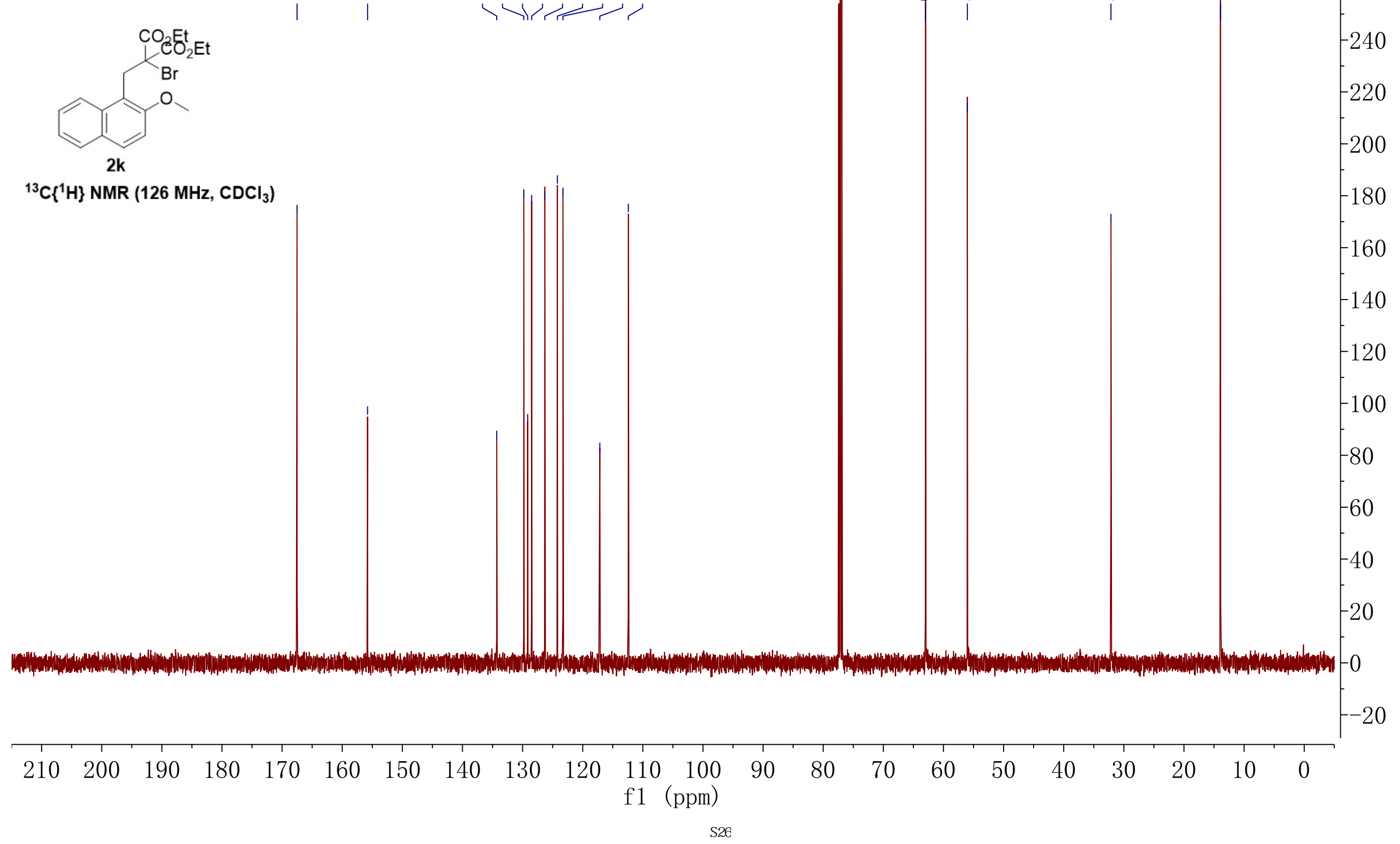



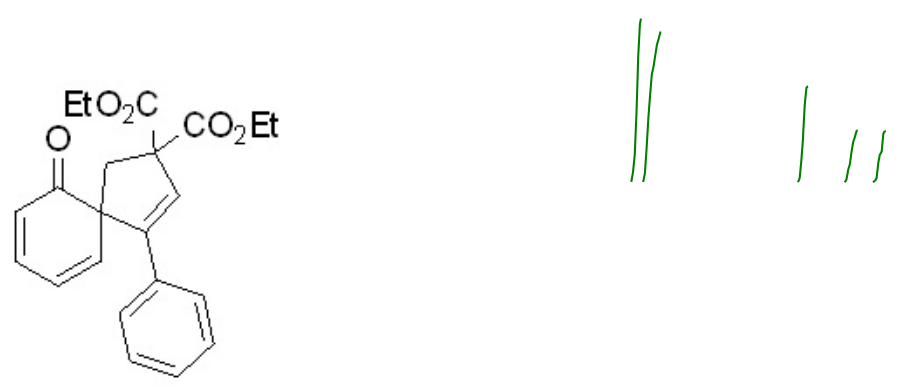

3aa

1H NMR (500 MHz, $\left.\mathrm{CDCl}_{3}\right)$

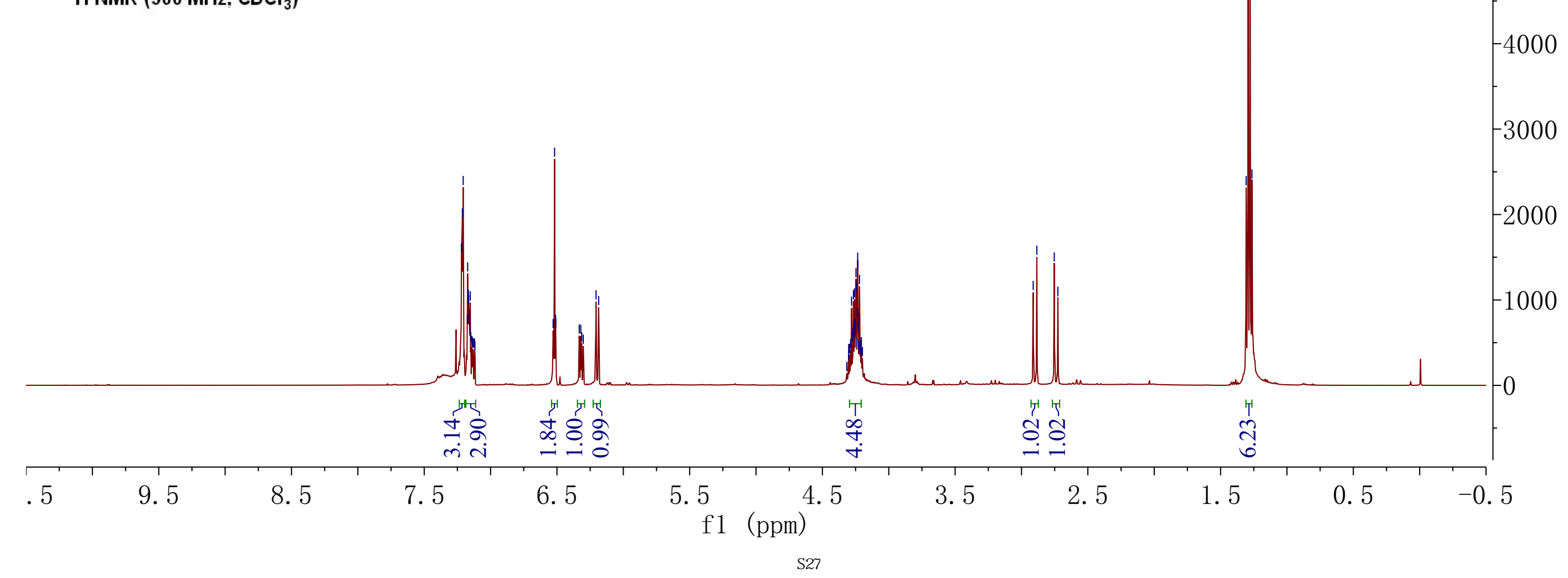



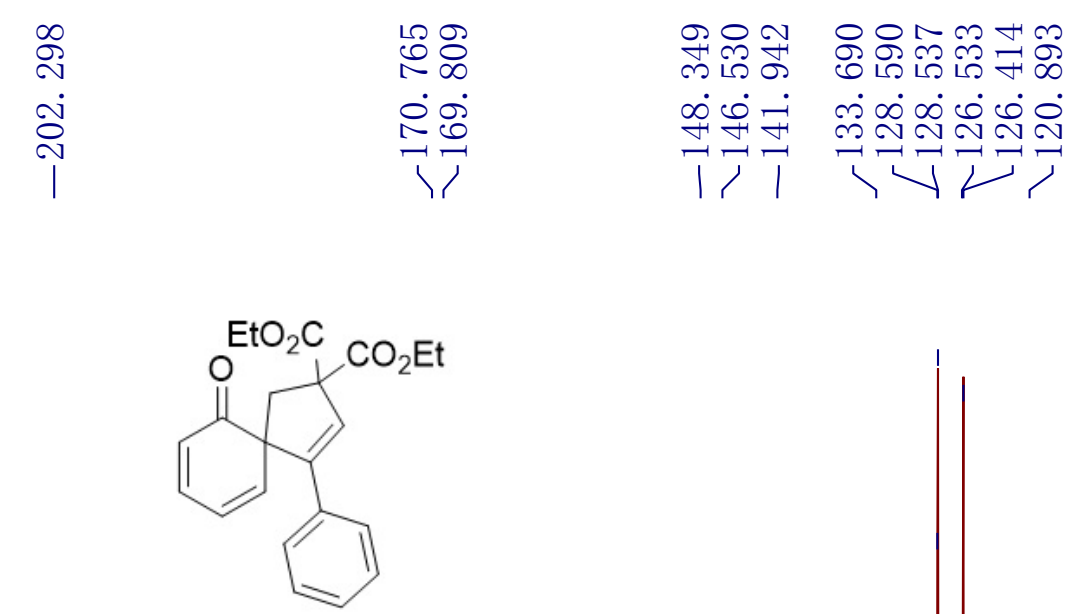

$3 a a$

${ }^{13} \mathrm{C}\left\{{ }^{1} \mathrm{H}\right\}$ NMR (126 MHz, $\left.\mathrm{CDCl}_{3}\right)$

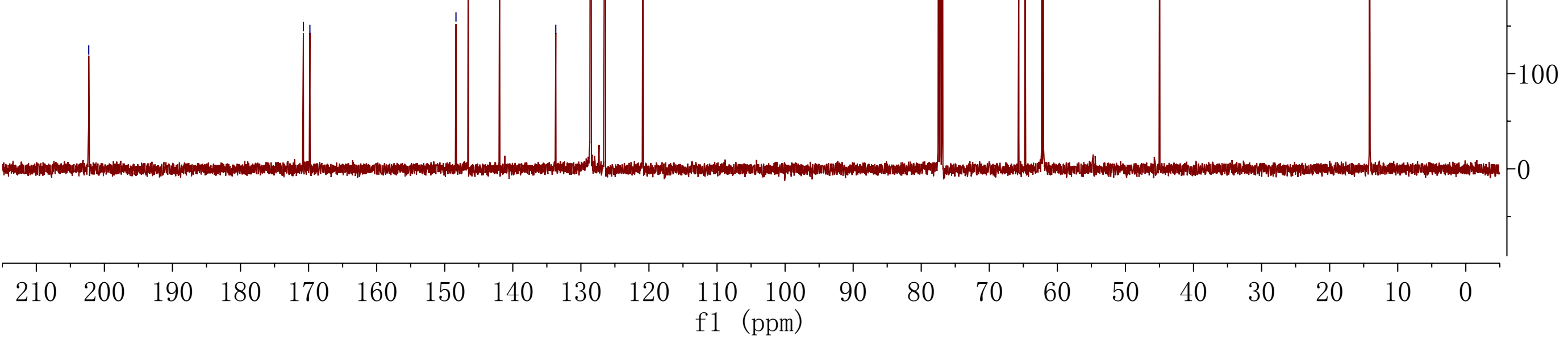




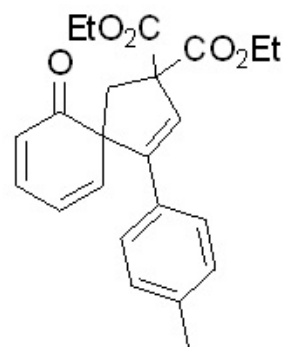

II II

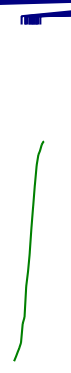

3ba

${ }^{1} \mathrm{H} \mathrm{NMR}\left(400 \mathrm{MHz}, \mathrm{CDCl}_{3}\right)$

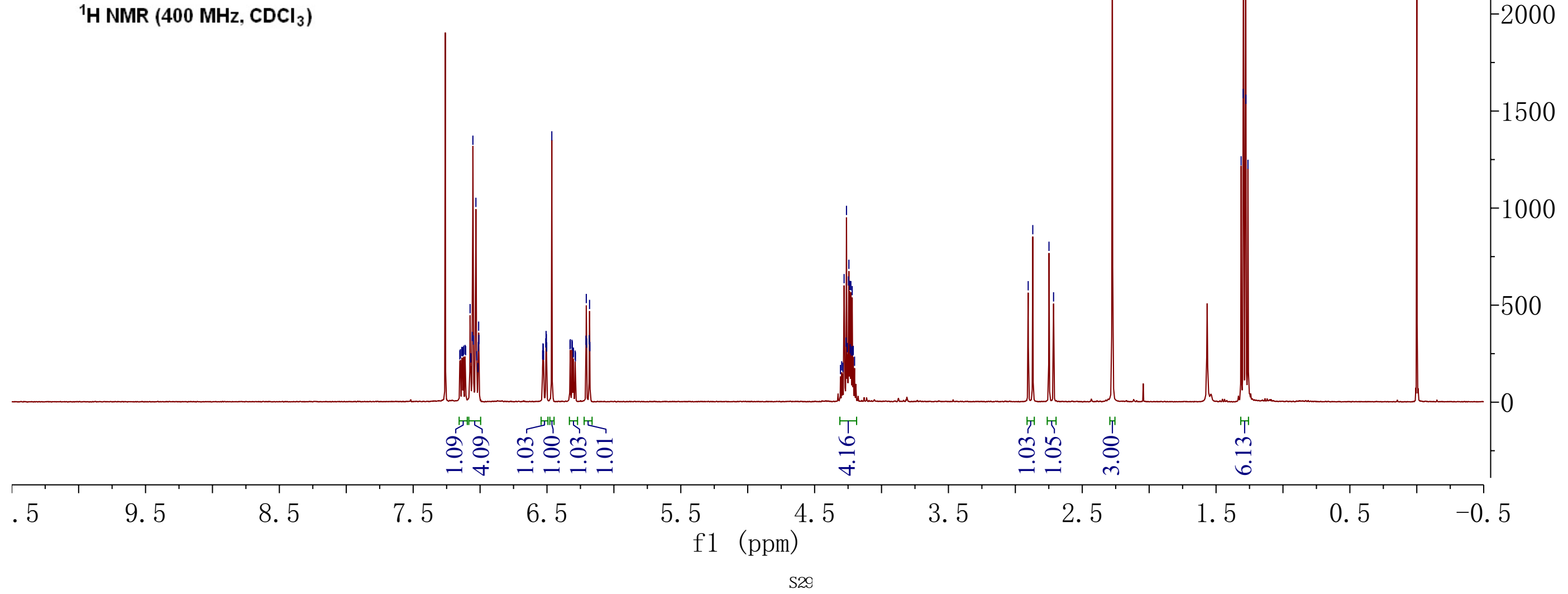



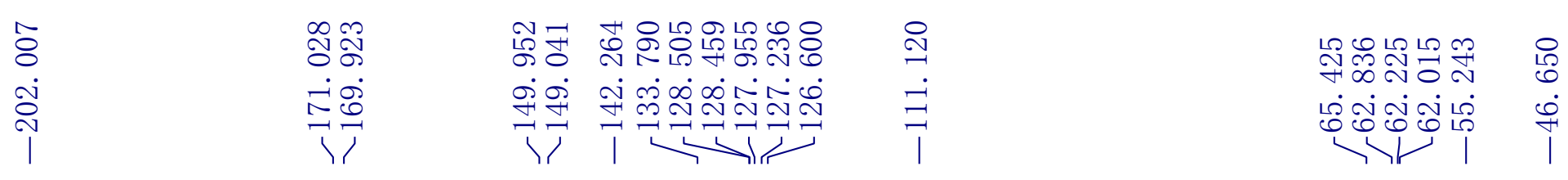

$\underset{\text { 崩 }}{\stackrel{+}{+}}$

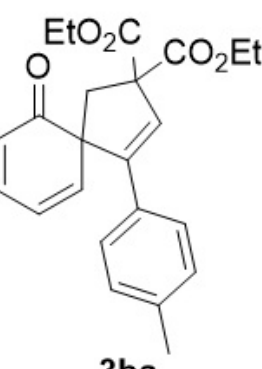

${ }^{13} \mathrm{C}\left\{{ }^{1} \mathrm{H}\right\}$ NMR (100 MHz, $\left.\mathrm{CDCl}_{3}\right)$

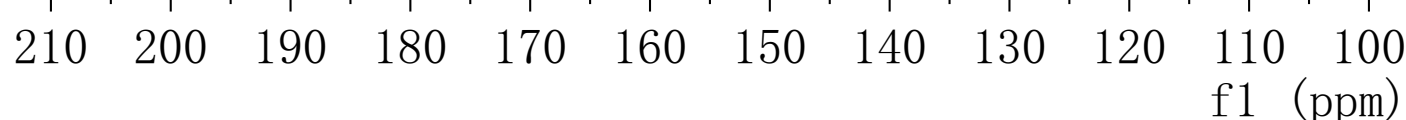



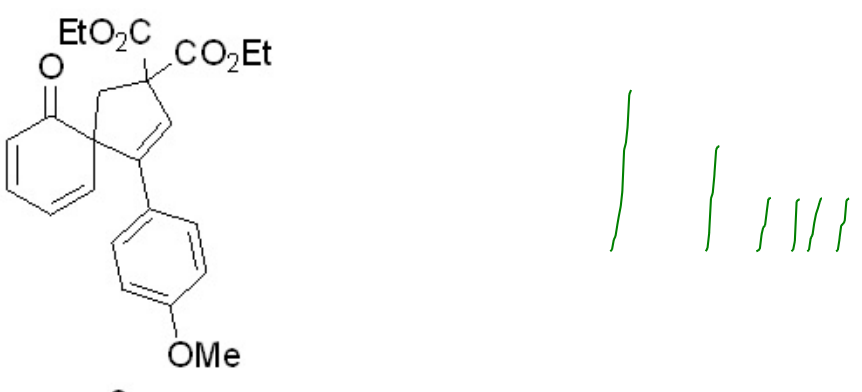

$3 \mathrm{ca}$

${ }^{1} \mathrm{H}$ NMR $\left(400 \mathrm{MHz}, \mathrm{CDCl}_{3}\right)$

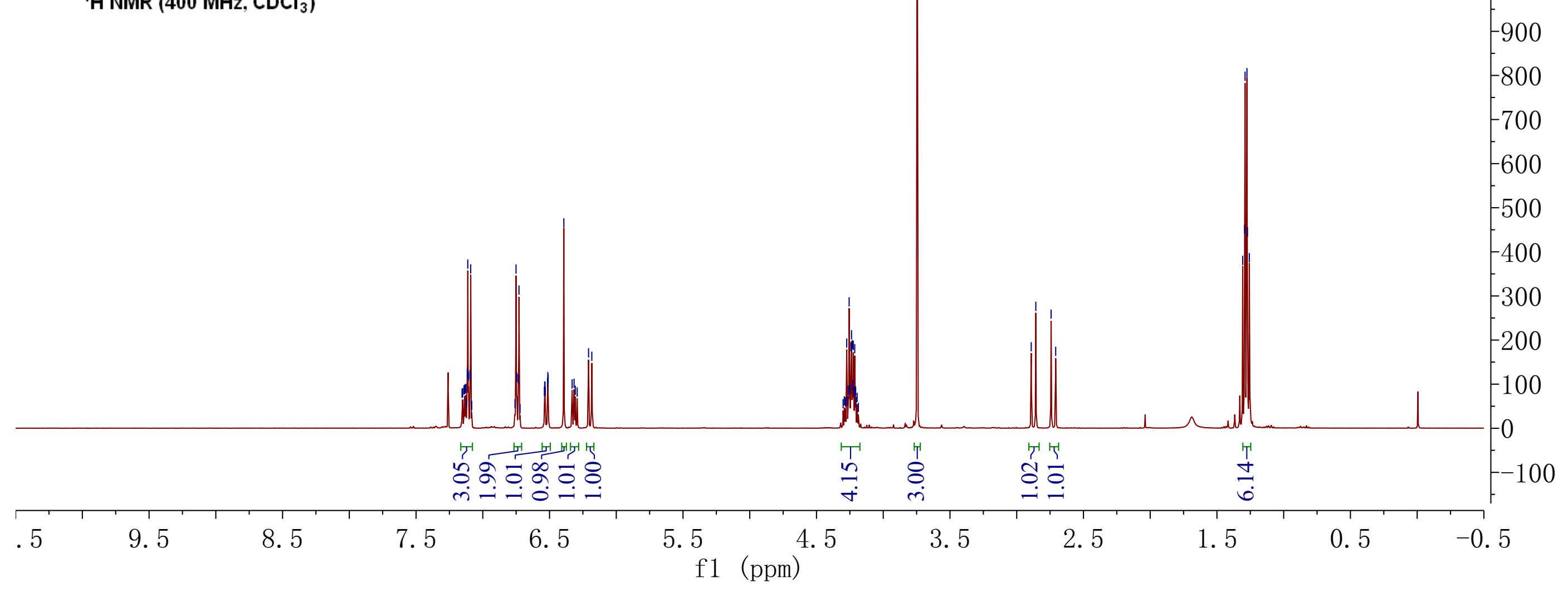




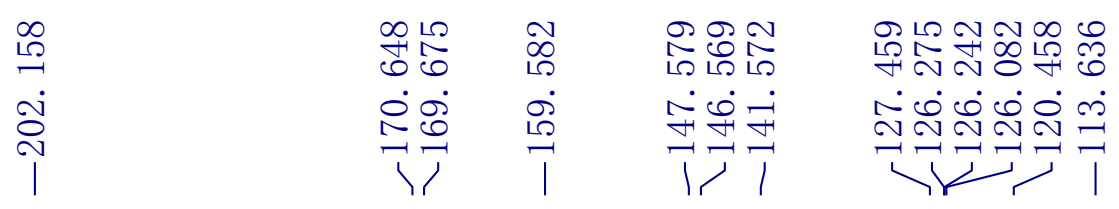

$$
\begin{aligned}
& \text { 유무요용 } \\
& \text { ம் சீं் ம் }
\end{aligned}
$$

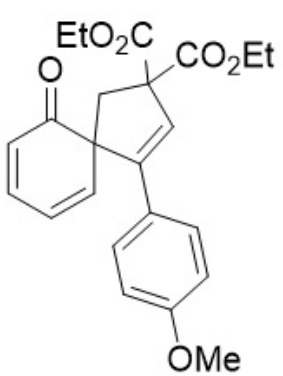

${ }^{13} \mathrm{C}\left\{{ }^{1} \mathrm{H}\right\}$ NMR $\left(100 \mathrm{MHz}, \mathrm{CDCl}_{3}\right)$

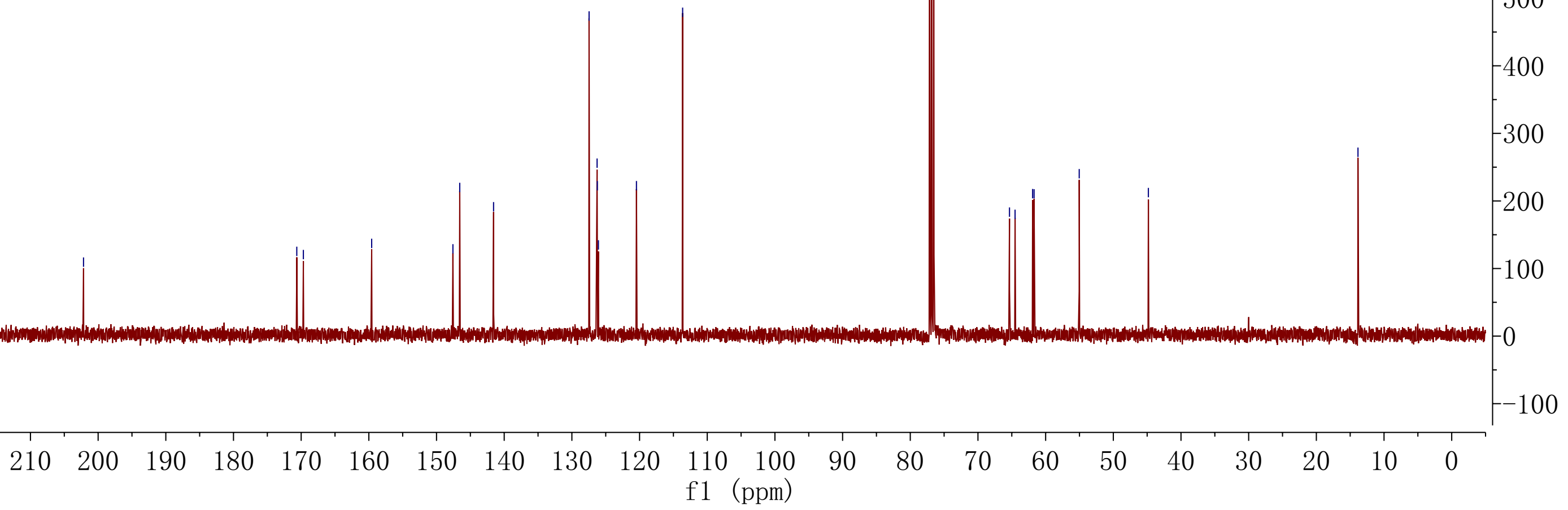



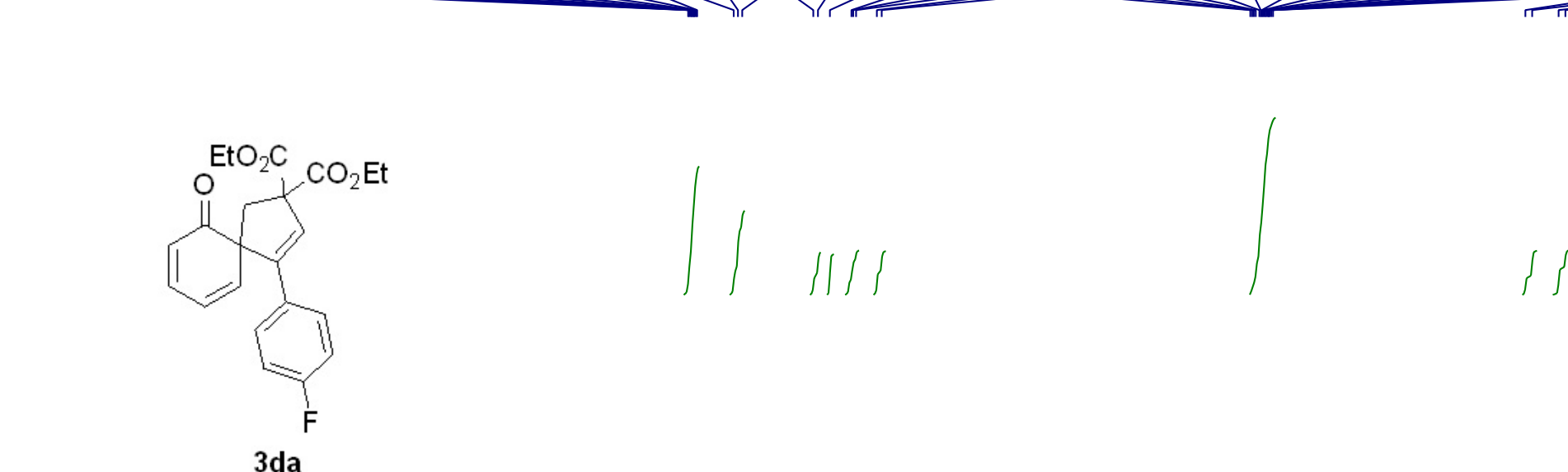

${ }^{1} \mathrm{H} \mathrm{NMR}\left(400 \mathrm{MHz}, \mathrm{CDCl}_{3}\right)$

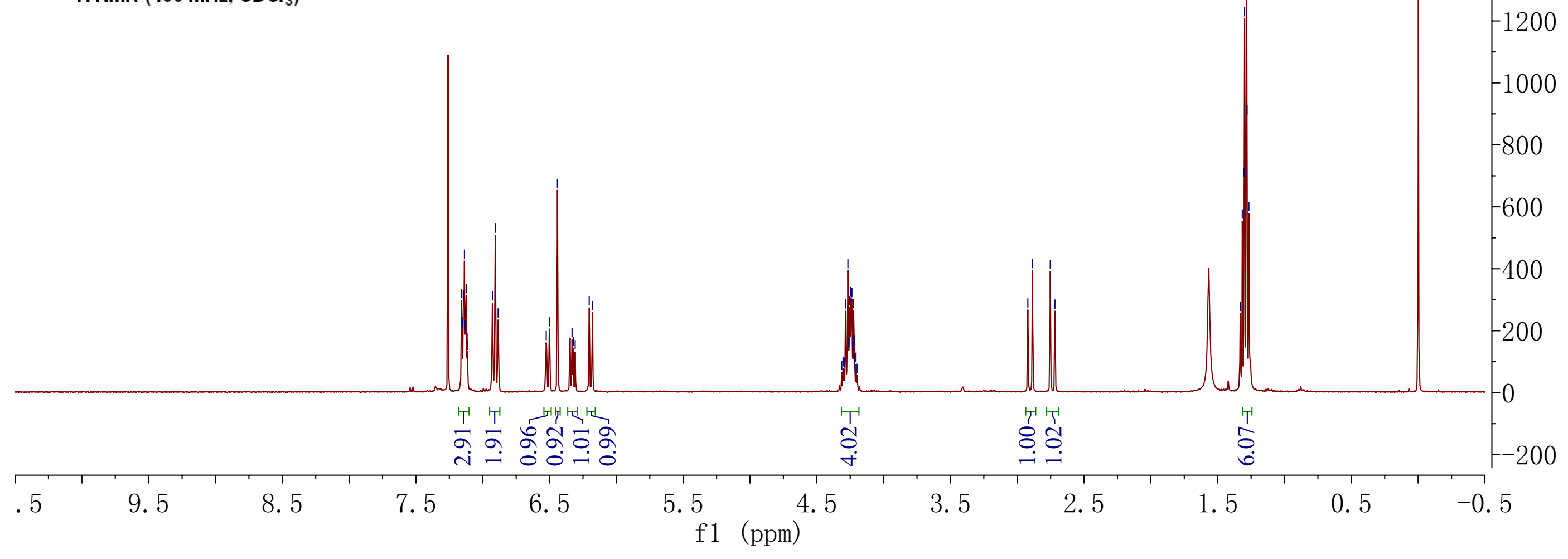



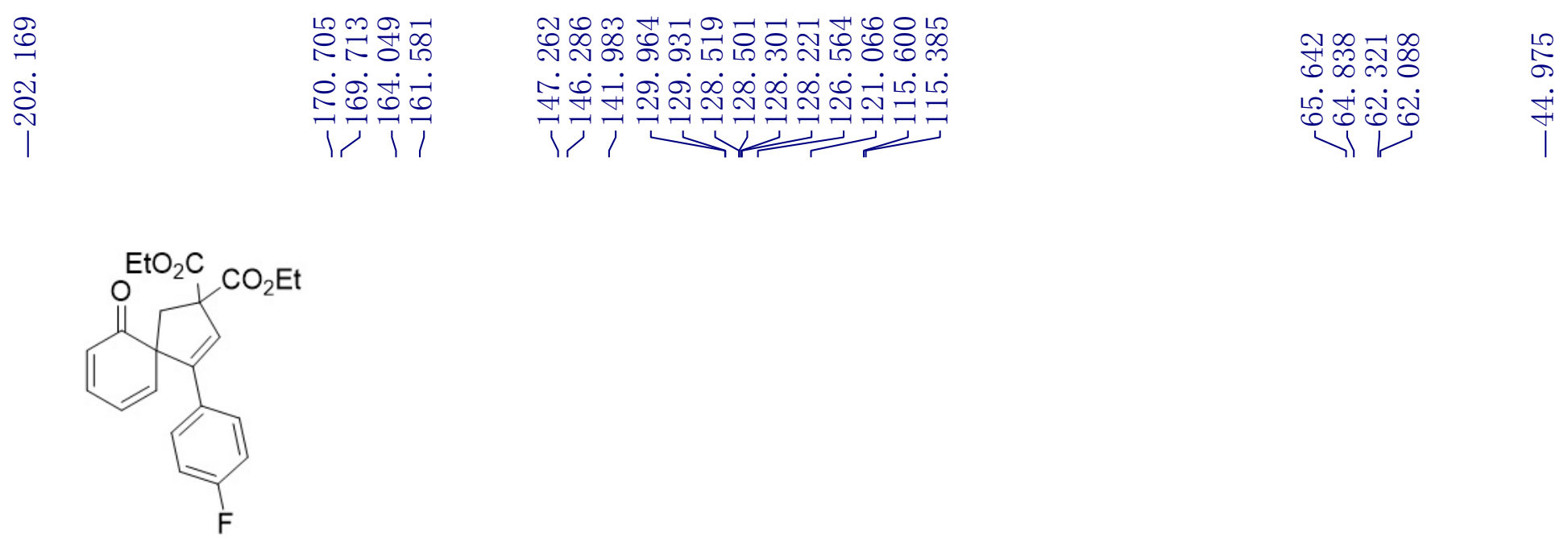

3da

${ }^{13} \mathrm{C}\left\{{ }^{1} \mathrm{H}\right\}$ NMR $\left(100 \mathrm{MHz}, \mathrm{CDCl}_{3}\right)$

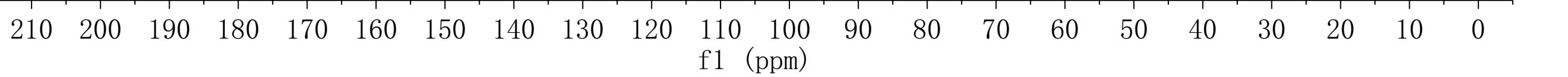




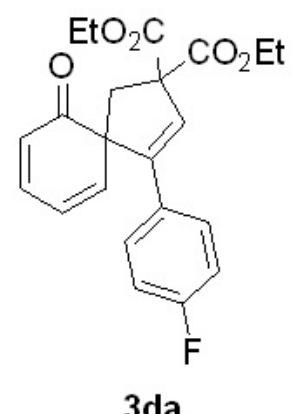

${ }^{19} \mathrm{~F} \mathrm{NMR}\left(376 \mathrm{MHz}, \mathrm{CDCl}_{3}\right)$

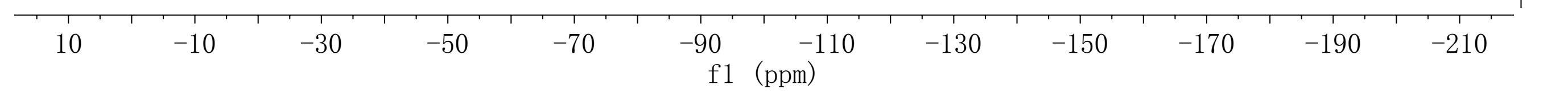



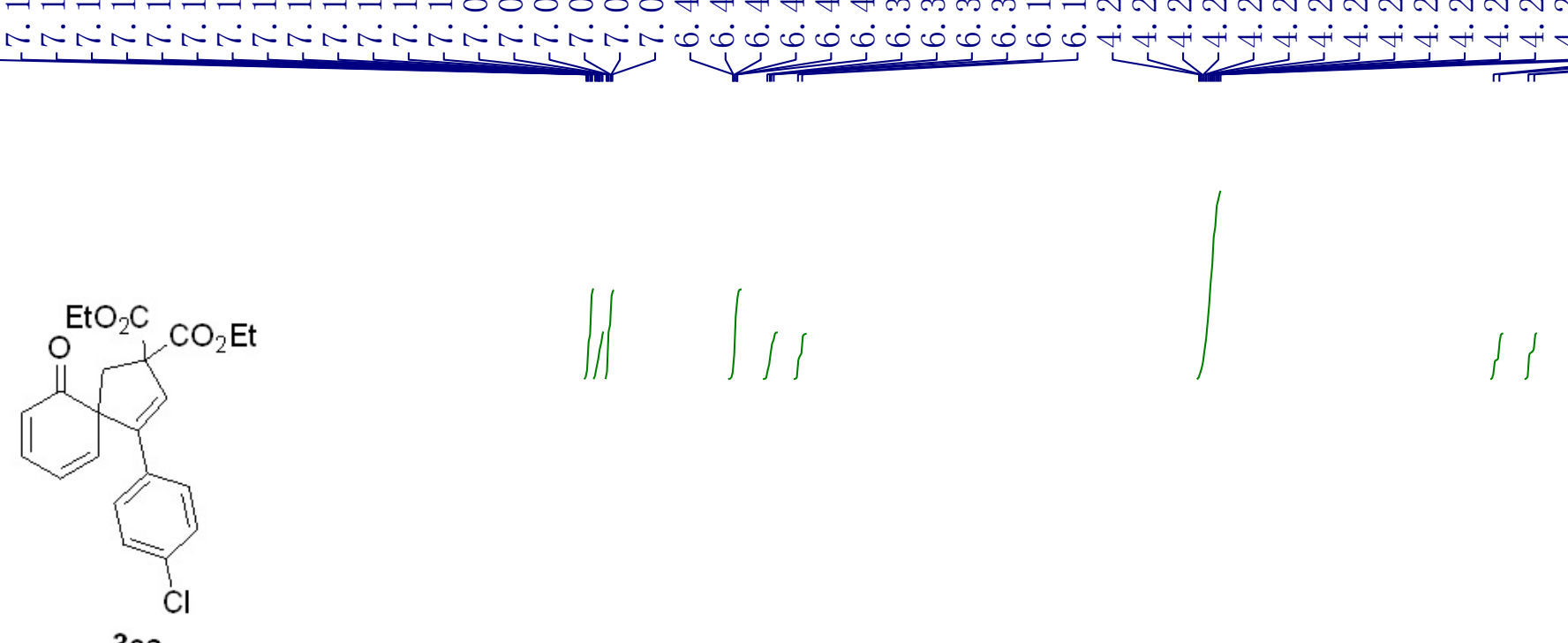

3ea

\section{${ }^{1} \mathrm{H} \mathrm{NMR}\left(500 \mathrm{MHz}, \mathrm{CDCl}_{3}\right)$}

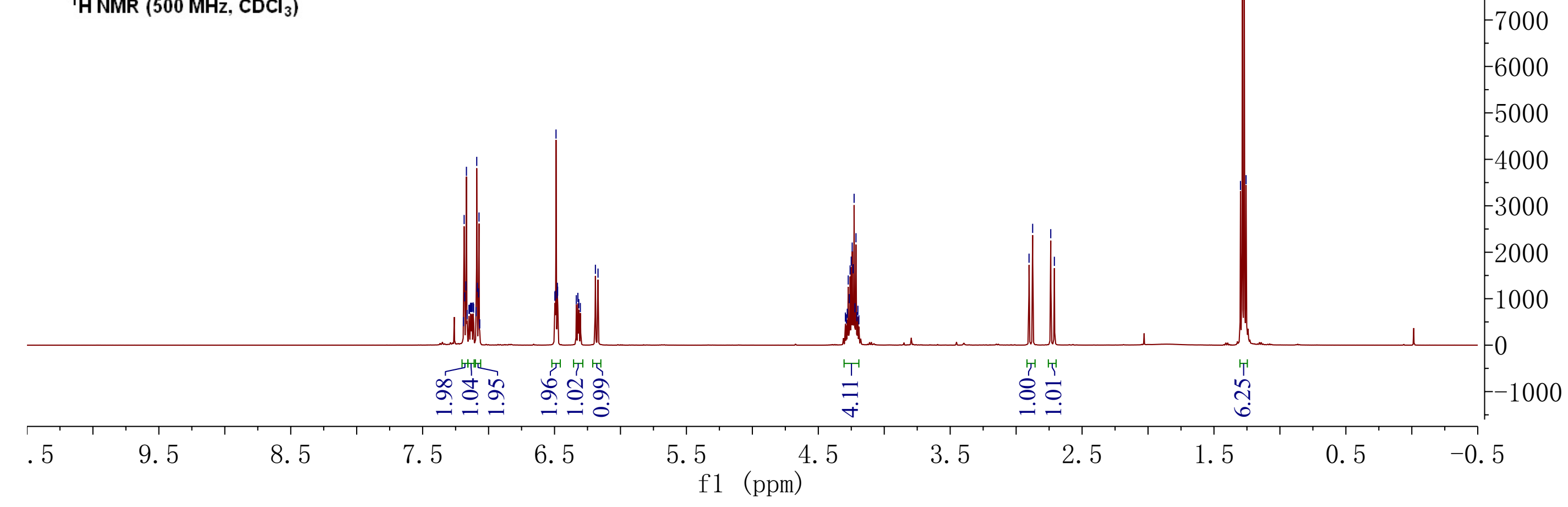


$\mathrm{OtO}_{2} \mathrm{C} \mathrm{CO}_{2} \mathrm{Et}$

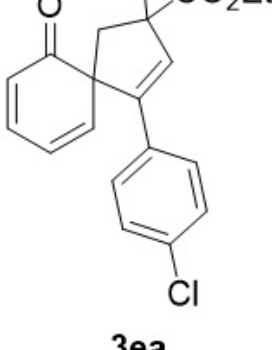

${ }^{13} \mathrm{C}\left\{{ }^{1} \mathrm{H}\right\}$ NMR $\left(126 \mathrm{MHz}, \mathrm{CDCl}_{3}\right)$

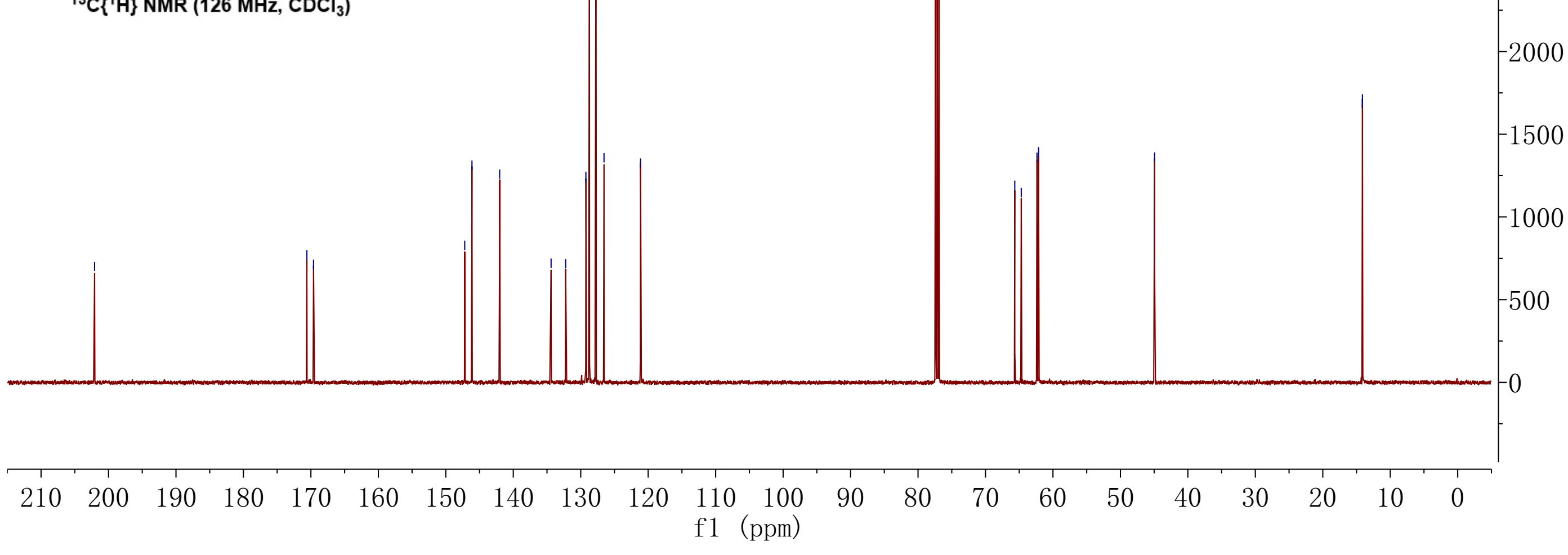



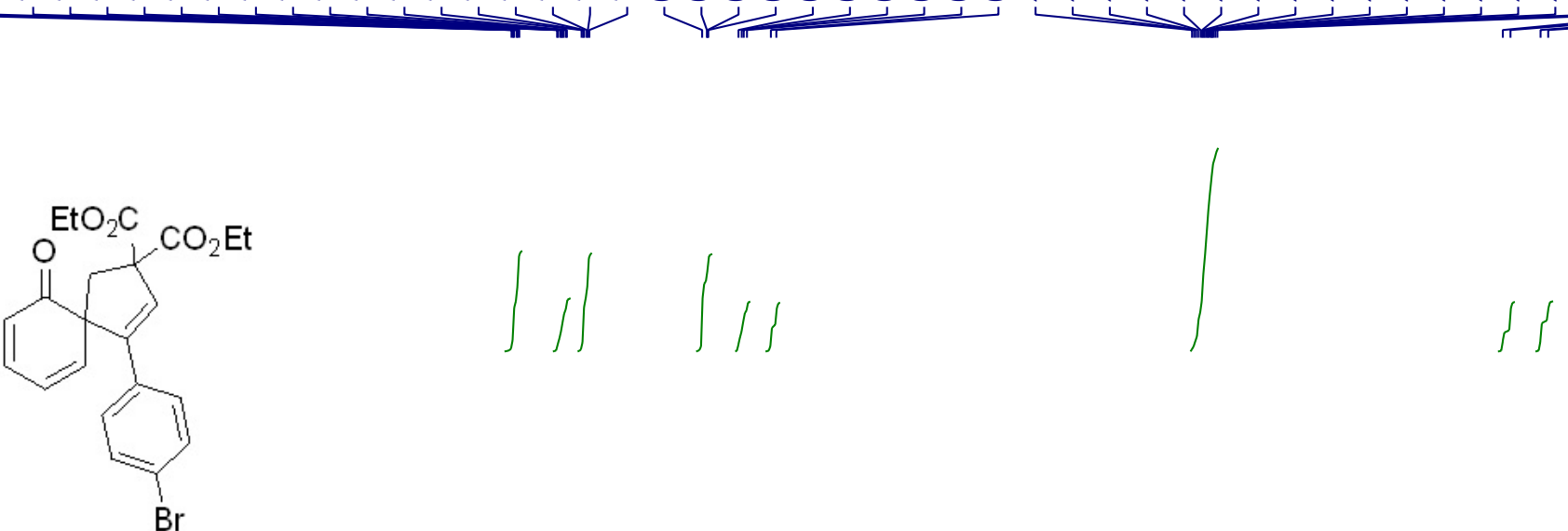

5500

$3 \mathrm{fa}$

${ }^{1} \mathrm{H} \mathrm{NMR}\left(400 \mathrm{MHz}, \mathrm{CDCl}_{3}\right)$ 


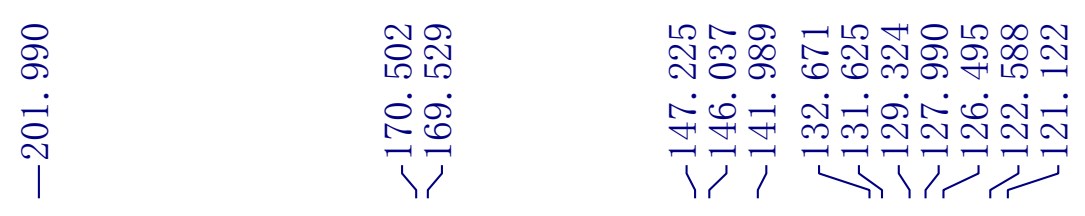

\begin{tabular}{|c|}
\hline 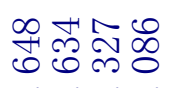 \\
\hline نِ نِ فِ \\
\hline
\end{tabular}

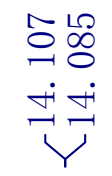

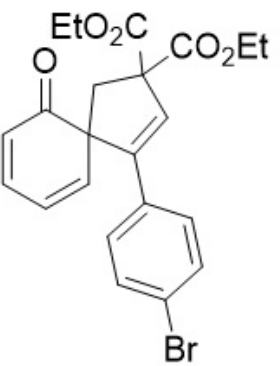

$3 \mathrm{fa}$

${ }^{13} \mathrm{C}\left\{{ }^{1} \mathrm{H}\right\}$ NMR $\left(100 \mathrm{MHz}, \mathrm{CDCl}_{3}\right)$

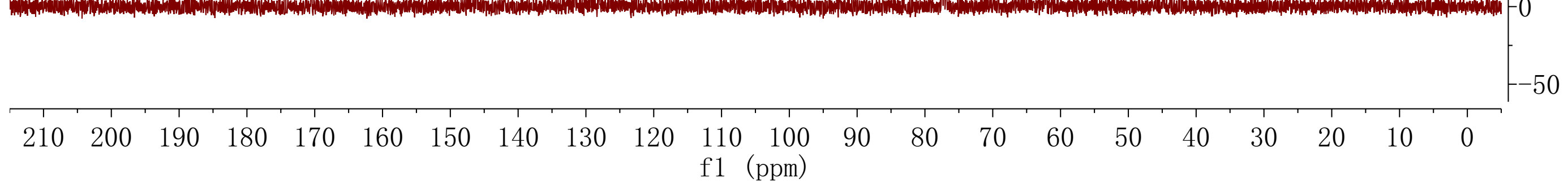



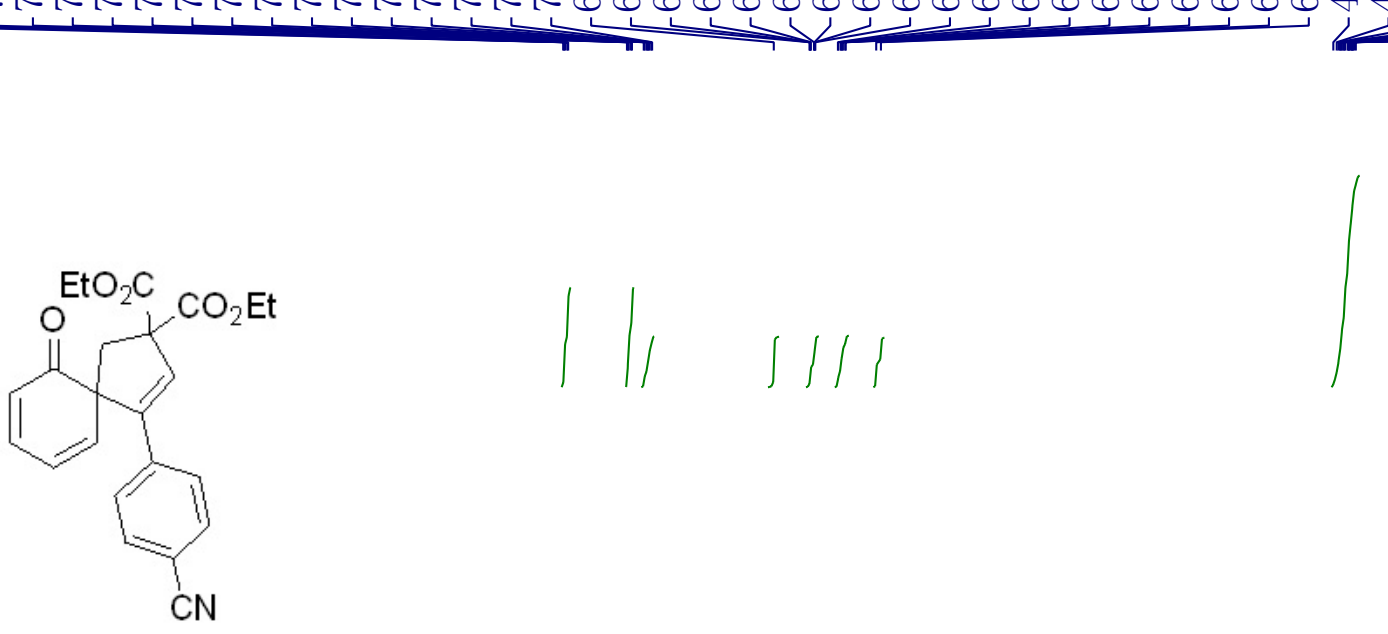

3 ga

${ }^{1} \mathrm{H}$ NMR (500 MHz, $\left.\mathrm{CDCl}_{3}\right)$

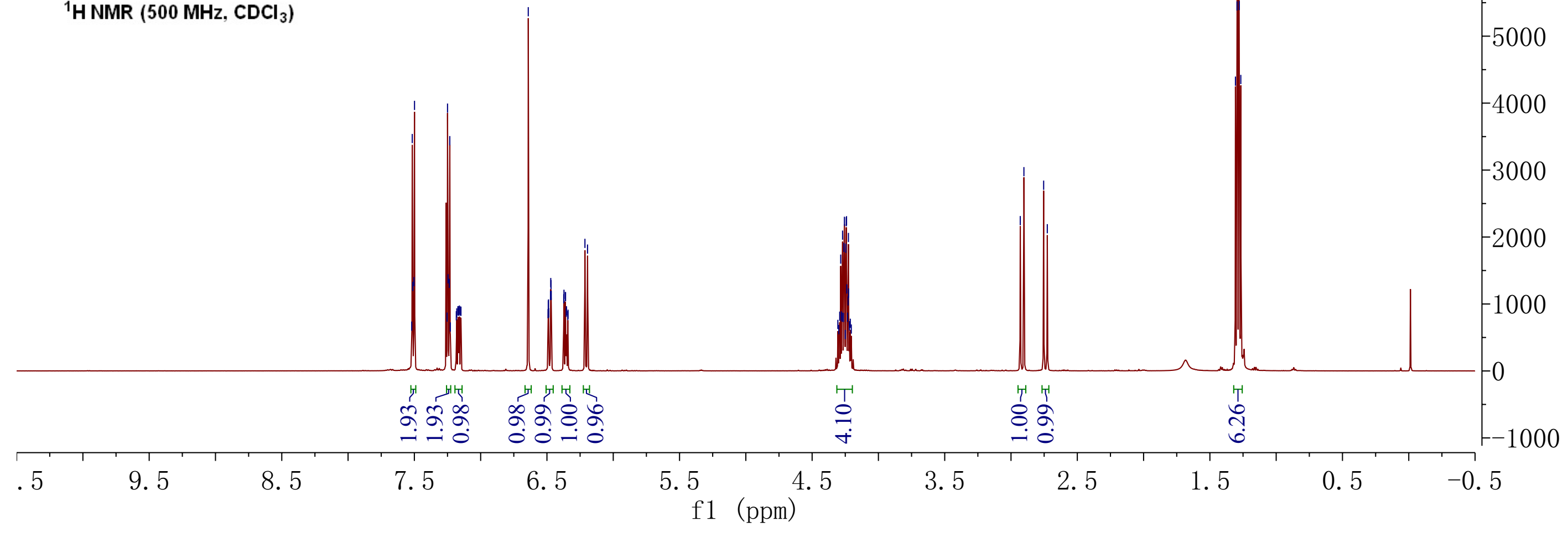




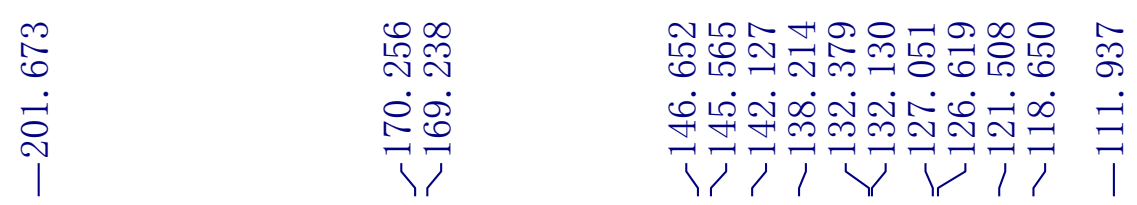

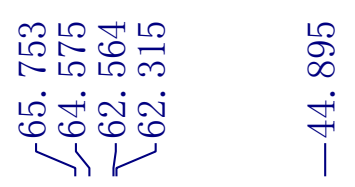

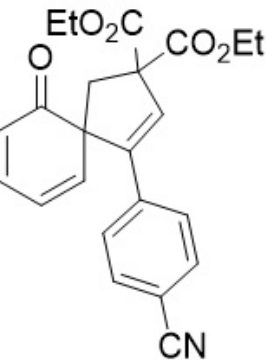

3ga

${ }^{13} \mathrm{C}\left\{{ }^{1} \mathrm{H}\right\}$ NMR $\left(126 \mathrm{MHz}, \mathrm{CDCl}_{3}\right)$

-1600
-1400
-1200
-1000
-800
-600
-400
-200
-0
-200

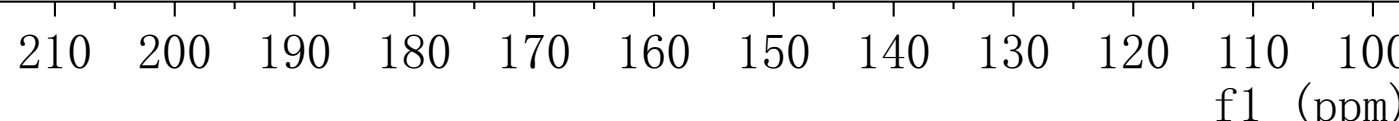




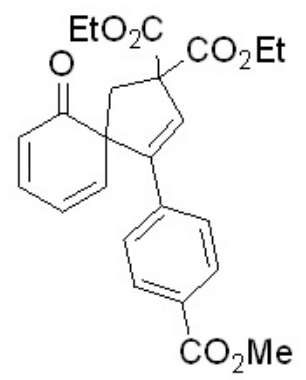

3ha

${ }^{1} \mathrm{H}$ NMR $\left(400 \mathrm{MHz}, \mathrm{CDCl}_{3}\right)$
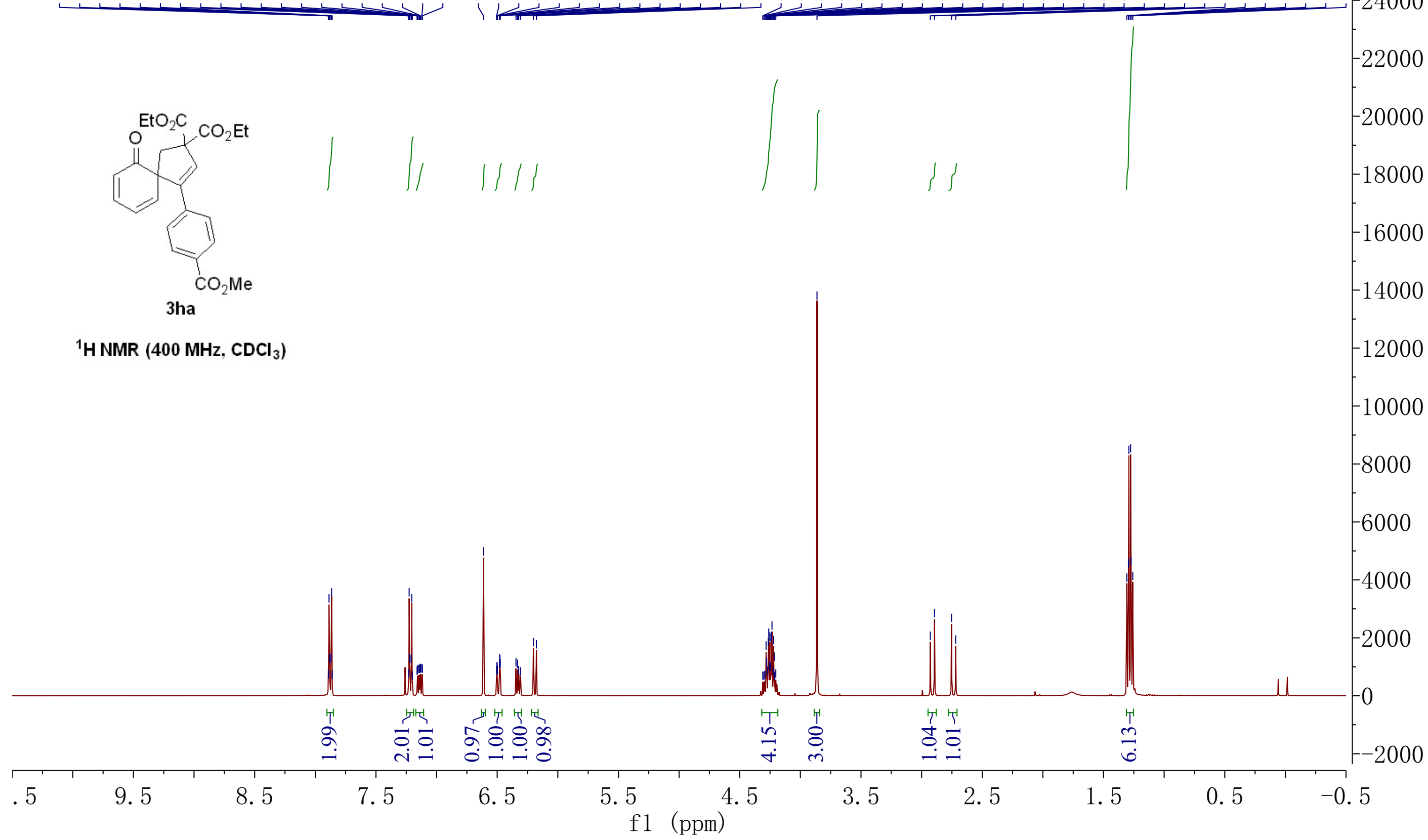

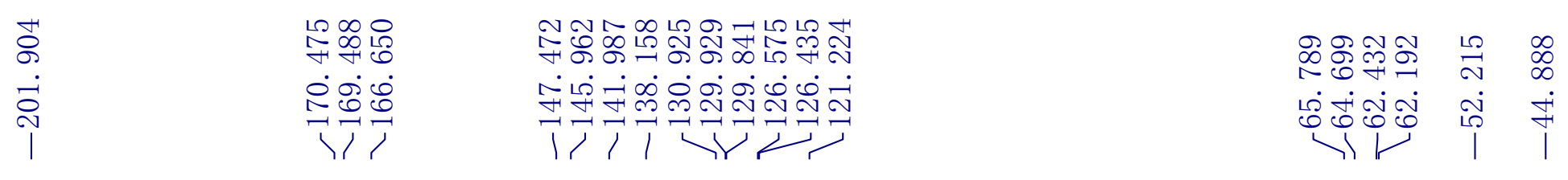

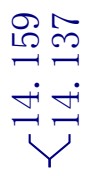

1400

$\mathrm{EtO}_{2} \mathrm{C} \mathrm{CO}_{2} \mathrm{Et}$

3ha

${ }^{13} \mathrm{C}\{1 \mathrm{H}\} \mathrm{NMR}\left(100 \mathrm{MHz}, \mathrm{CDCl}_{3}\right)$

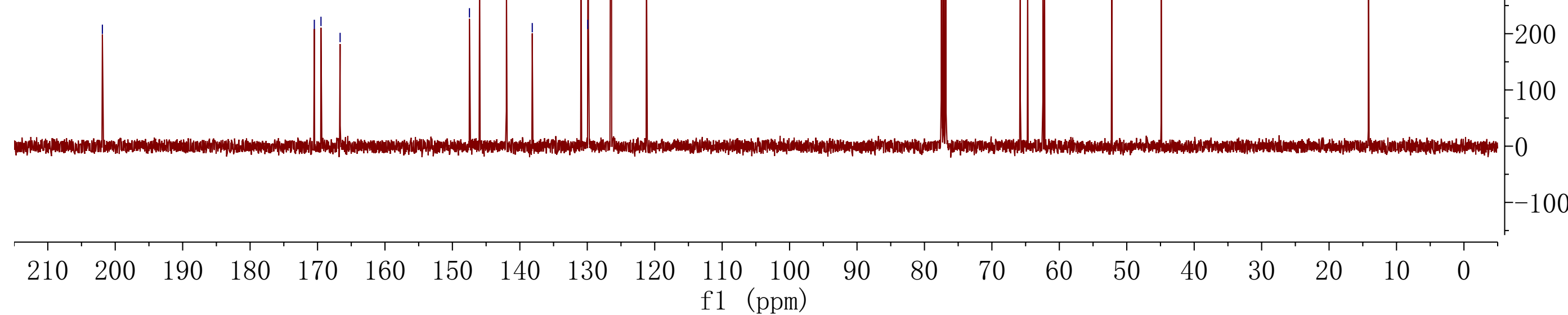



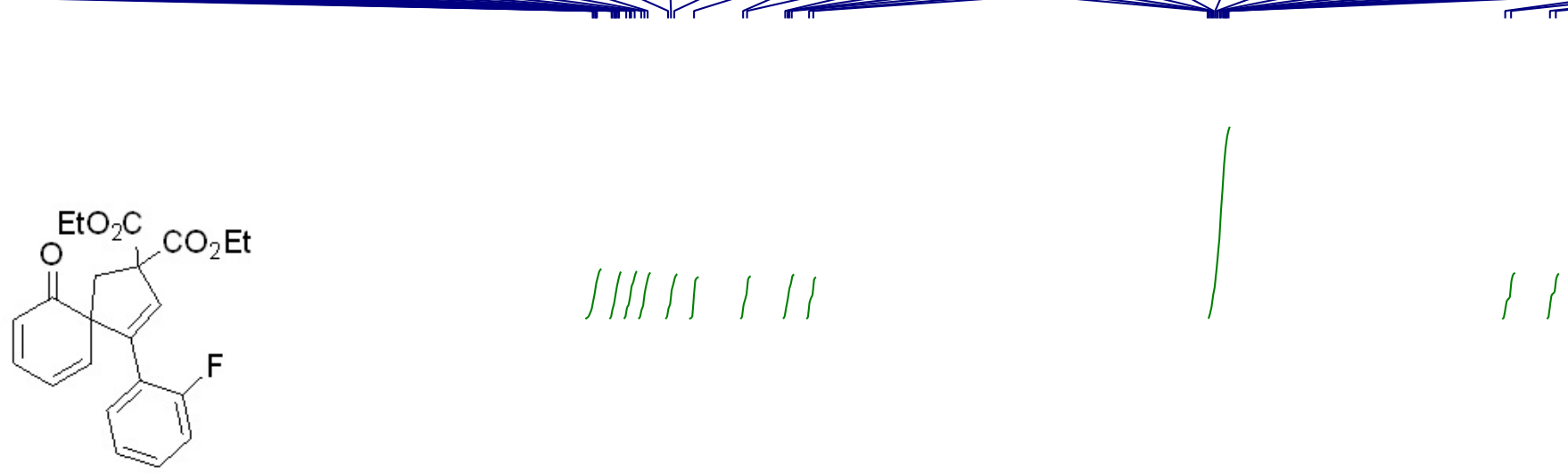

3ia

${ }^{1} \mathrm{H}$ NMR $\left(500 \mathrm{MHz}, \mathrm{CDCl}_{3}\right)$

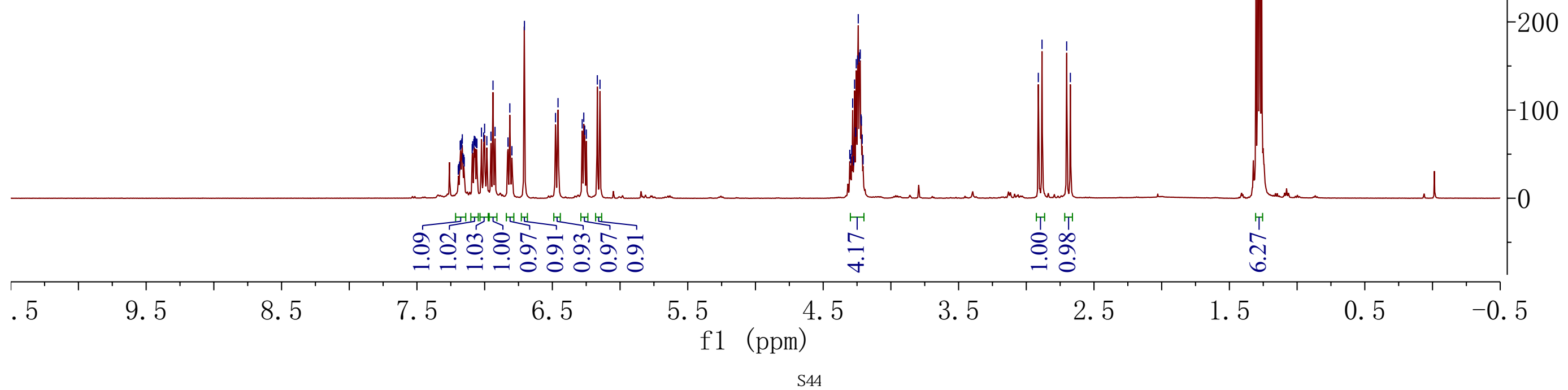




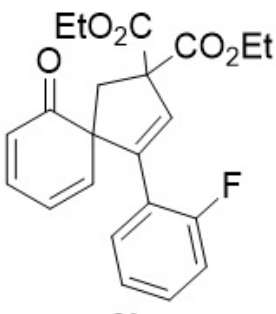

3ia

${ }^{13} \mathrm{C}\left\{{ }^{1} \mathrm{H}\right\}$ NMR (126 MHz, $\left.\mathrm{CDCl}_{3}\right)$

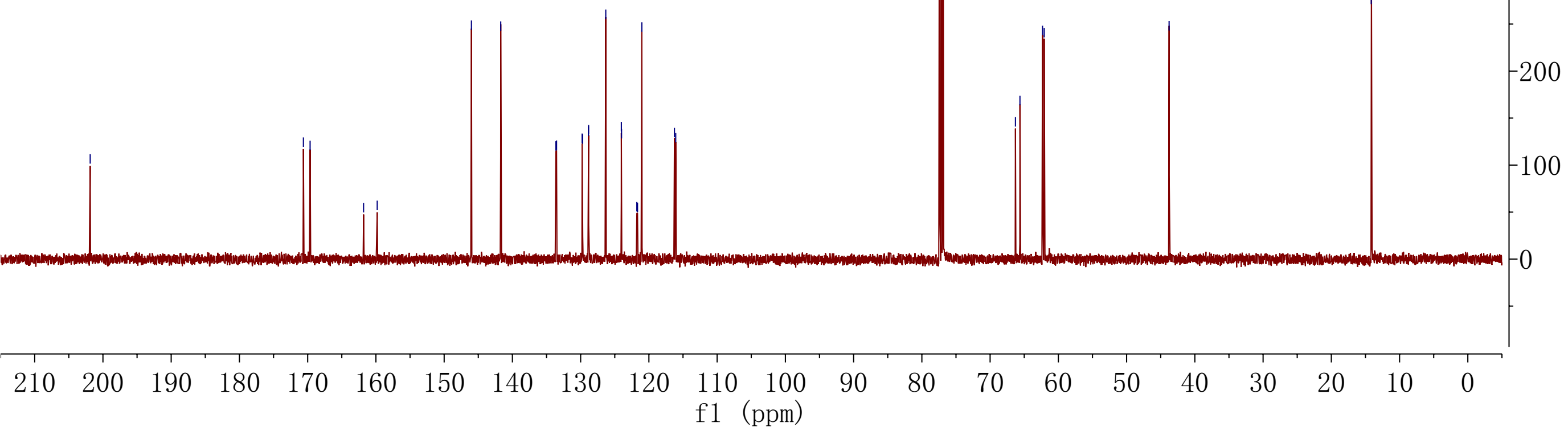




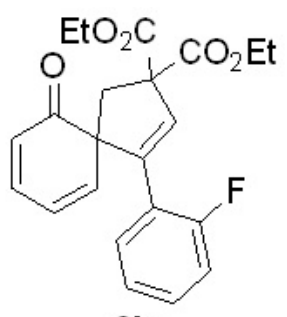

${ }^{19} \mathrm{~F}$ NMR $\left(470 \mathrm{MHz}, \mathrm{CDCl}_{3}\right)$ 

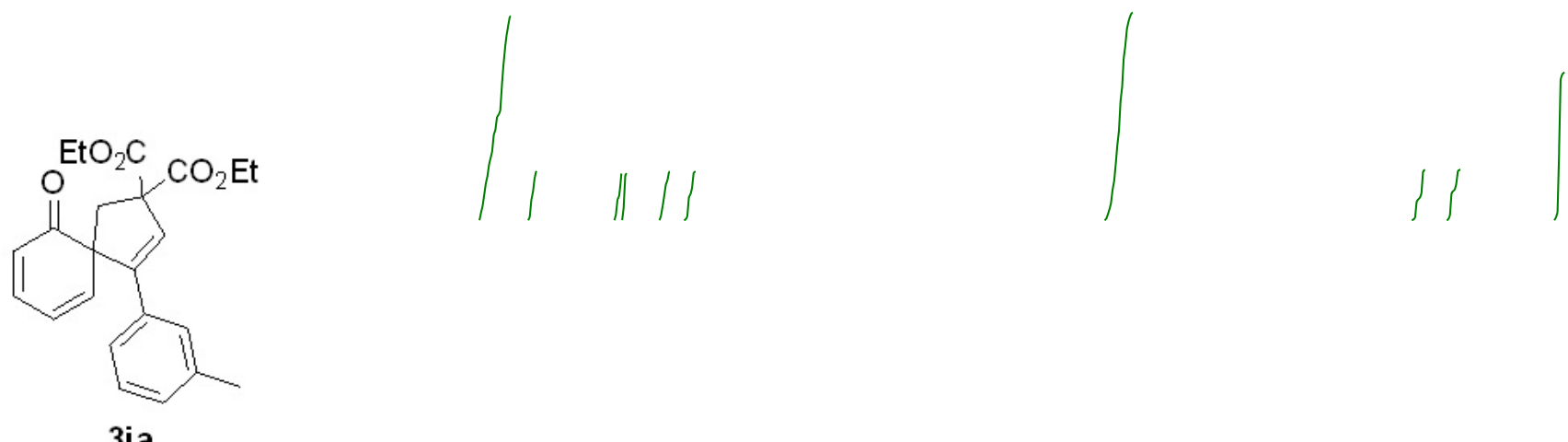

3ja

${ }^{1} \mathrm{HNMR}\left(500 \mathrm{MHz}, \mathrm{CDCl}_{3}\right)$

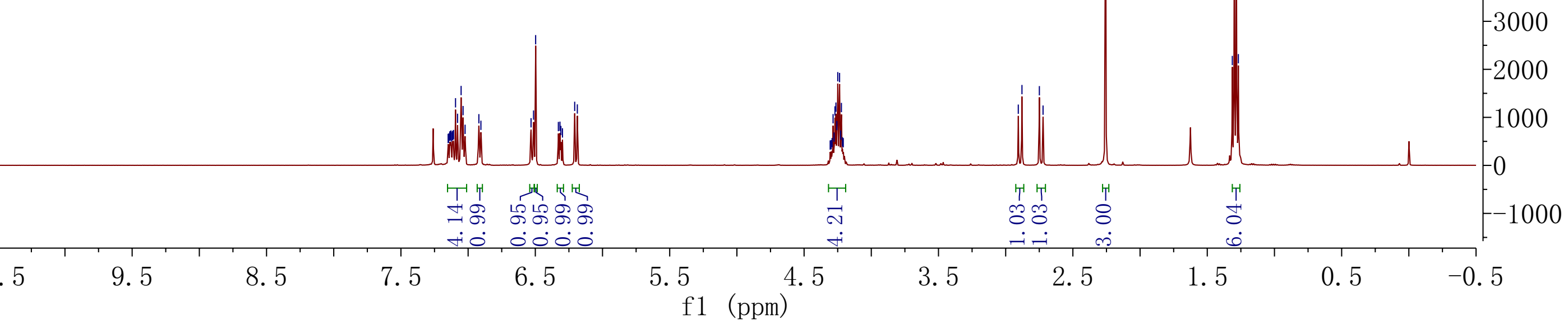



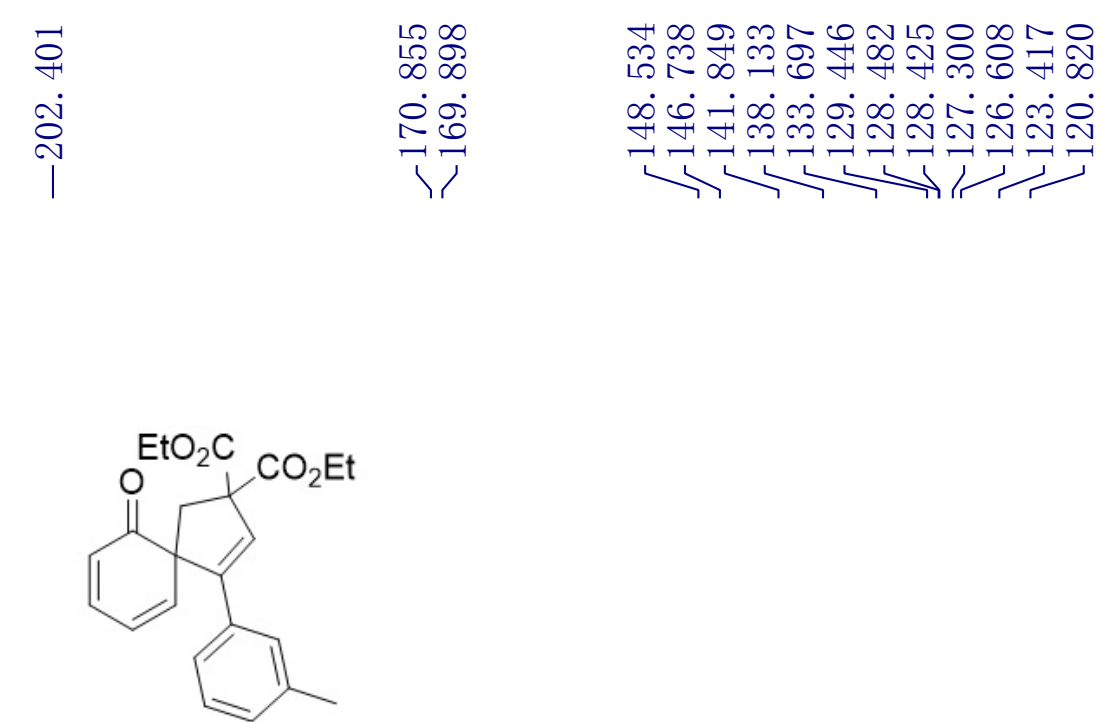

3ja

${ }^{13} \mathrm{C}\left\{{ }^{1} \mathrm{H}\right\}$ NMR (126 MHz, $\left.\mathrm{CDCl}_{3}\right)$
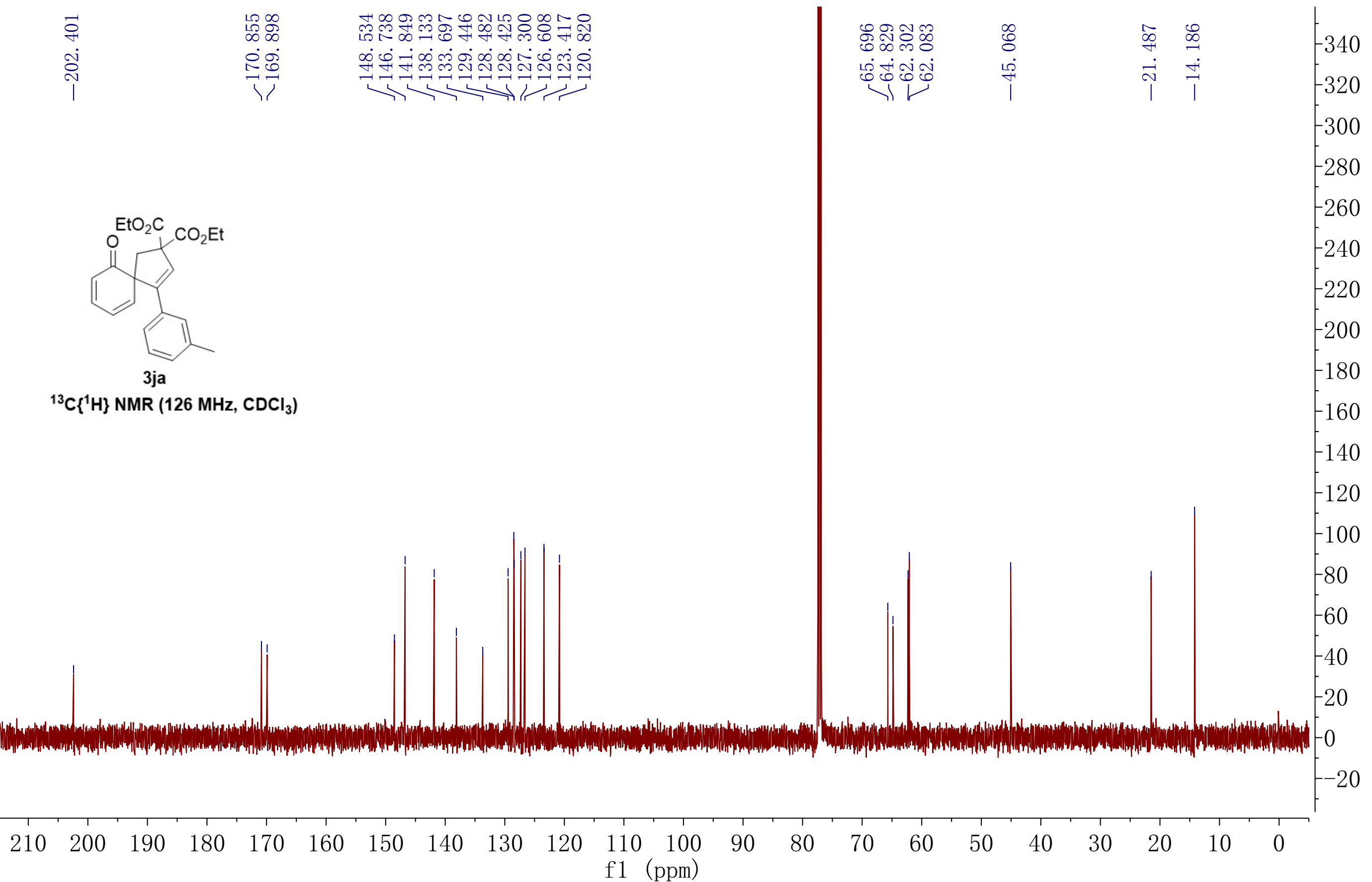

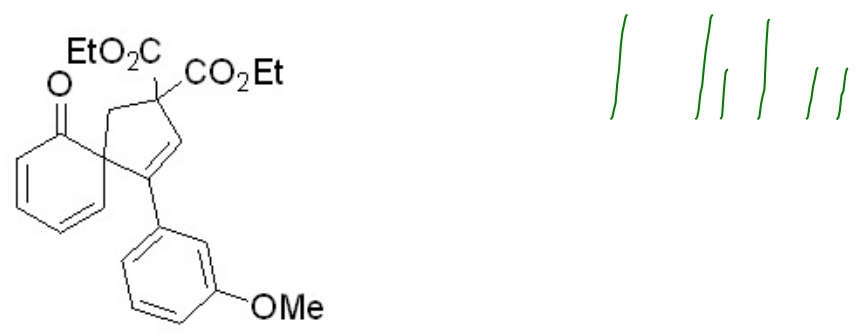

$3 \mathrm{ka}$

${ }^{1} \mathrm{H} \mathrm{NMR}\left(500 \mathrm{MHz}, \mathrm{CDCl}_{3}\right)$

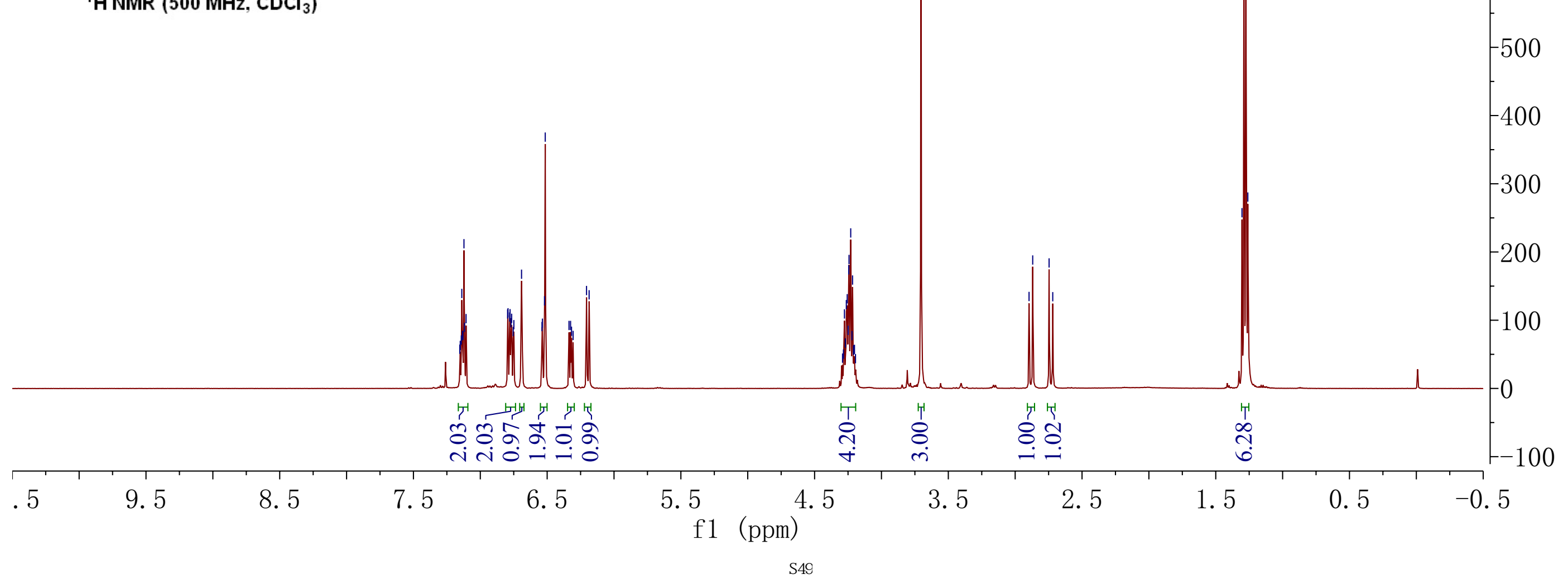




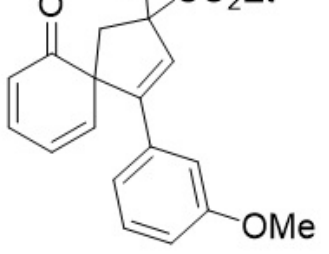

3ka

${ }^{13} \mathrm{C}\left\{{ }^{1} \mathrm{H}\right\}$ NMR $\left(126 \mathrm{MHz}, \mathrm{CDCl}_{3}\right)$

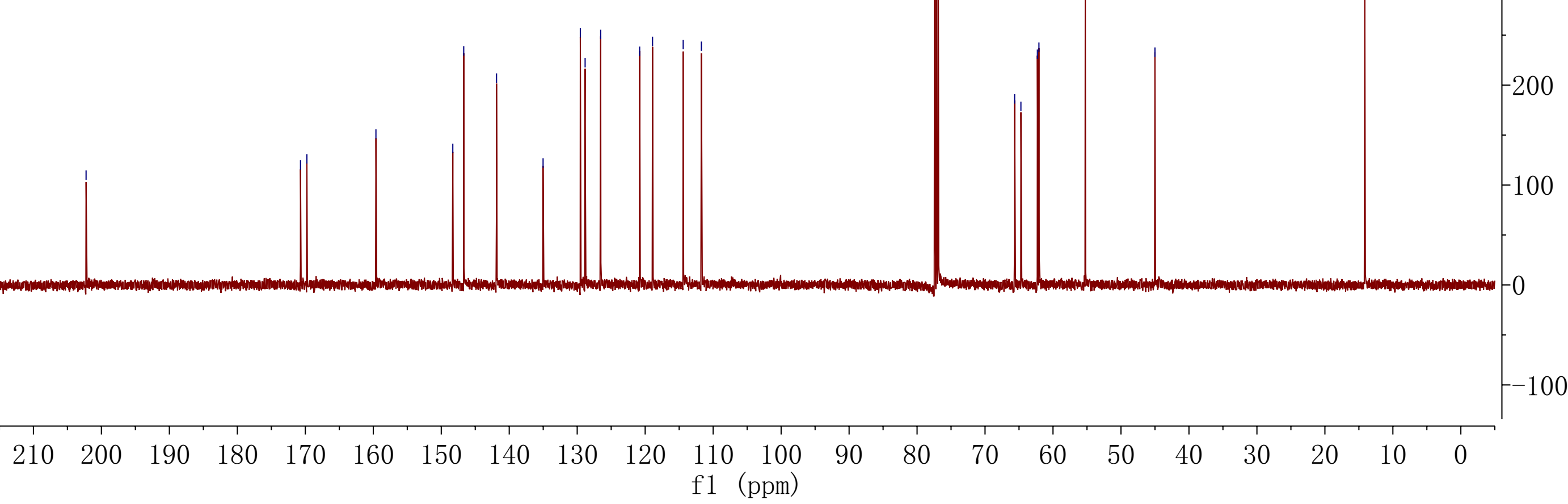



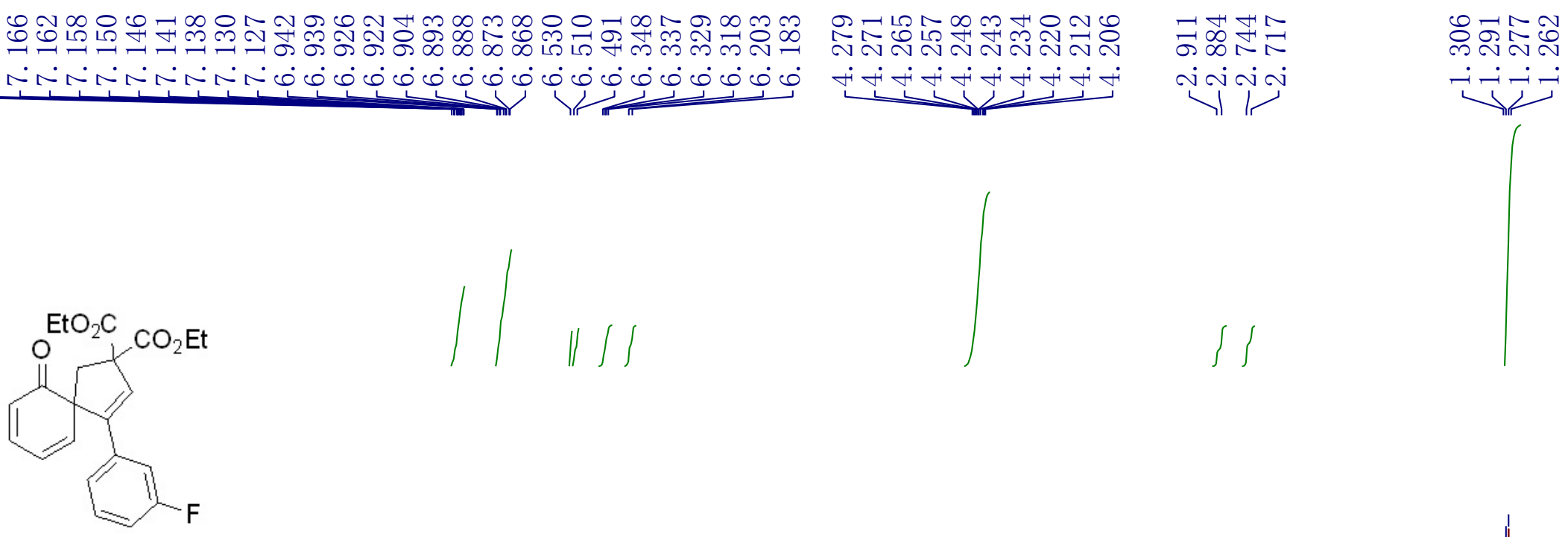

$31 \mathrm{a}$

${ }^{1} \mathrm{H} \mathrm{NMR}\left(500 \mathrm{MHz}, \mathrm{CDCl}_{3}\right)$

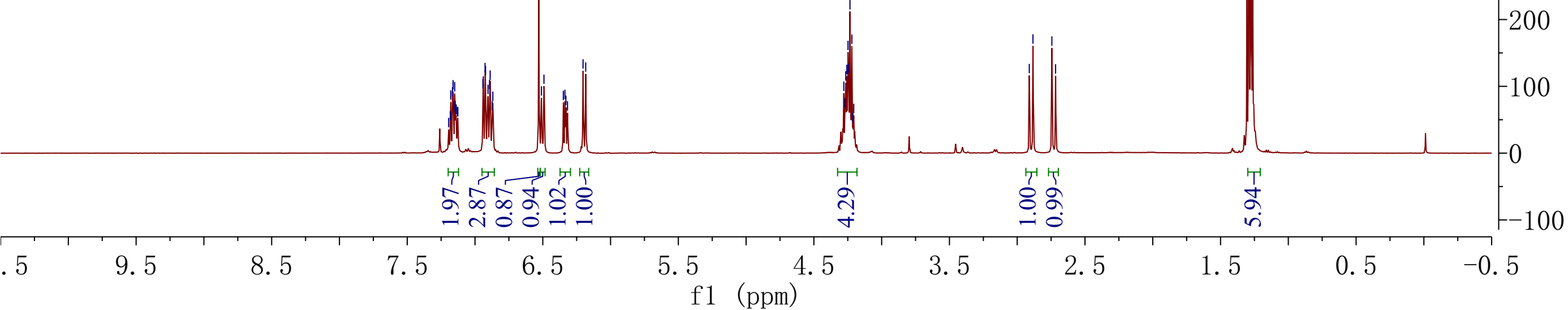




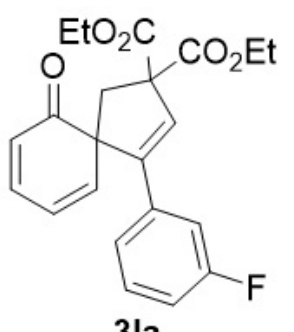

3la

${ }^{13} \mathrm{C}\{1 \mathrm{H}\}$ NMR $\left(126 \mathrm{MHz}, \mathrm{CDCl}_{3}\right)$ 


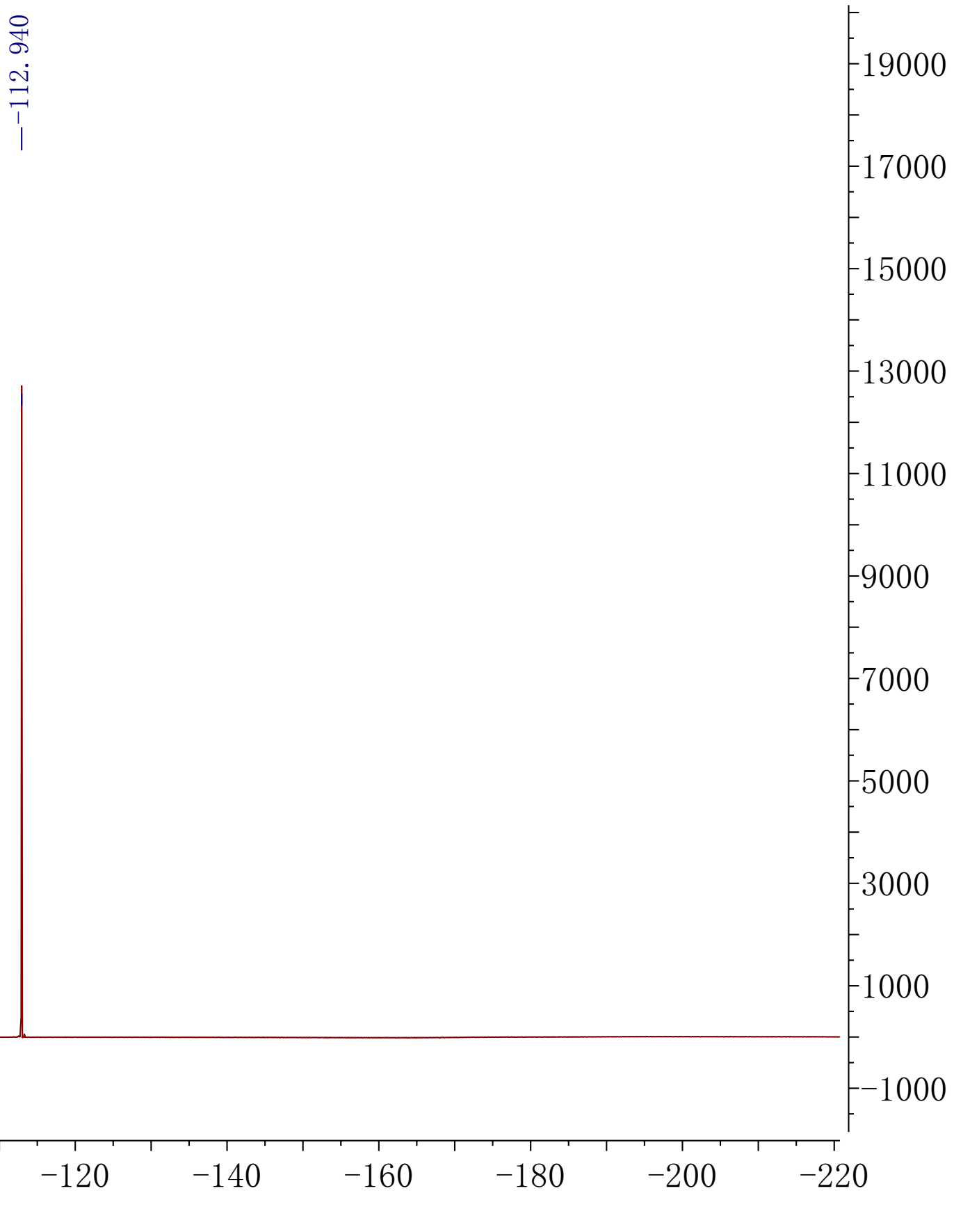



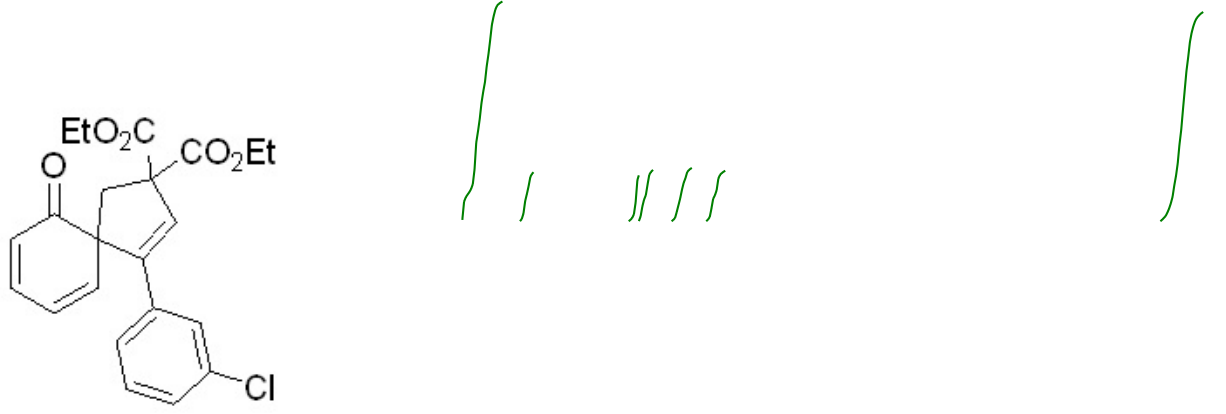

$3 \mathrm{ma}$

${ }^{1} \mathrm{H}$ NMR $\left(400 \mathrm{MHz}, \mathrm{CDCl}_{3}\right)$

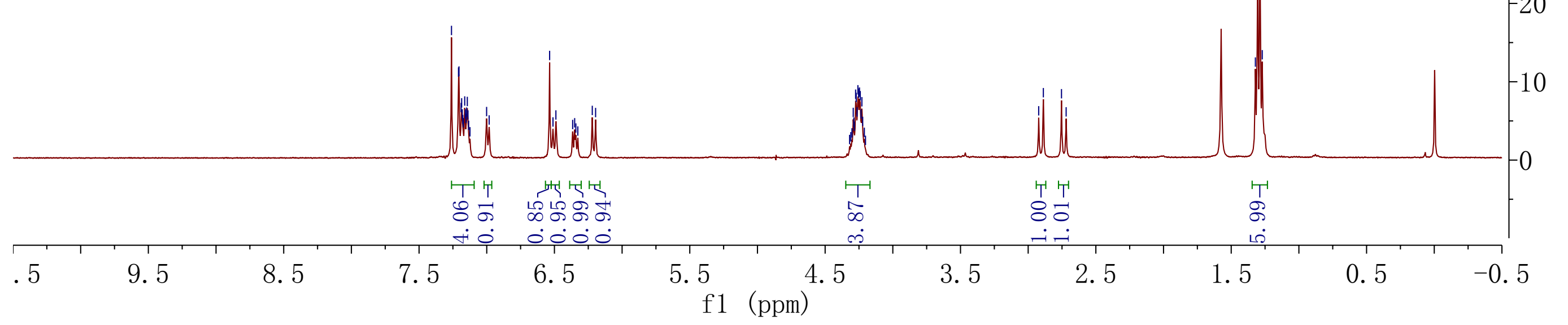



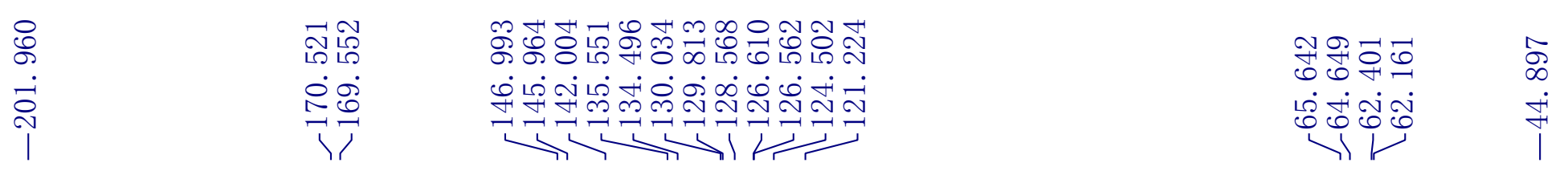

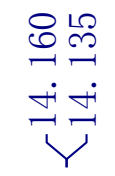

${ }^{13} \mathrm{C}\left\{{ }^{1} \mathrm{H}\right\}$ NMR $\left(126 \mathrm{MHz}, \mathrm{CDCl}_{3}\right)$

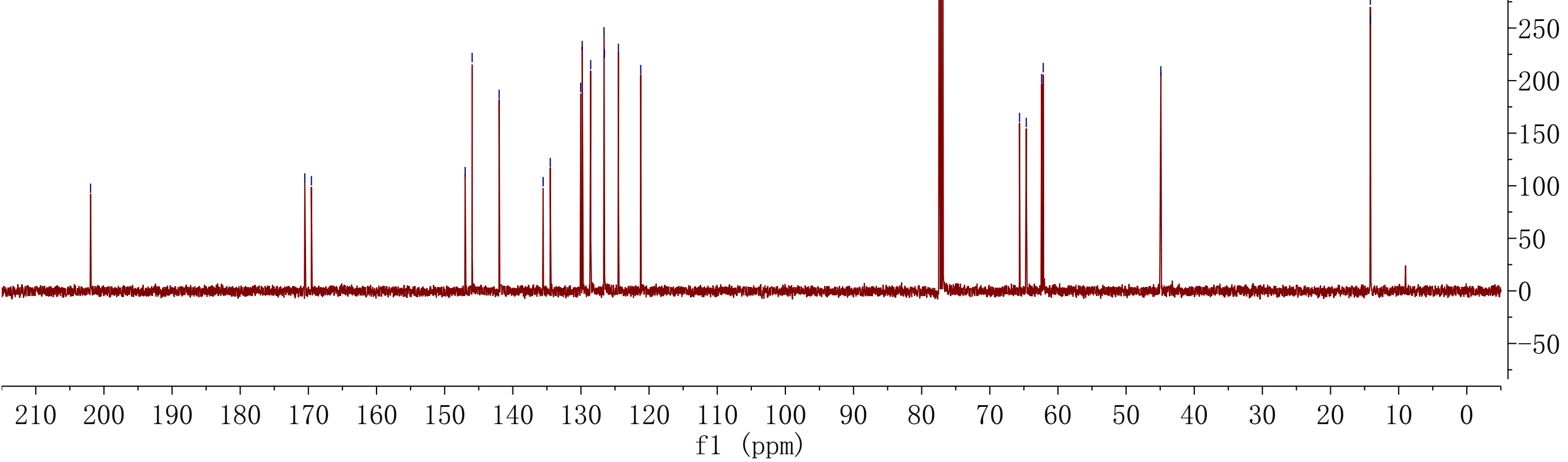



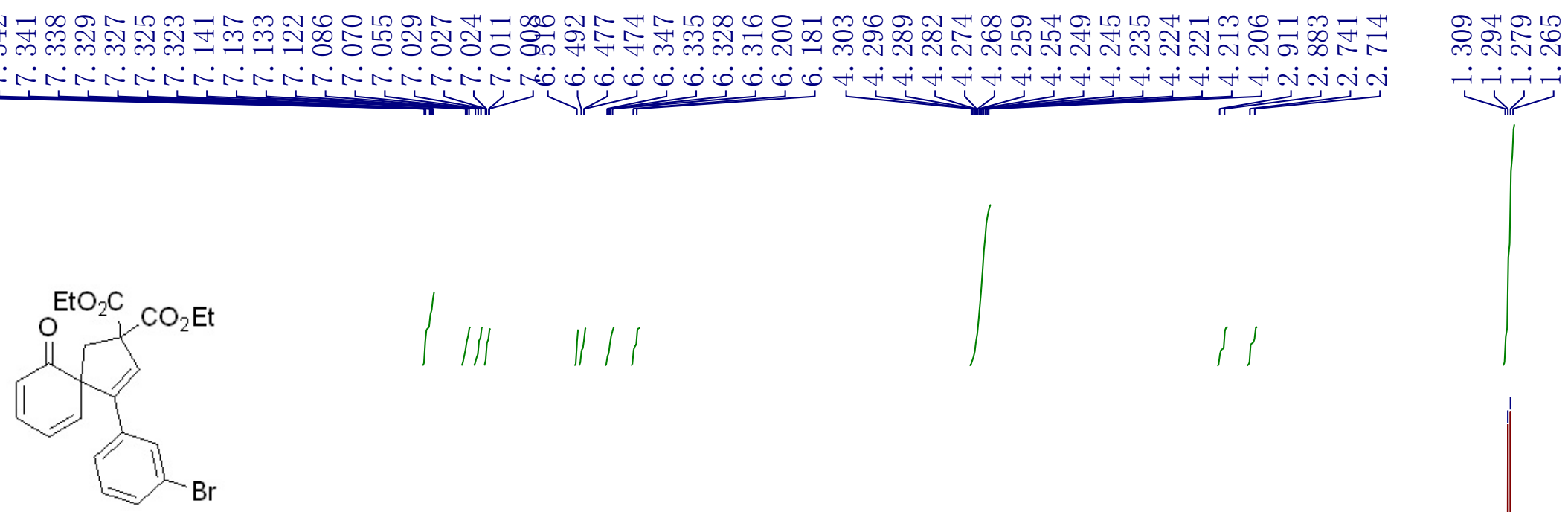

3na

${ }^{1} \mathrm{H}$ NMR $\left(500 \mathrm{MHz}, \mathrm{CDCl}_{3}\right)$

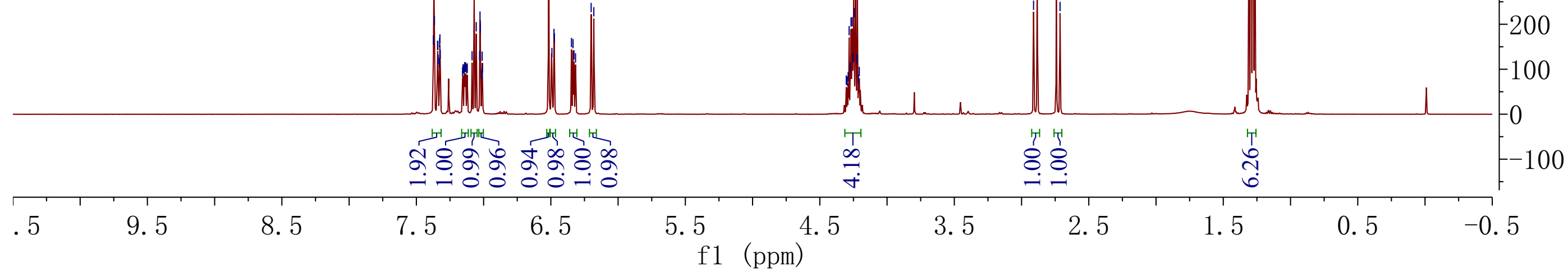



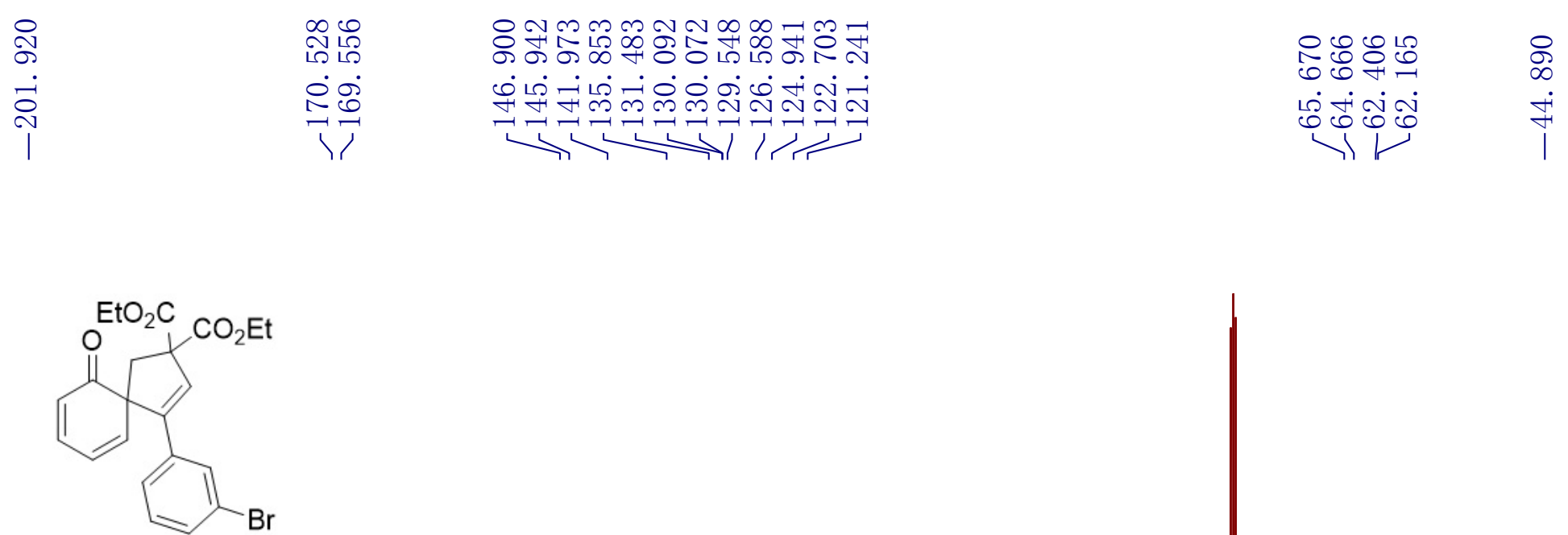

3na

$\mathrm{Br}$

${ }^{13} \mathrm{C}\left\{{ }^{1} \mathrm{H}\right\}$ NMR (126 MHz, $\left.\mathrm{CDCl}_{3}\right)$

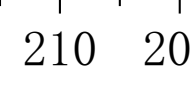

190

180

170

$60 \quad 150$

140

130

20

$\begin{array}{lr}110 & 100 \\ \text { f1 } & (\mathrm{ppm})\end{array}$ 

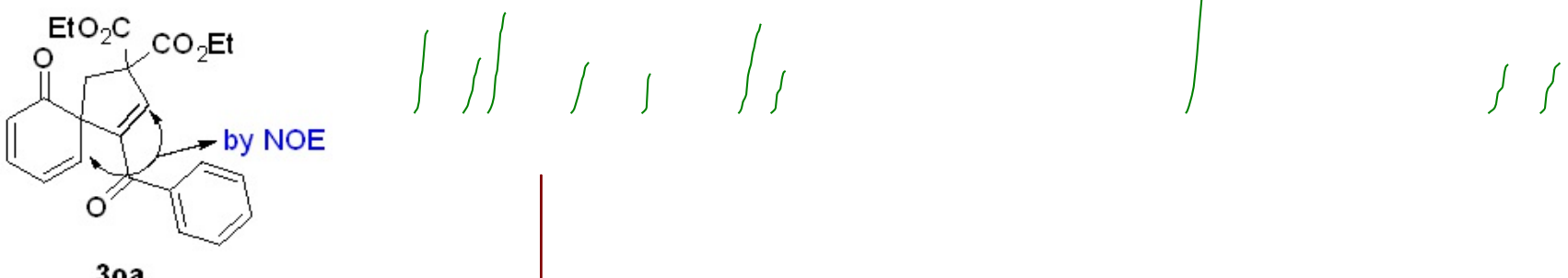

${ }^{1} \mathrm{H} \mathrm{NMR}\left(400 \mathrm{MHz}, \mathrm{CDCl}_{3}\right)$

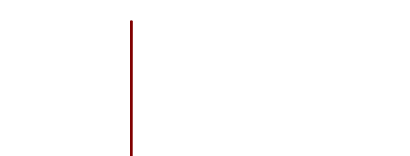




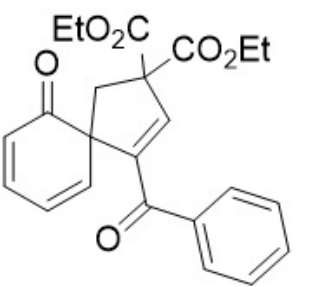

3 oa

${ }^{13} \mathrm{C}\left\{{ }^{1} \mathrm{H}\right\}$ NMR $\left(100 \mathrm{MHz}, \mathrm{CDCl}_{3}\right)$ 


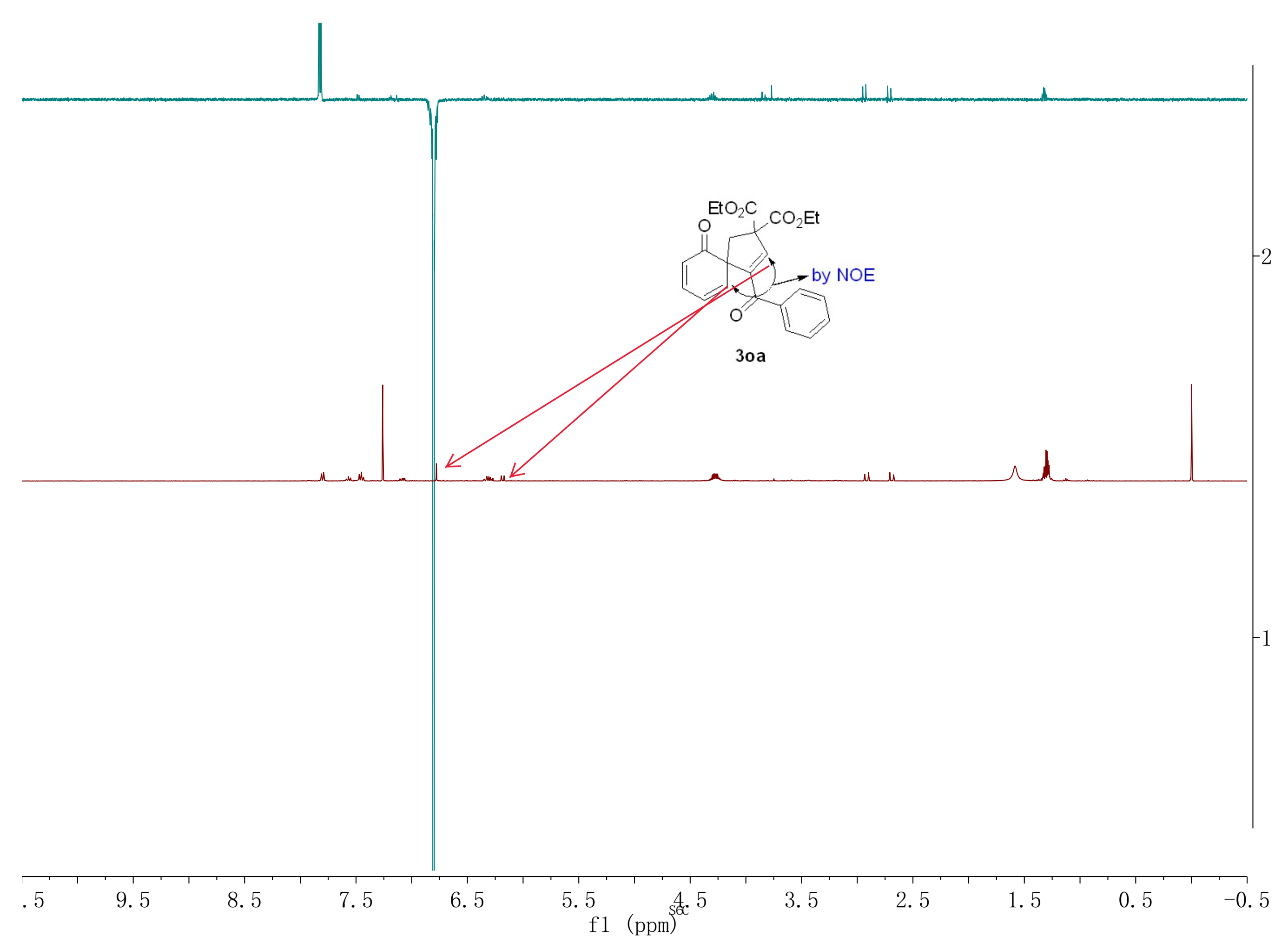



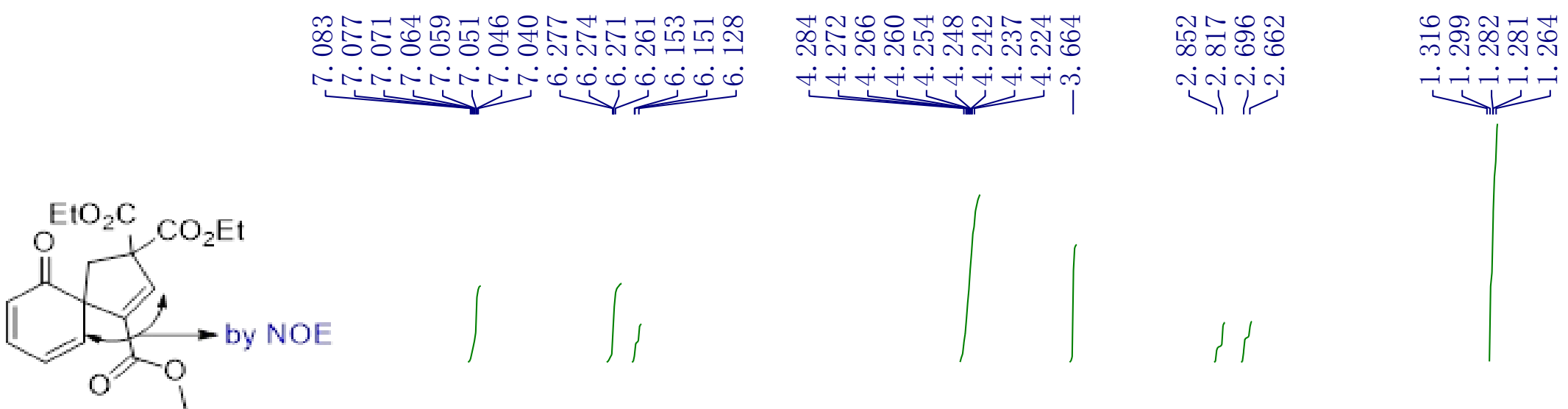

3pa

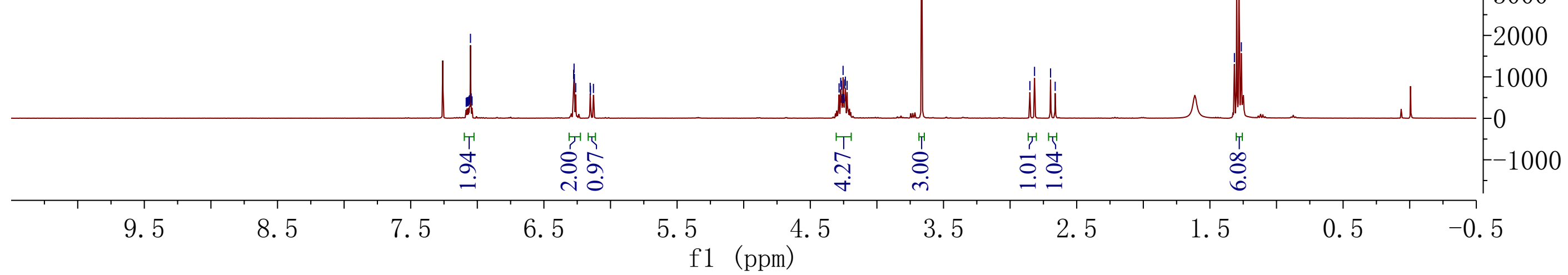




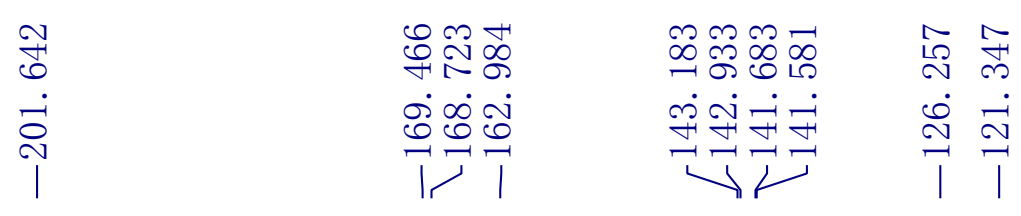

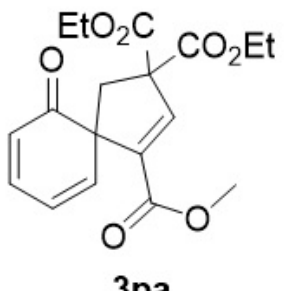

نإ

${ }^{13} \mathrm{C}\left\{{ }^{1} \mathrm{H}\right\}$ NMR $\left(100 \mathrm{MHz}, \mathrm{CDCl}_{3}\right)$

$\begin{array}{llllllllllllllllllllll}210 & 200 & 190 & 180 & 170 & 160 & 150 & 140 & 130 & 120 & \begin{array}{c}110 \\ \mathrm{f} 1\end{array}(\mathrm{ppm}) & 90 & 80 & 70 & 60 & 50 & 40 & 30 & 20 & 10 & 0\end{array}$




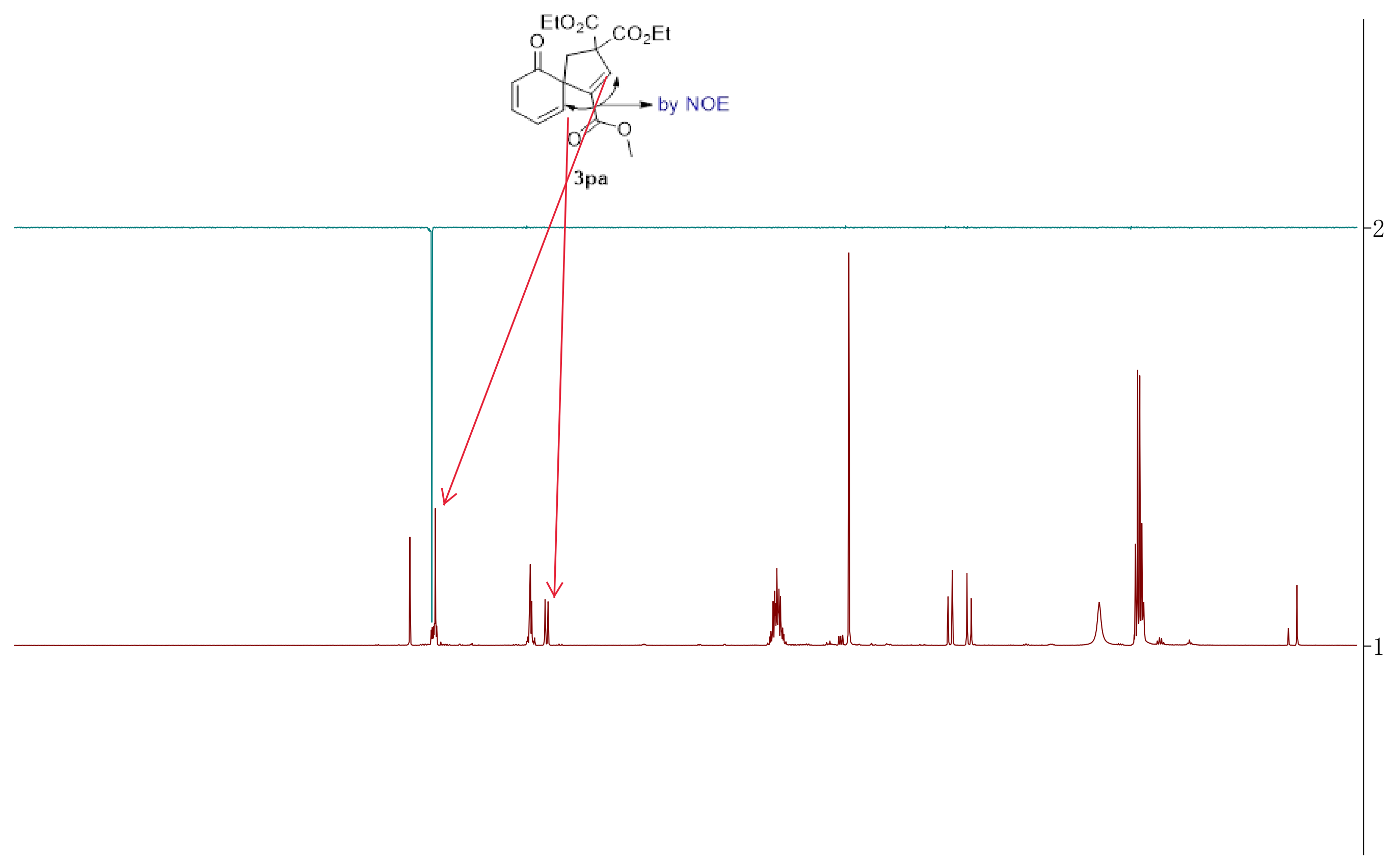

\begin{tabular}{|c|c|c|c|c|c|c|c|c|c|}
\hline 9.5 & 8.5 & 7.5 & 6.5 & $\begin{array}{l}5.5 \\
f 1\end{array}$ & $\mathrm{~mm}^{563} 5$ & 3.5 & 2.5 & 1.5 & 0.5 \\
\hline
\end{tabular}




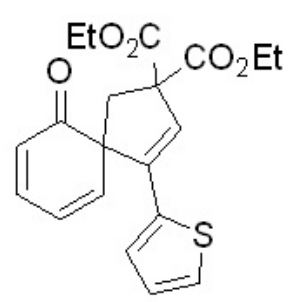

3qa

${ }^{1} \mathrm{H}$ NMR $\left(400 \mathrm{MHz}, \mathrm{CDCl}_{3}\right)$
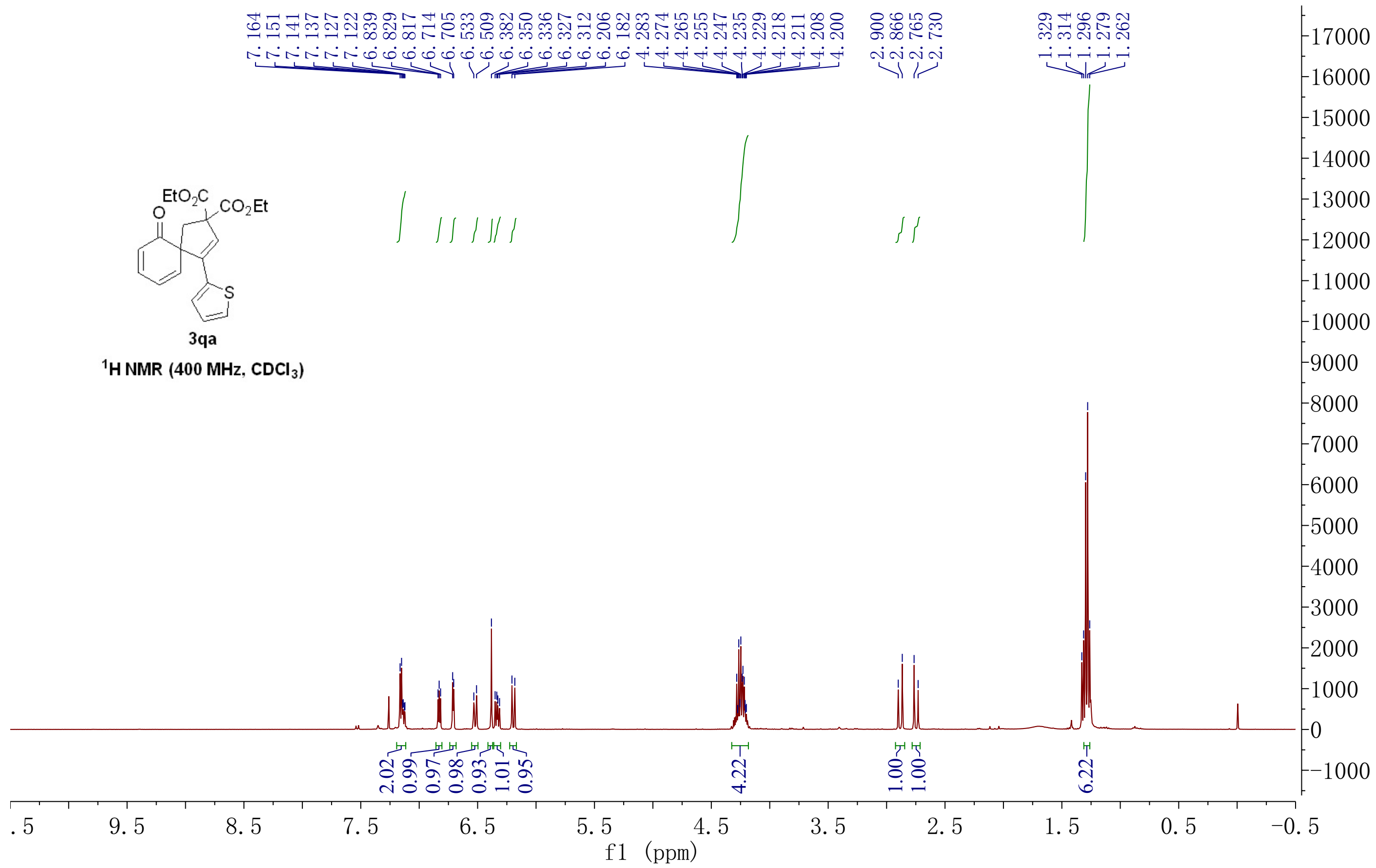


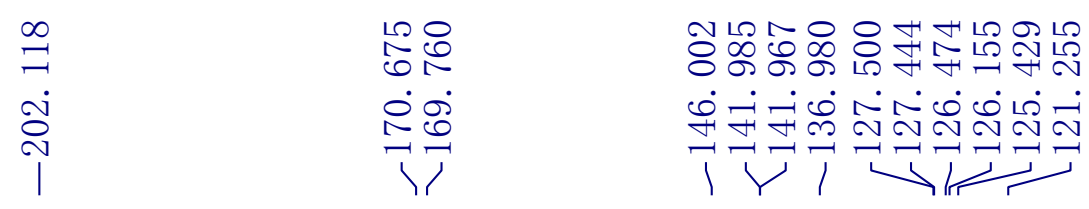

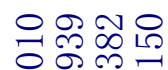

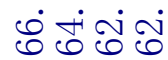

\%

เ্்

옹드

ن்

$\mathrm{EtO}_{2} \mathrm{C} \mathrm{CO}_{2} \mathrm{Et}$

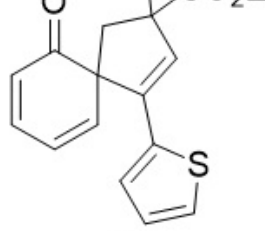

3qa

${ }^{13} \mathrm{C}\left\{{ }^{1} \mathrm{H}\right\} \mathrm{NMR}\left(100 \mathrm{MHz}, \mathrm{CDCl}_{3}\right)$

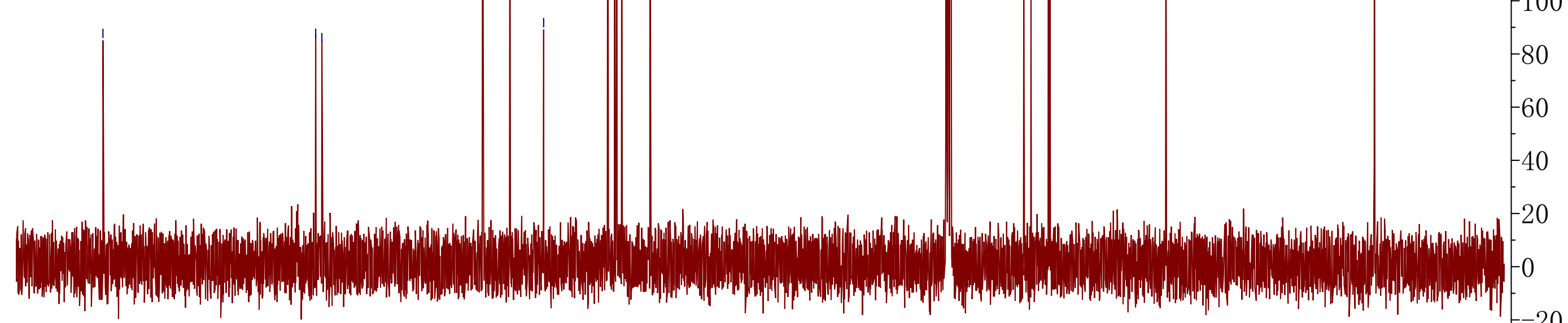

190180

170

150

$40 \quad 130$

120

f1 (ppm) 


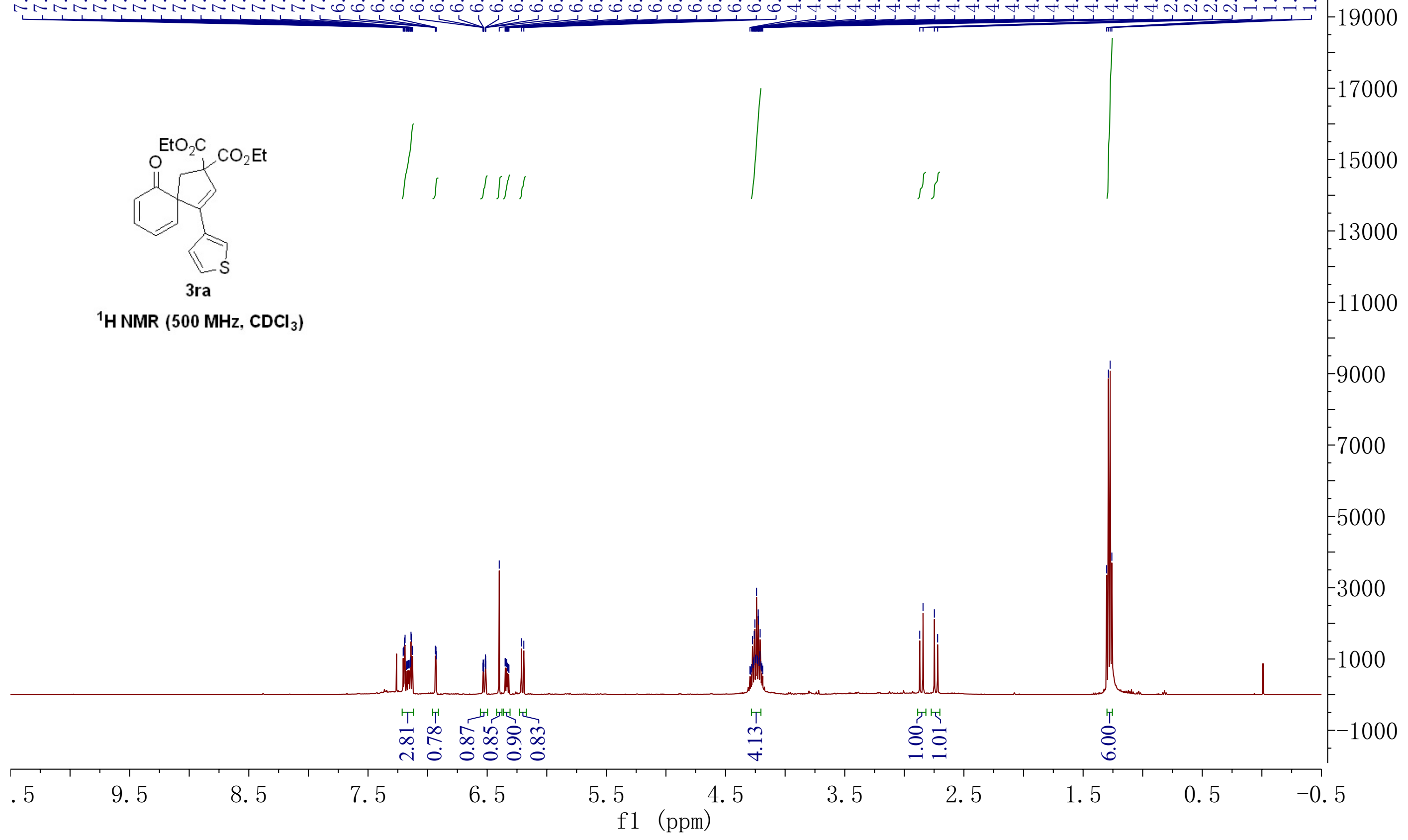




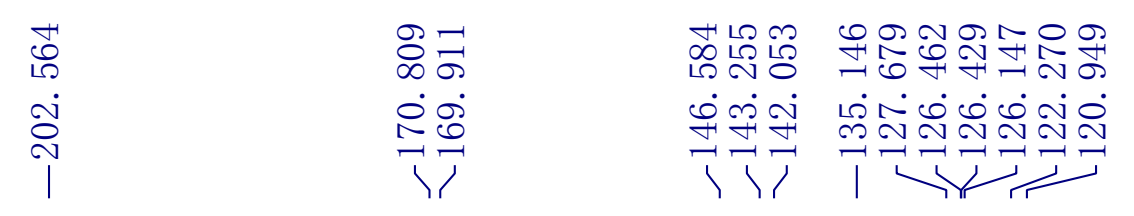

మ

เ्ن

पर

$\underset{\infty}{\infty}$

+

${ }^{13} \mathrm{C}\left\{{ }^{1} \mathrm{H}\right\}$ NMR (126 MHz, $\left.\mathrm{CDCl}_{3}\right)$

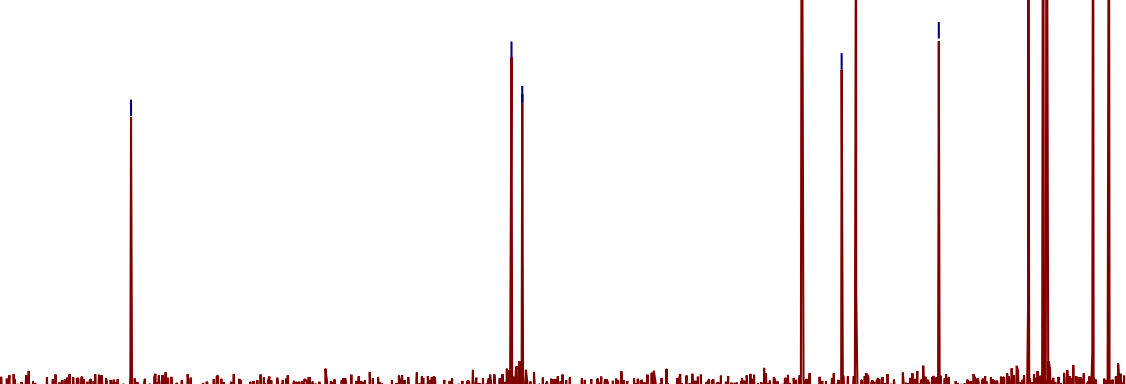

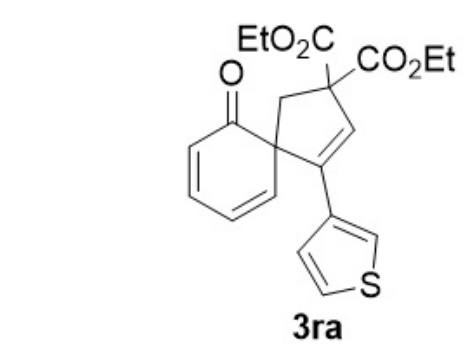

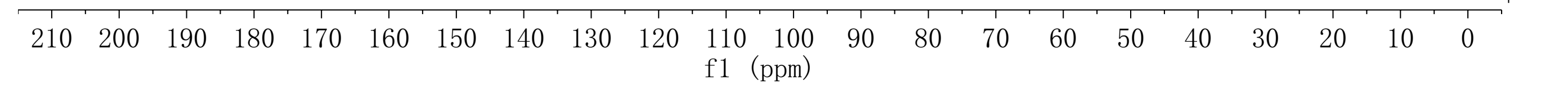



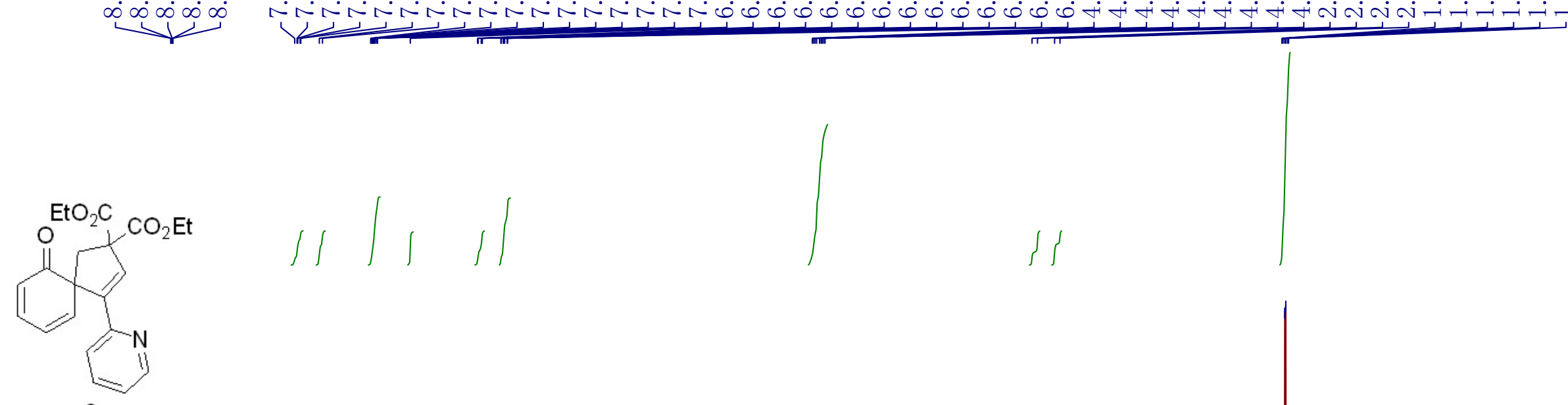

${ }^{1} \mathrm{H}$ NMR $\left(400 \mathrm{MHz}, \mathrm{CDCl}_{3}\right)$

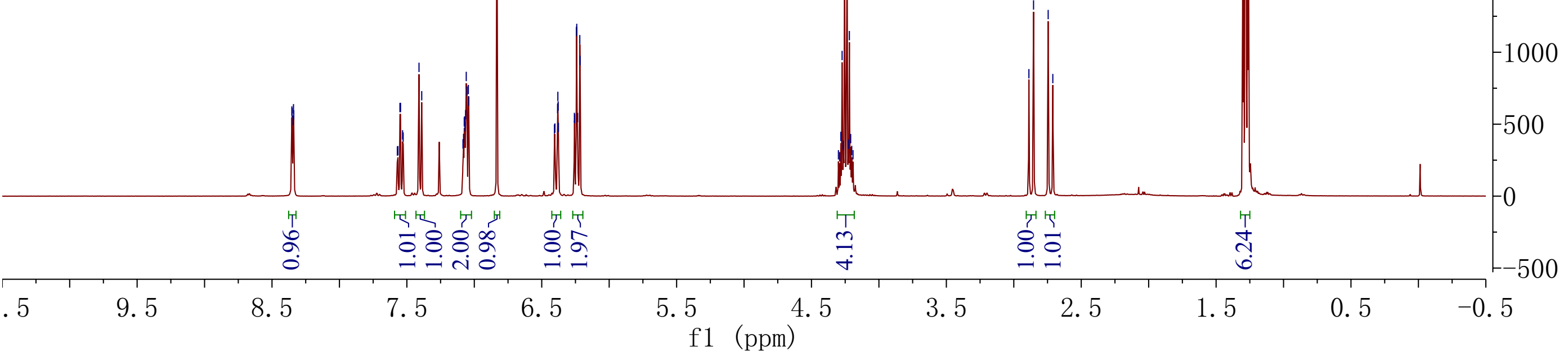




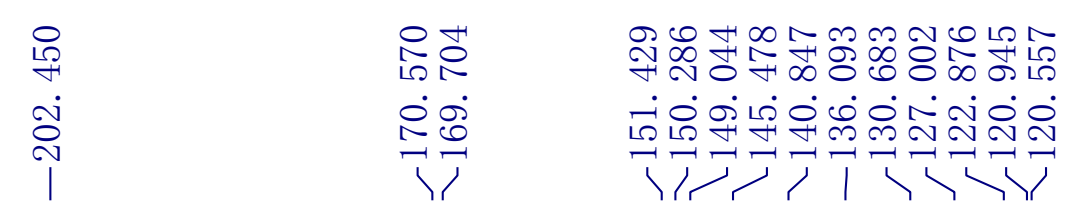

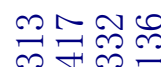

$\dot{0} \boldsymbol{0} \dot{0} \boldsymbol{0}$

เก



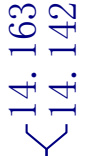

$\mathrm{EtO}_{2} \mathrm{C} \mathrm{CO}_{2} \mathrm{Et}$

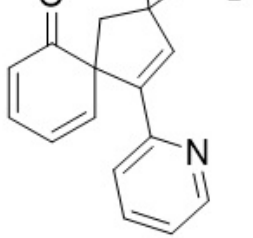

3sa

${ }^{13} \mathrm{C}\left\{{ }^{1} \mathrm{H}\right\}$ NMR (100 MHz, $\left.\mathrm{CDCl}_{3}\right)$ |

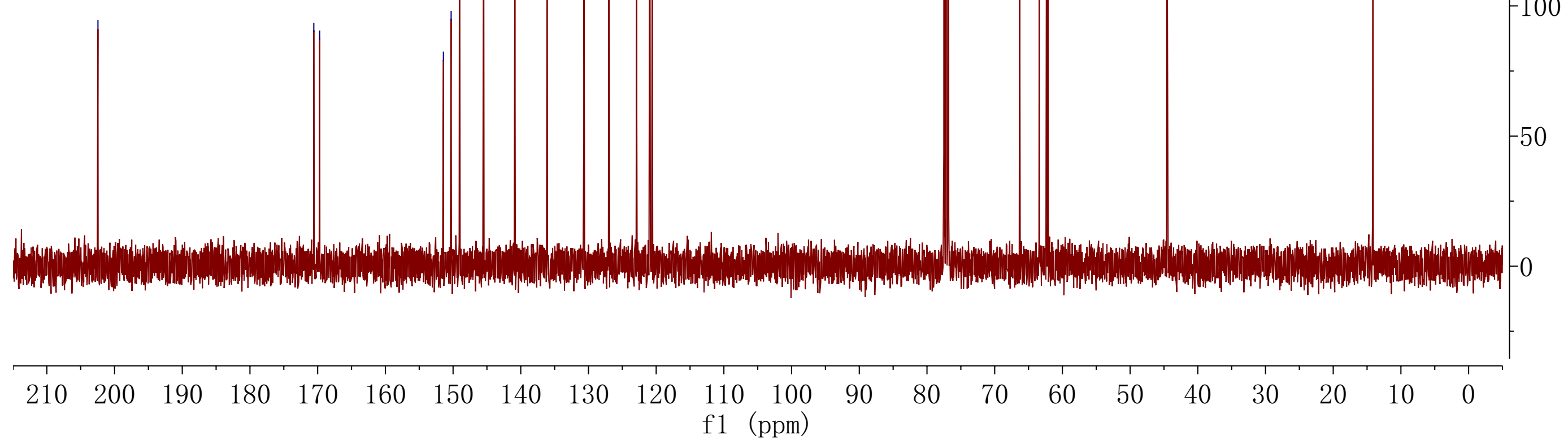



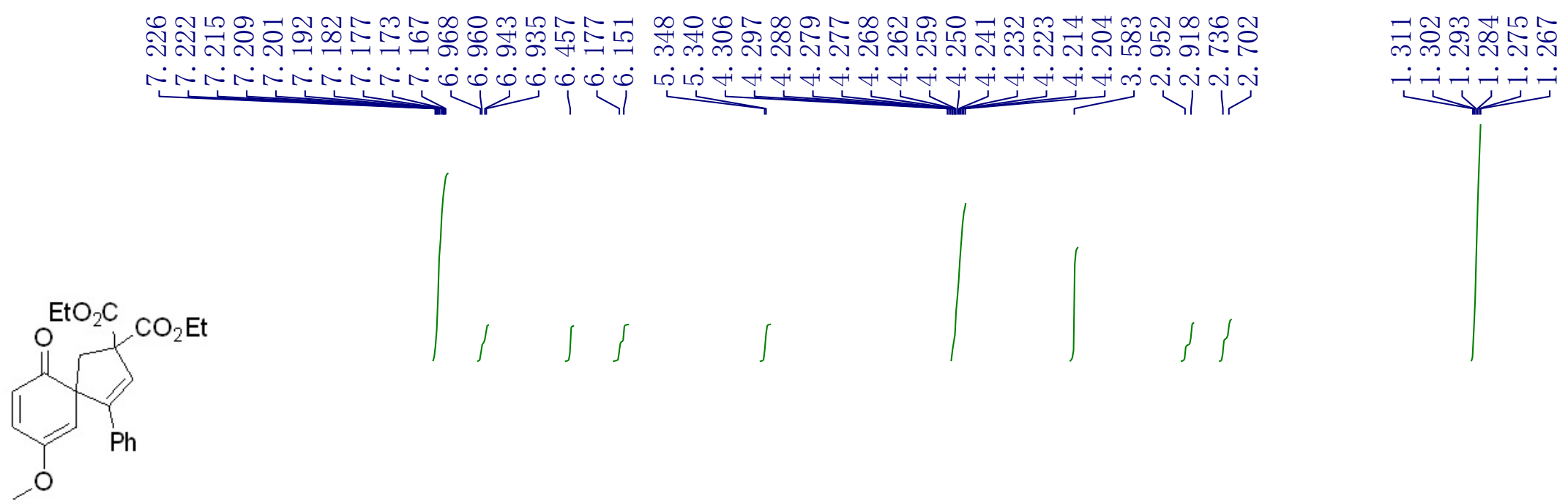

$3 a b$

${ }^{1} \mathrm{H}$ NMR $\left(400 \mathrm{MHz}, \mathrm{CDCl}_{3}\right)$

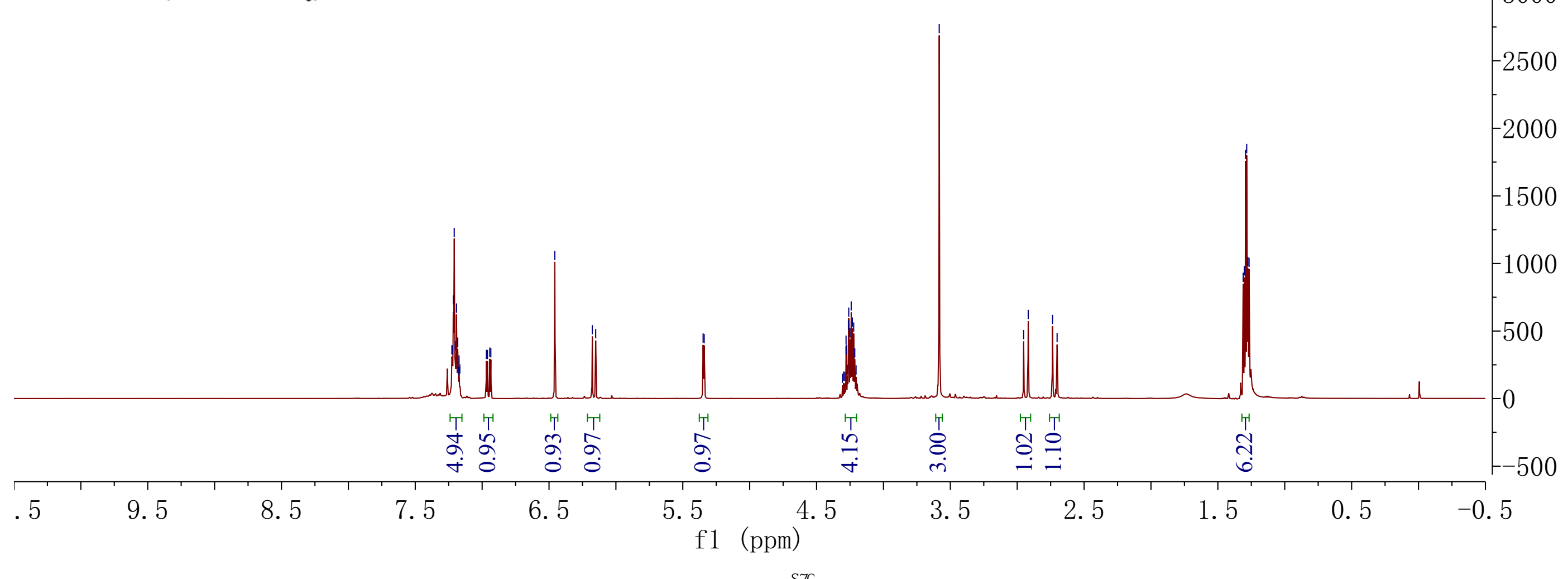




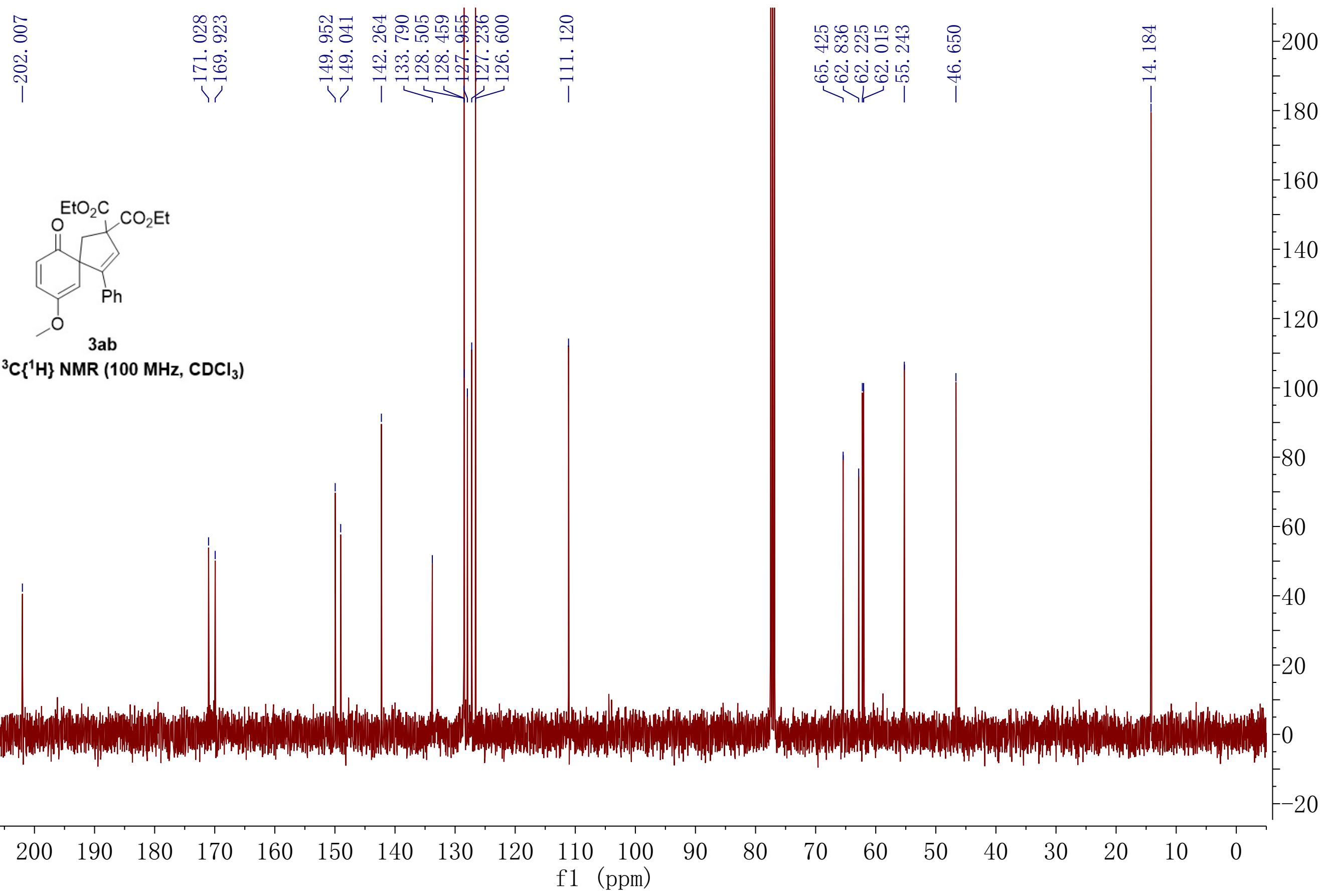



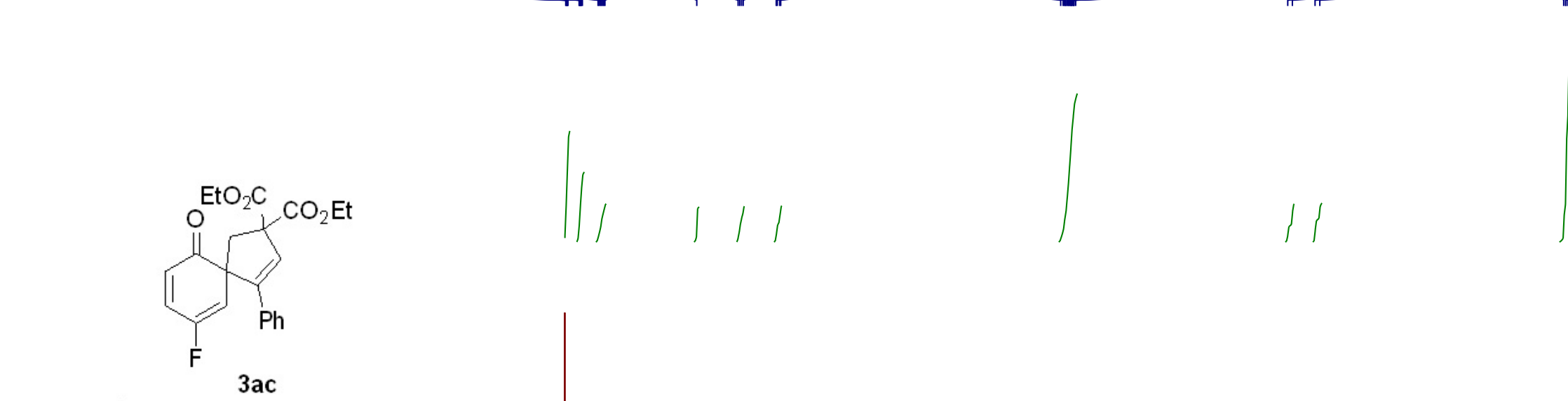

${ }^{1} \mathrm{H}$ NMR $\left(500 \mathrm{MHz}, \mathrm{CDCl}_{3}\right)$
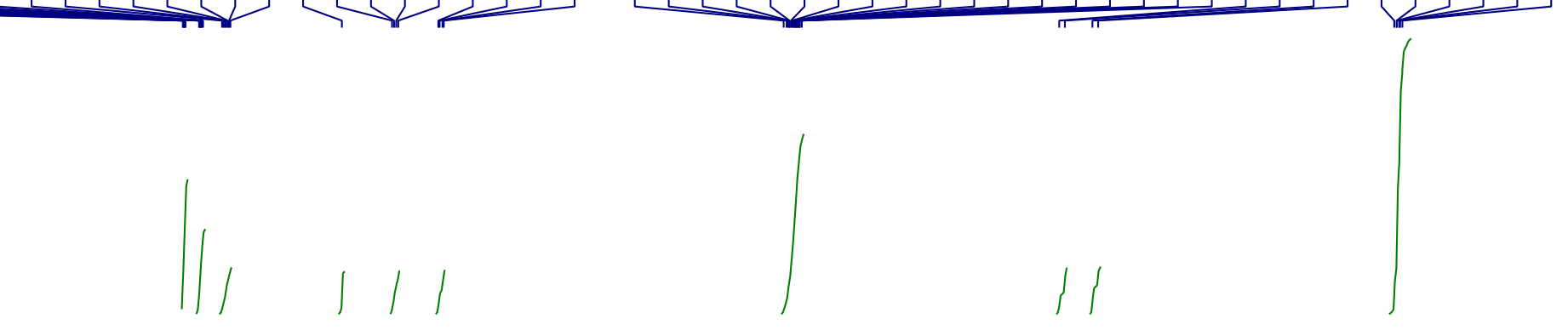

$-4500$

4000

3500

3000

2500

2000

1500
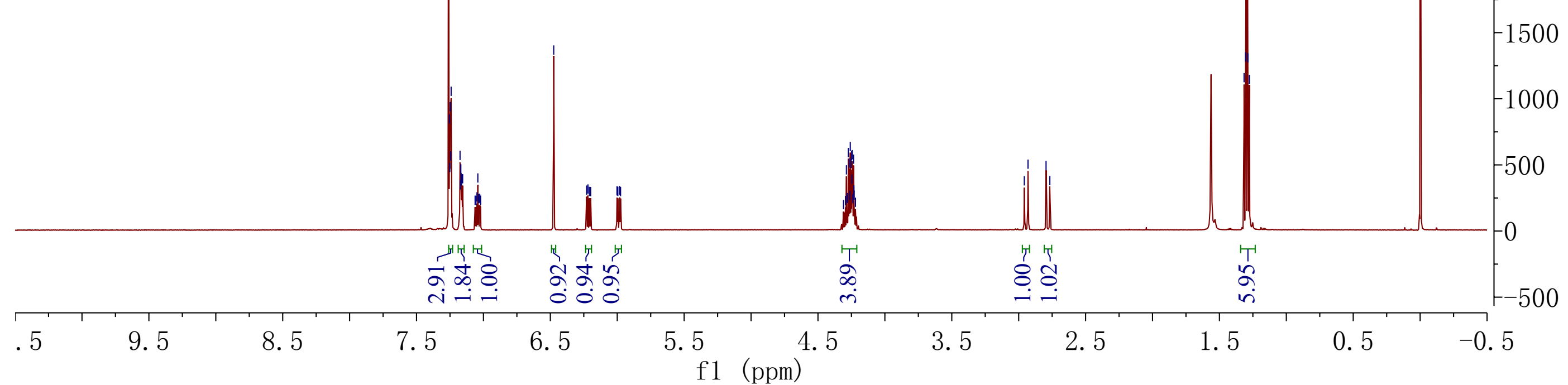


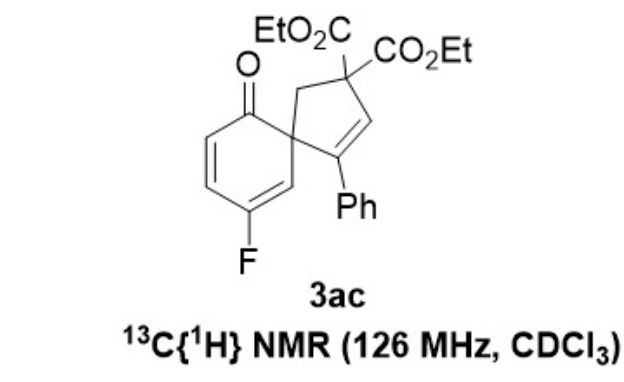

3ac

${ }^{13} \mathrm{C}\left\{{ }^{1} \mathrm{H}\right\}$ NMR $\left(126 \mathrm{MHz}, \mathrm{CDCl}_{3}\right)$
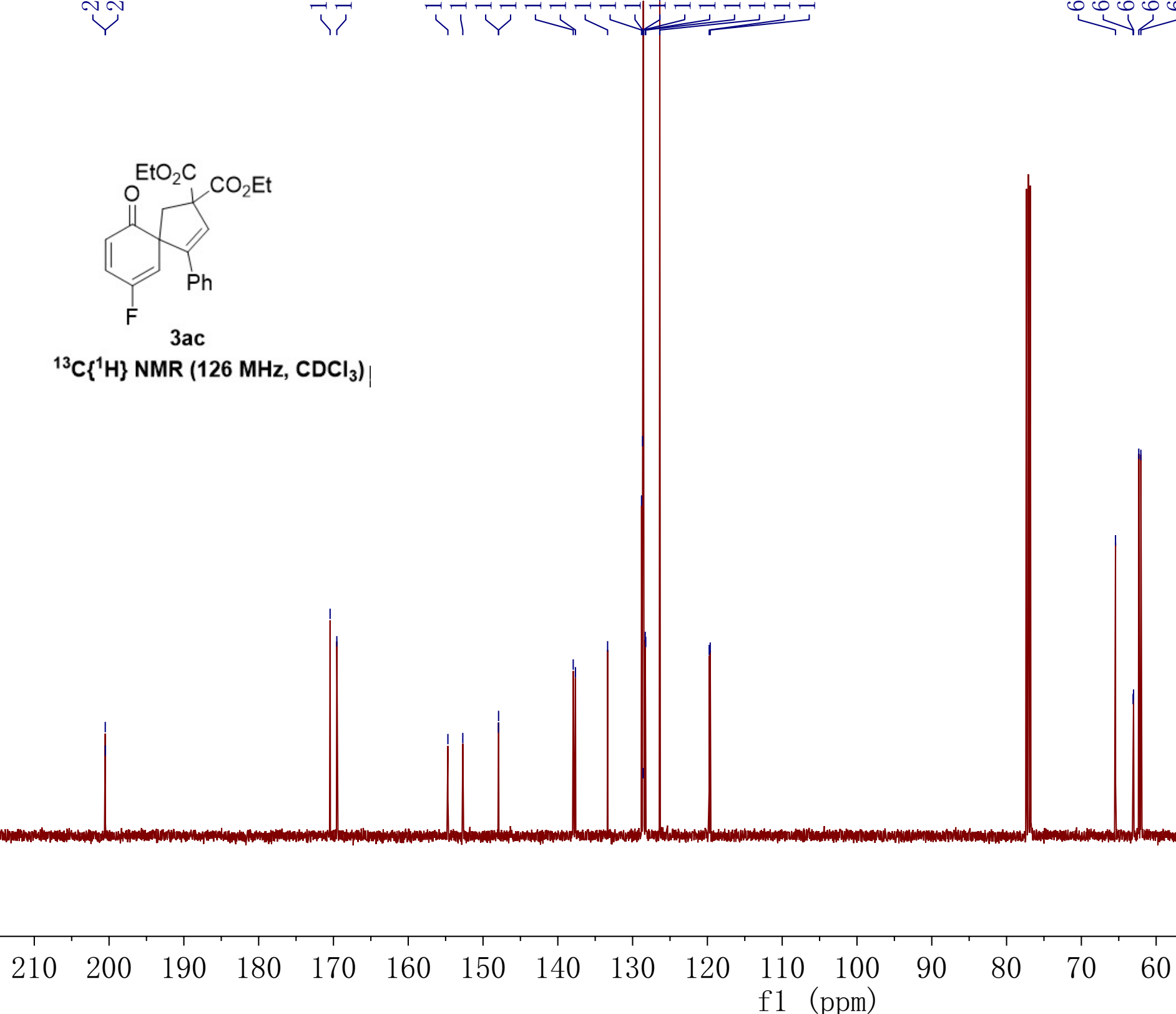


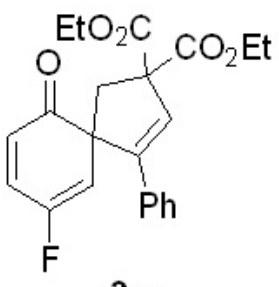

${ }^{19} \mathrm{~F} \mathrm{NMR}\left(470 \mathrm{MHz}, \mathrm{CDCl}_{3}\right)$
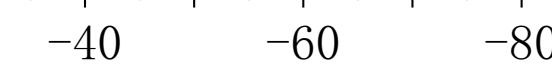

$-100$

$\begin{array}{llllllll}-120 & -140 & -160 & -180 & -200 & -220\end{array}$




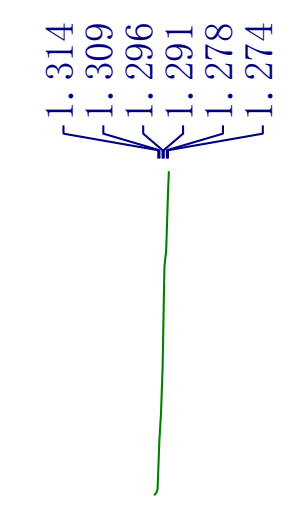

-18000
-17000
-16000
-15000
-14000
-13000
-12000
-11000
-10000
-9000
-8000
-7000
-6000
-5000
-4000
-3000
-2000
-1000
-0
--1000
-5

${ }^{1} \mathrm{H}$ NMR $\left(400 \mathrm{MHz}, \mathrm{CDCl}_{3}\right)$
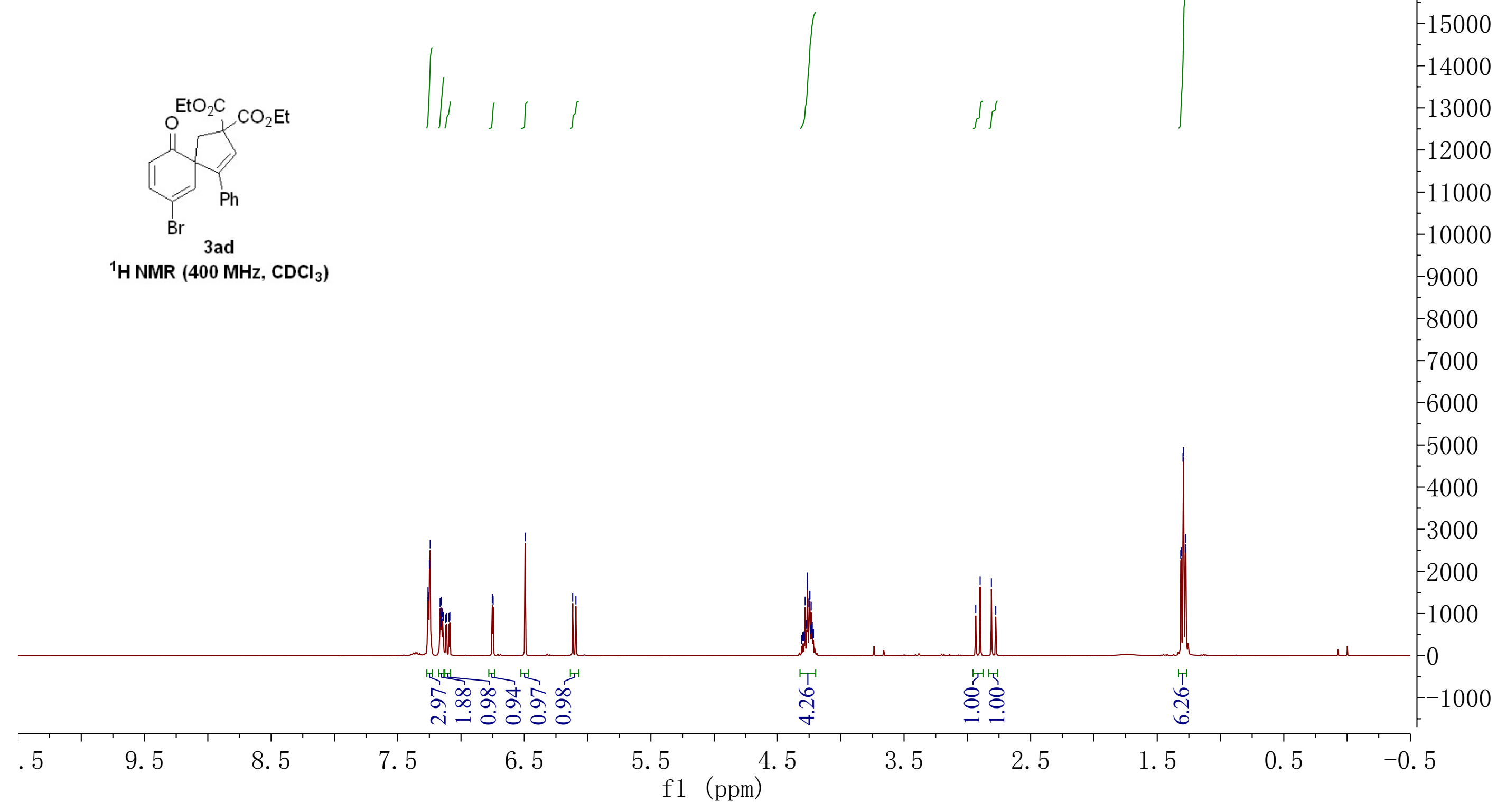


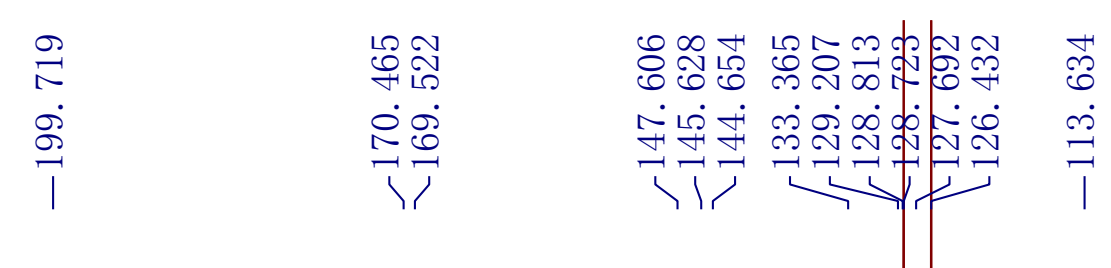

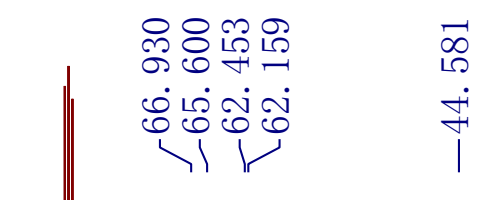

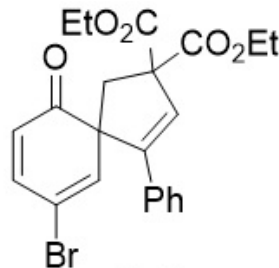

$3 \mathrm{ad}$

${ }^{13} \mathrm{C}\left\{{ }^{1} \mathrm{H}\right\}$ NMR (100 MHz, $\left.\mathrm{CDCl}_{3}\right)$

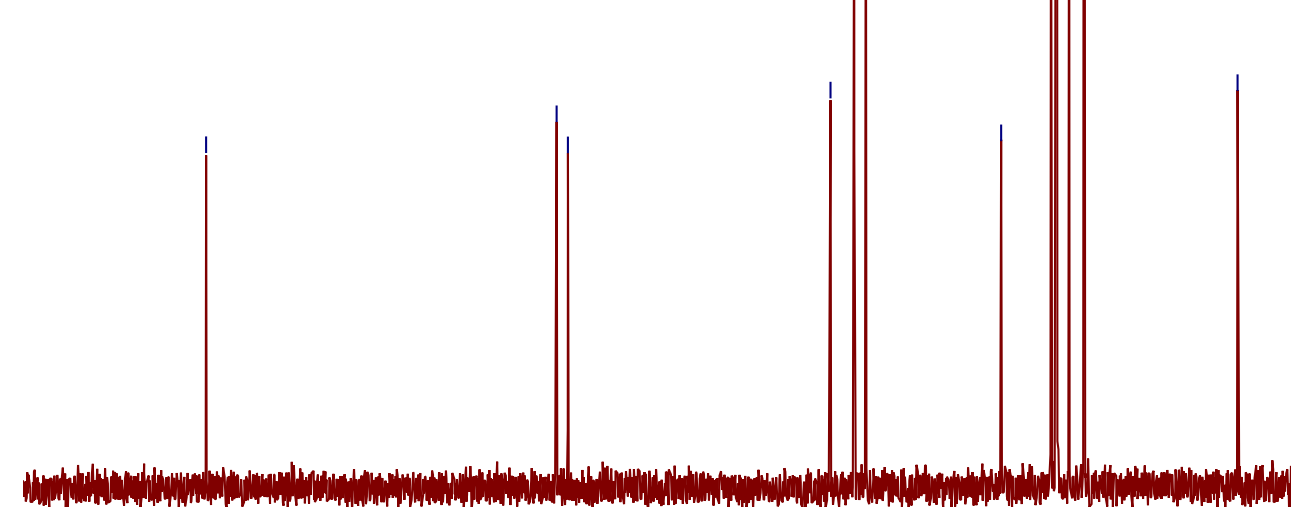




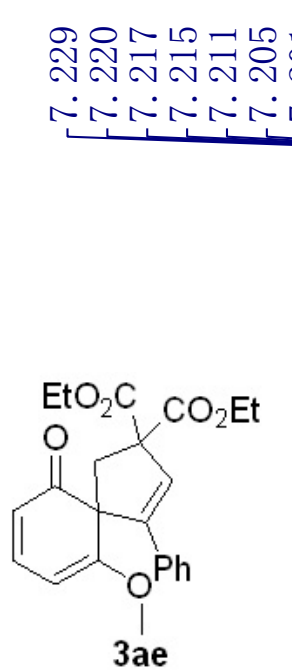

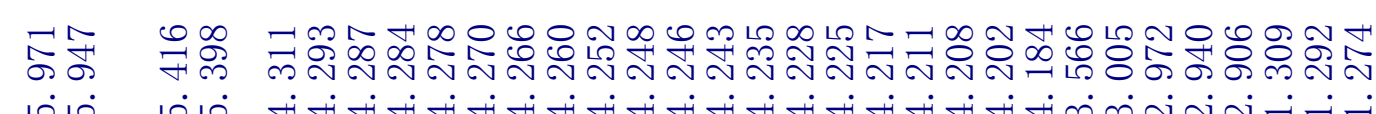

${ }^{1} \mathrm{H} \mathrm{NMR}\left(400 \mathrm{MHz}, \mathrm{CDCl}_{3}\right)$

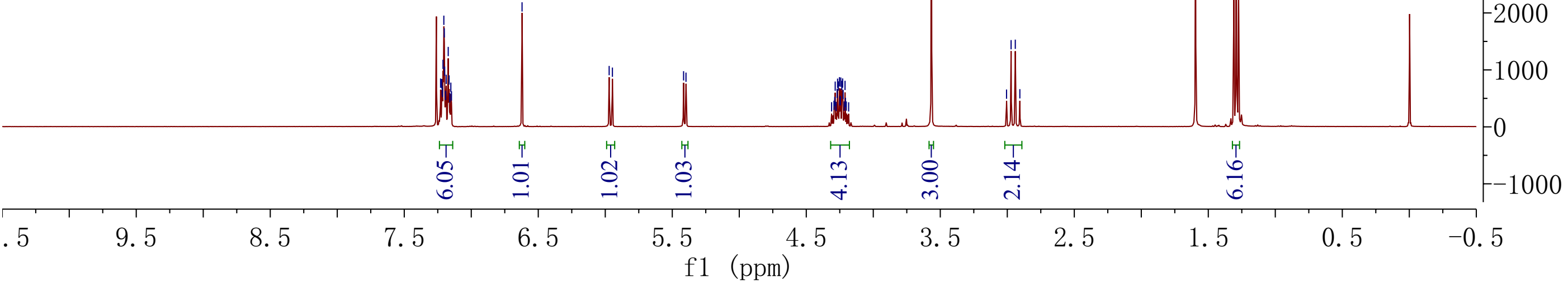




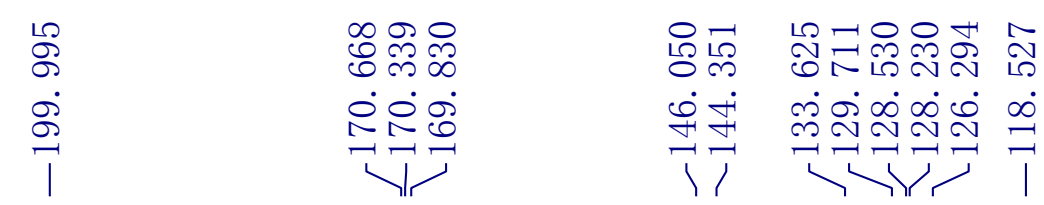
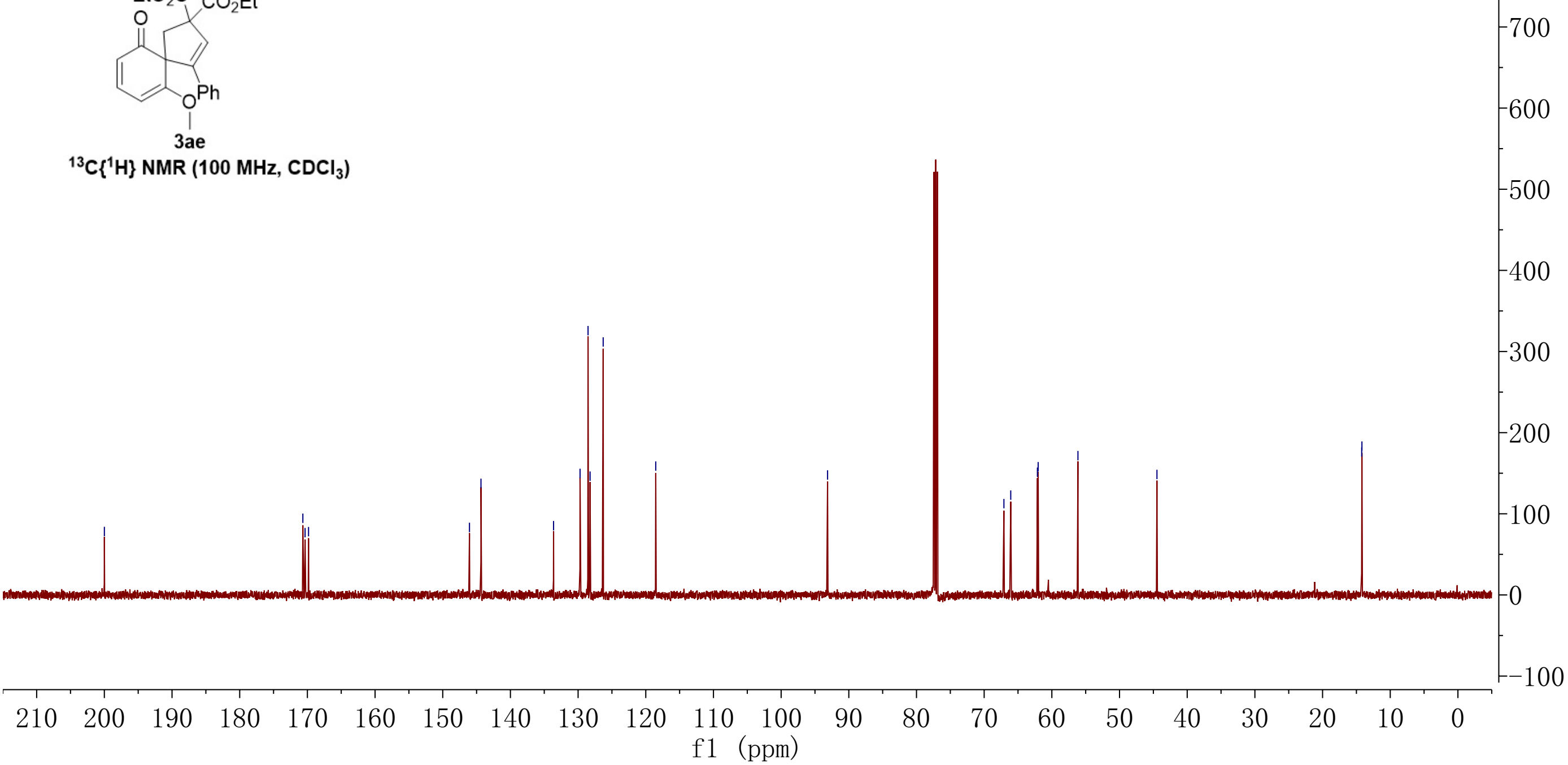

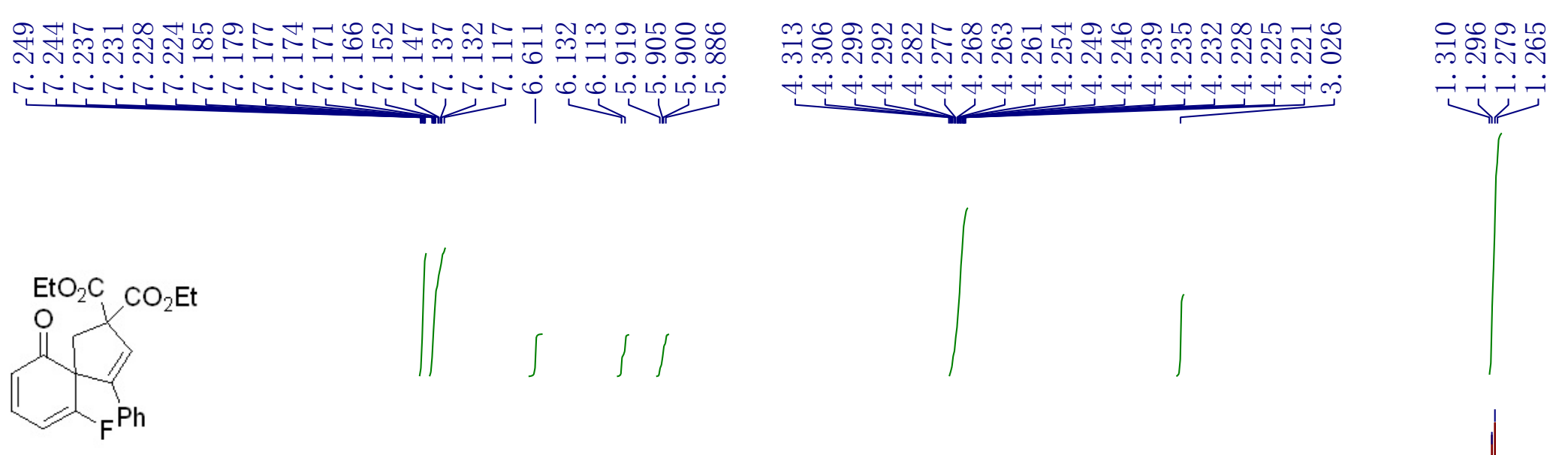

3af

${ }^{1} \mathrm{H} \mathrm{NMR}\left(400 \mathrm{MHz}, \mathrm{CDCl}_{3}\right)$

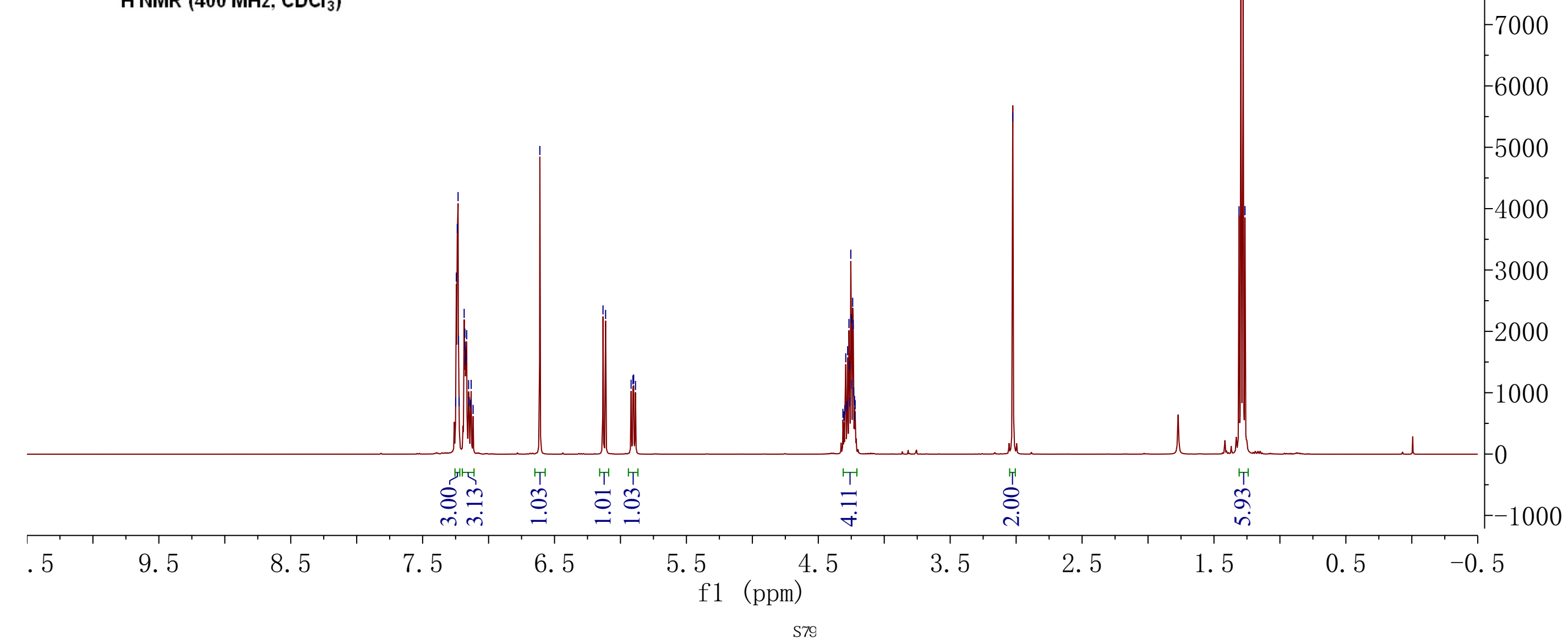




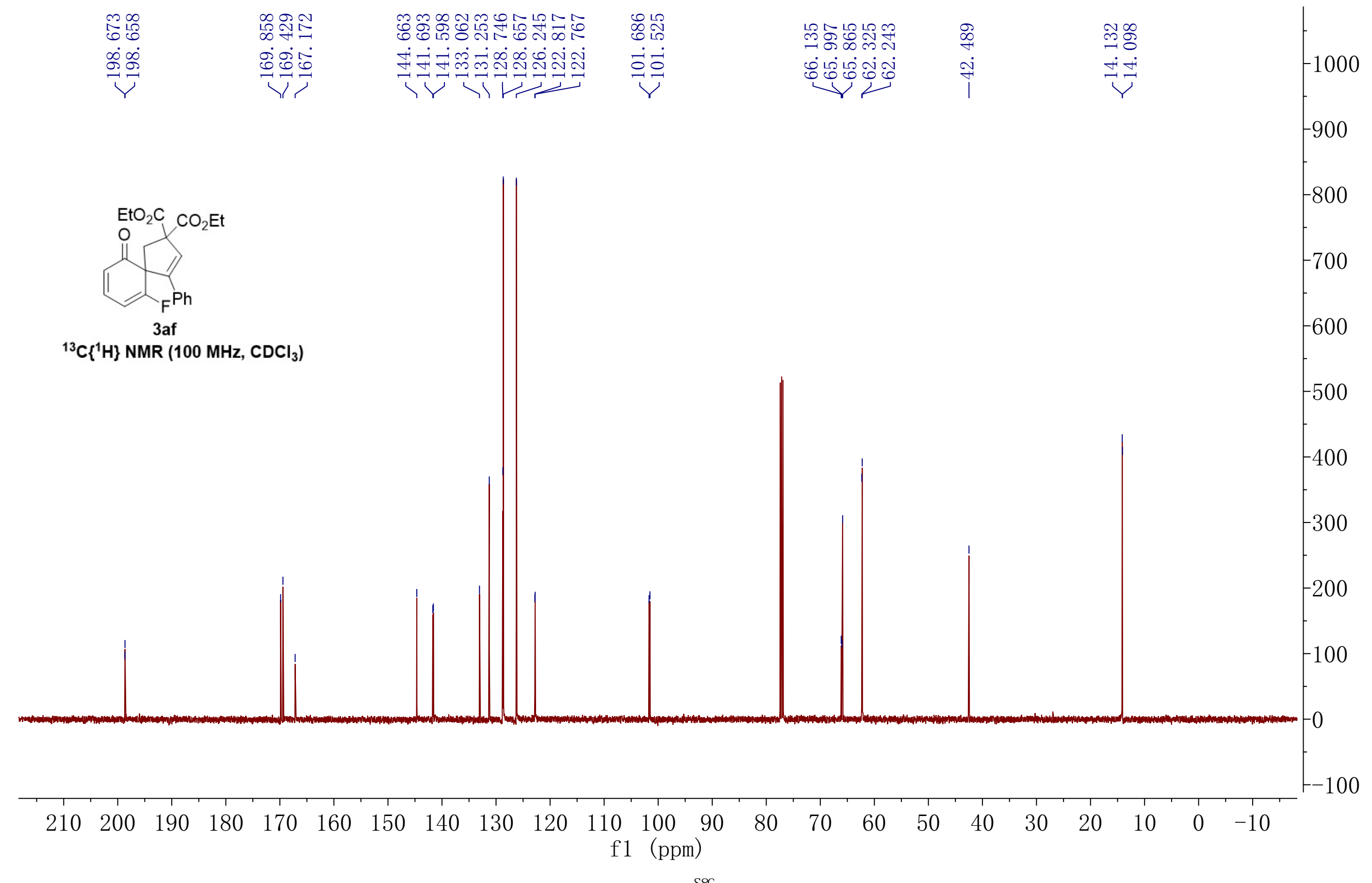


$\mathrm{EtO}_{2} \mathrm{C} \mathrm{CO}_{2} \mathrm{Et}$

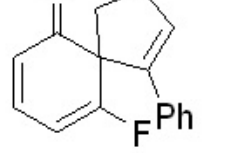

${ }^{19} \mathrm{~F} \mathrm{NMR}\left(376 \mathrm{MHz}, \mathrm{CDCl}_{3}\right)$ 
$\mathrm{EtO}_{2} \mathrm{C} \mathrm{CO}_{2} \mathrm{Et}$

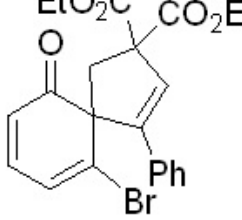

3 ag

${ }^{1} \mathrm{H} \mathrm{NMR}\left(400 \mathrm{MHz}, \mathrm{CDCl}_{3}\right)$
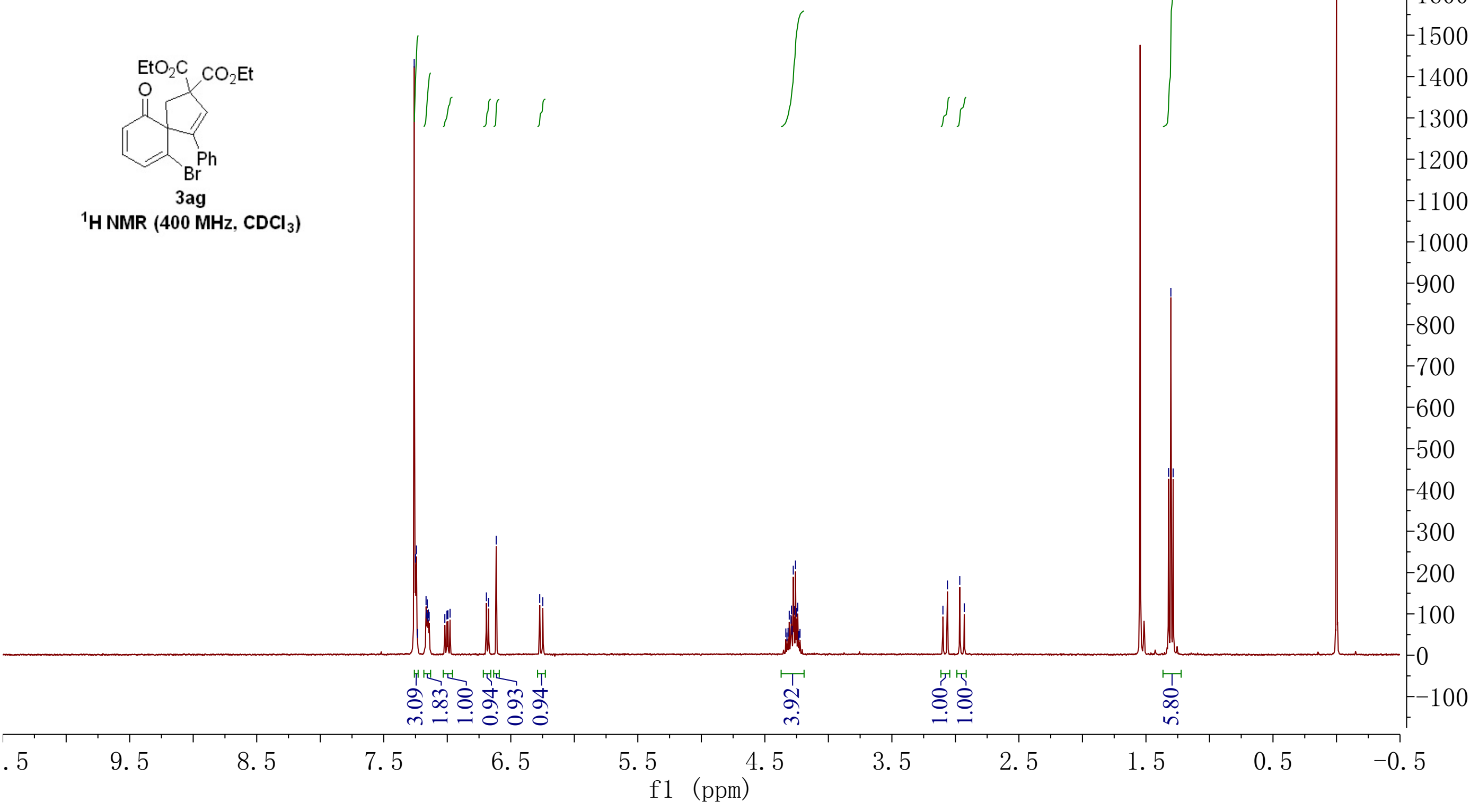

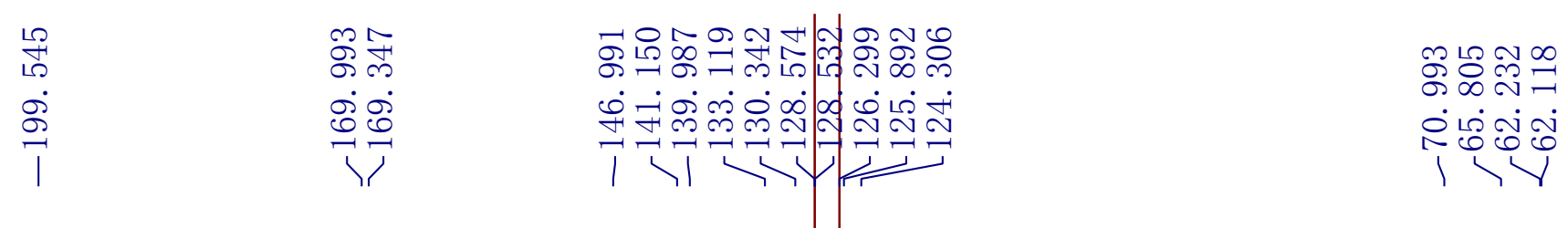

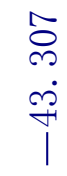

$\mathrm{EtO}_{2} \mathrm{C}-\mathrm{CO}_{2} \mathrm{Et}$

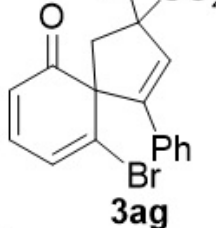

${ }^{13} \mathrm{C}\left\{{ }^{1} \mathrm{H}\right\} \mathrm{NMR}\left(100 \mathrm{MHz}, \mathrm{CDCl}_{3}\right)$ |

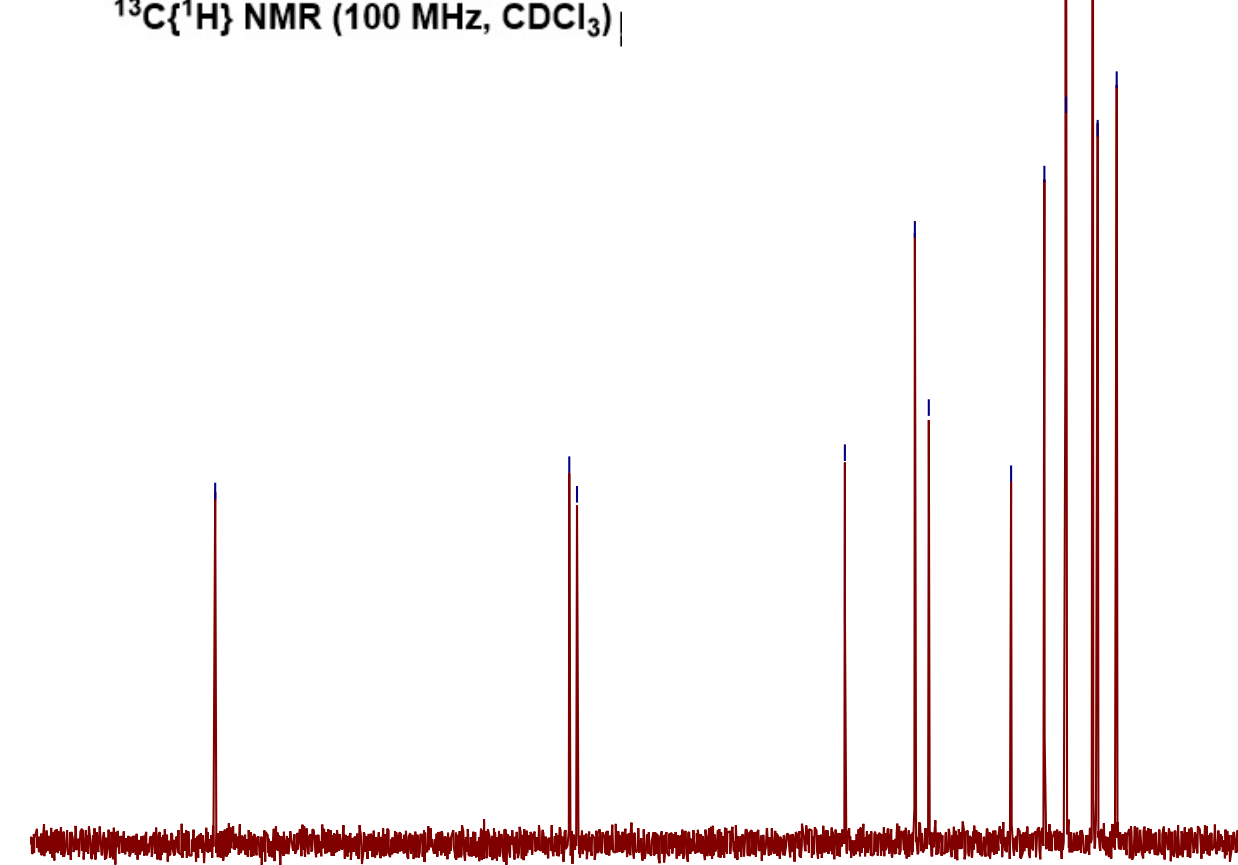

$\begin{array}{llllllllllllllllllllll}210 & 200 & 190 & 180 & 170 & 160 & 150 & 140 & 130 & 120 & \begin{array}{c}110 \\ \mathrm{f} 1\end{array}(\mathrm{pmm}) & 90 & 80 & 70 & 60 & 50 & 40 & 30 & 20 & 10 & 0\end{array}$



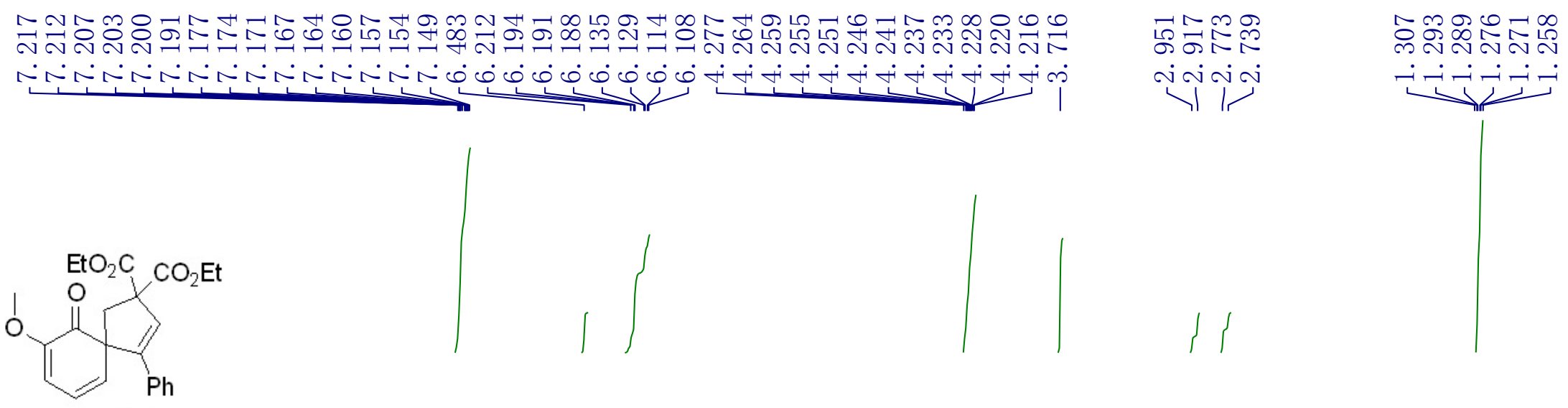

3ah

${ }^{1} \mathrm{H}$ NMR (400 MHz, $\left.\mathrm{CDCl}_{3}\right)$

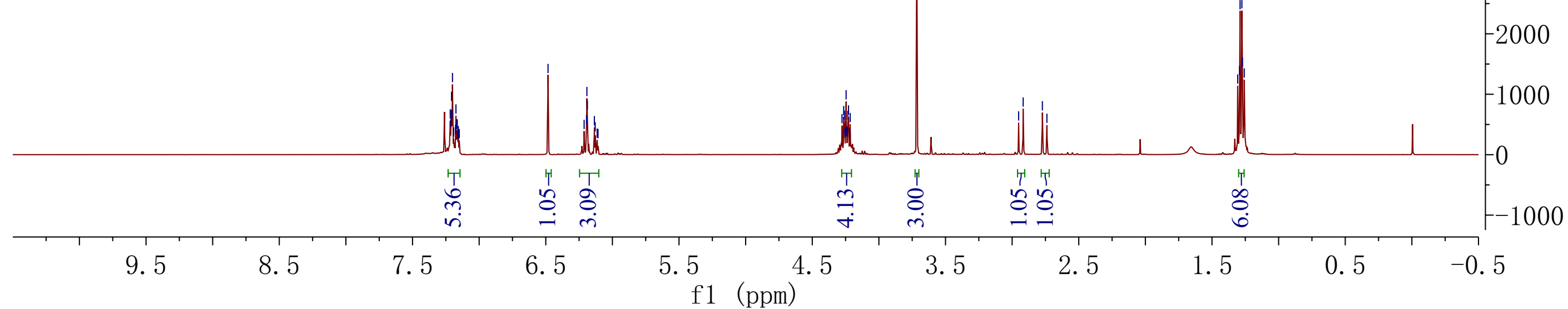




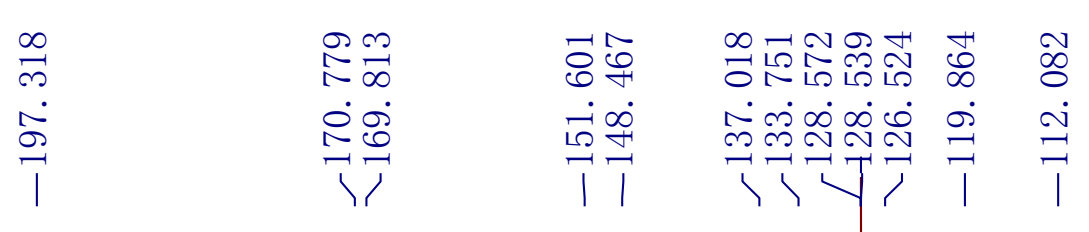

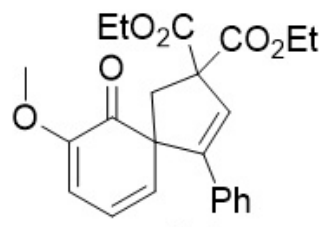

${ }^{13} \mathrm{C}\left\{{ }^{1} \mathrm{H}\right\}$ NMR $\left(100 \mathrm{MHz}, \mathrm{CDCl}_{3}\right)$

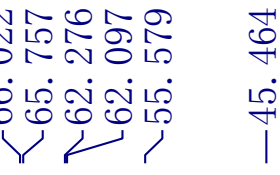

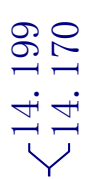




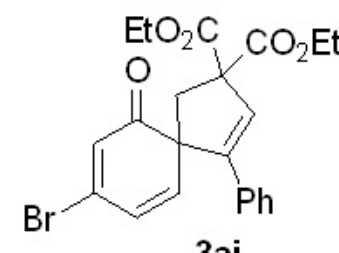

\section{${ }^{1} \mathrm{H}$ NMR $\left(400 \mathrm{MHz}, \mathrm{CDCl}_{3}\right)$}

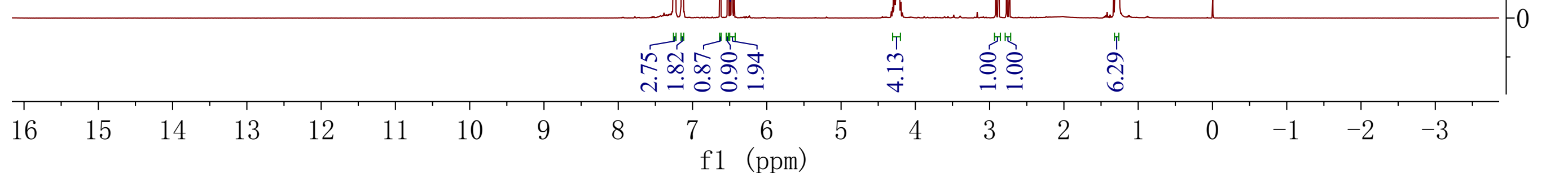




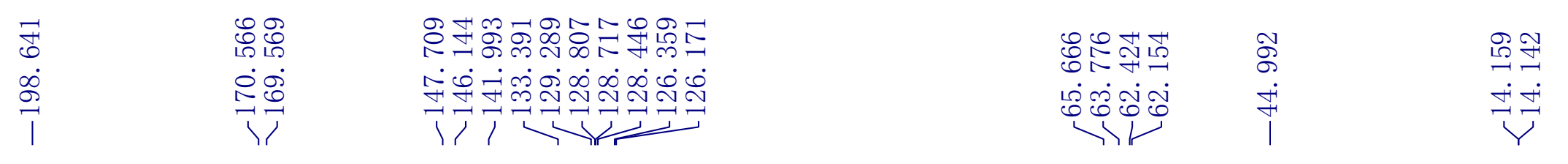

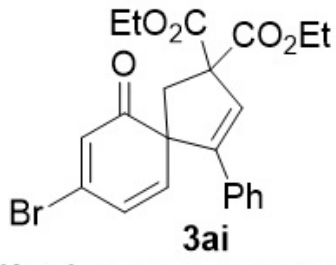

${ }^{13} \mathrm{C}\left\{{ }^{1} \mathrm{H}\right\}$ NMR $\left(100 \mathrm{MHz}, \mathrm{CDCl}_{3}\right)$

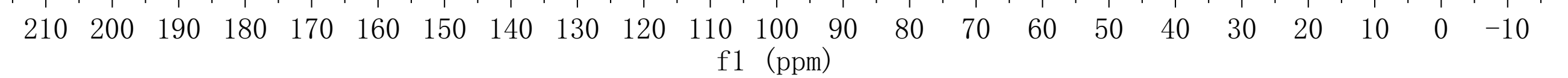


$\mathrm{EtO}_{2} \mathrm{C}$ $\mathrm{EtO}_{2} \mathrm{C}$ -

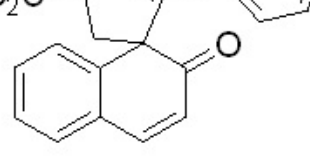

3ak

${ }^{1} \mathrm{H}$ NMR $\left(500 \mathrm{MHz}, \mathrm{CDCl}_{3}\right)$
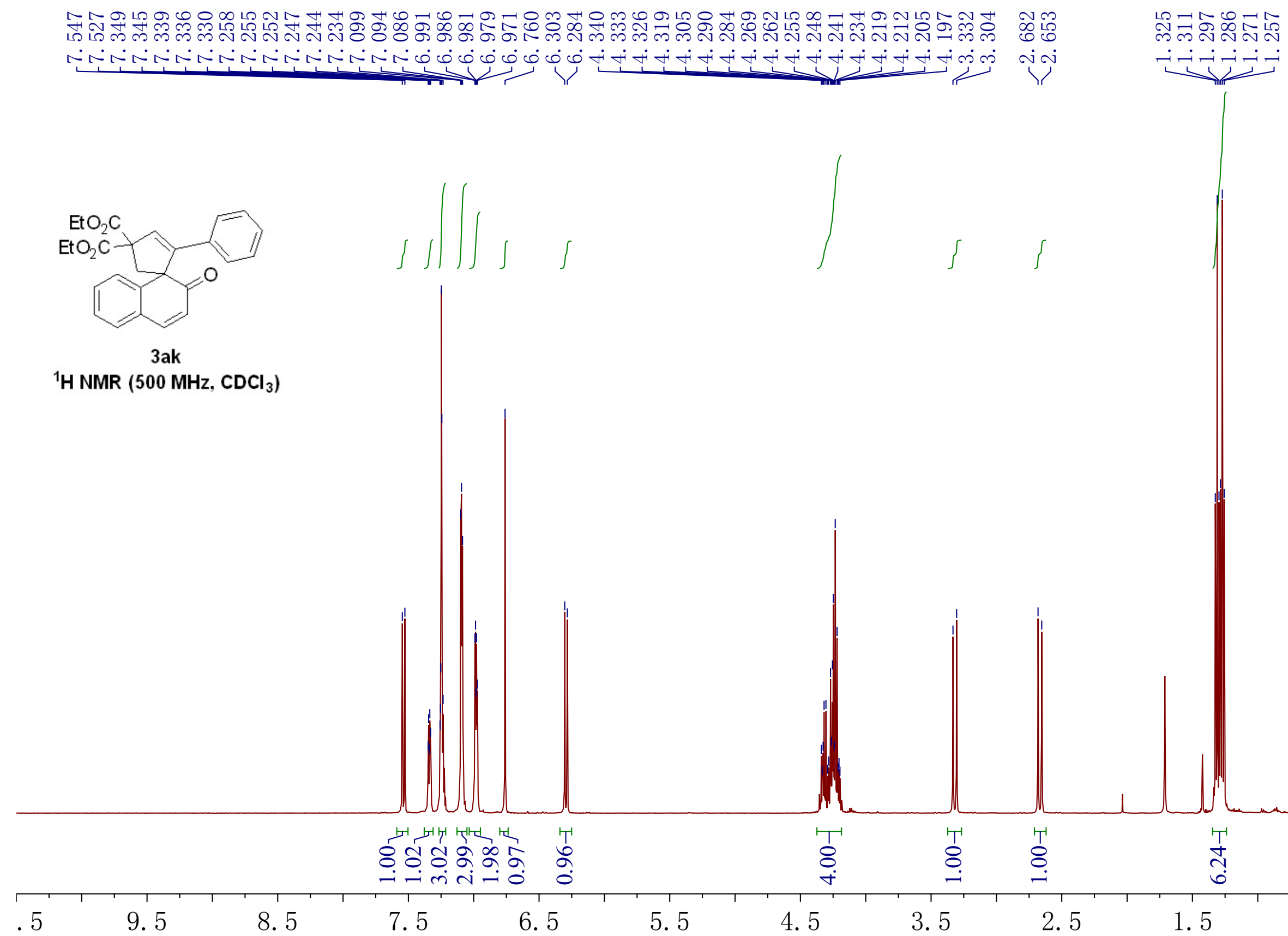

9.5

8. 5

6. 5

5.5

f1 (ppm)

4. 5

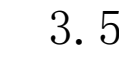

3. 5

2.5

0.5

$-0.5$ 


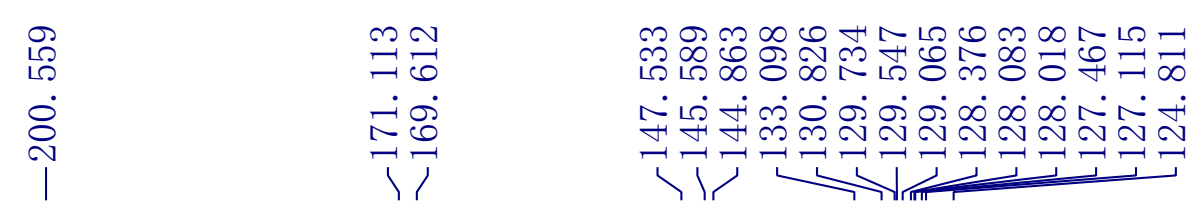

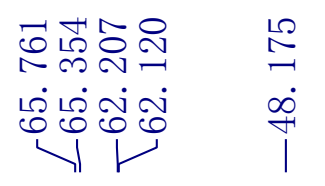

$\mathrm{EtO}_{2} \mathrm{C}$

$\mathrm{EtO}_{2} \mathrm{C}$

C

ak

${ }^{13} \mathrm{C}\left\{{ }^{1} \mathrm{H}\right\}$ NMR (126 MHz, $\left.\mathrm{CDCl}_{3}\right)$

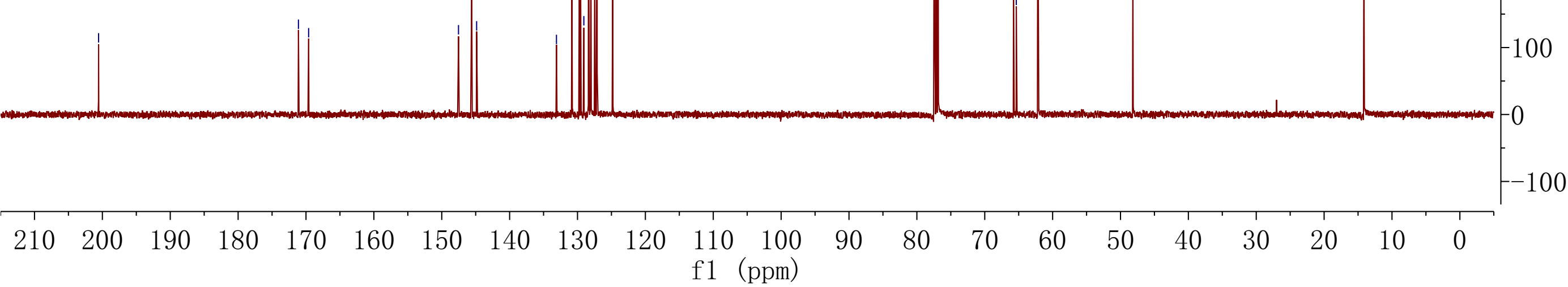

